CENTRO UNIVERSITÁRIO FEI

MARINA JULIANA GONÇALVES

ADOÇÃO DA TECNOLOGIA DA INFORMAÇÃO EM SAÚDE SOB A PERSPECTIVA DO CUSTO EFETIVIDADE

São Bernardo do Campo 
MARINA JULIANA GONÇALVES

\title{
ADOÇÃO DA TECNOLOGIA DA INFORMAÇÃO EM SAÚDE SOB A PERSPECTIVA DO CUSTO EFETIVIDADE
}

\begin{abstract}
Dissertação apresentada ao Centro Universitário FEI, como parte dos requisitos necessários para obtenção do título de Mestre em Engenharia Mecânica. Orientado pelo Prof. Claudia Aparecida Mattos.
\end{abstract}

São Bernardo do Campo 
Gonçalves, Marina Juliana .

ADOÇÃO DA TECNOLOGIA DA INFORMAÇÃO EM SAÚDE SOB A PERSPECTIVA DO CUSTO EFETIVIDADE / Marina Juliana

Gonçalves. São Bernardo do Campo, 2019.

89 f. : il.

Dissertação - Centro Universitário FEI.

Orientadora: Prof. ${ }^{a}$ Dra. Claudia Aparecida Mattos.

1. Tecnologia da informação. 2. Modelos de adoção de tecnologia. 3. Custo Efetividade. I. Mattos, Claudia Aparecida, orient. II. Título.

Elaborada pelo sistema de geração automática de ficha catalográfica da FEI com os dados fornecidos pelo(a) autor(a). 
Título do Trabalho: Adoção da tecnologia da informação em saúde sob a perspectiva do custo efetividade.

Área de Concentração: Produção

Orientador: Profa Dra Claudia Aparecida de Mattos

Data da realização da defesa: 06/11/2019

Avaliação da Banca Examinadora:

São Bernardo do Campo,

/ $\quad$ /

MEMBROS DA BANCA EXAMINADORA

Profa Dra Claudia Aparecida de Mattos

Ass. :

Prof. Dr. João Chang Junior

Ass.:

Profa Dra Célia Barbosa Assis

Ass. :

A Banca Julgadora acima-assinada atribuiu ao aluno o seguinte resultado:

APROVADO \

REPROVADO

\section{VERSÃO FINAL DA}

DISSERTACÃO

Aprovação do Coordenador do Programa de Pós-graduação

APROVO A VERSÃO FINAL DA DISSERTAÇÃO EM QUE FORAM INCLUÍDAS AS RECOMENDAÇÕES DA BANCA 
Alarico e Tânia, que são minha fortaleza.

Fernanda, minha alegria.

E à mim. 


\section{AGRADECIMENTOS}

Agradeço à Professora Claudia Aparecida Mattos, por todos os anos de orientação, desde a iniciação científica até o presente trabalho. Agradeço pela paciência, por tudo o que me ensinou, por ter acreditado em mim e pelas tantas oportunidades concedidas. Sua confiança, apoio e amizade foram fundamentais para meu aprimoramento pessoal e desenvolvimento acadêmico. Sua orientação segura e firme permitiu a concretização dos inúmeros projetos de pesquisa que realizamos juntas.

Agradeço aos meus pais pelo suporte durante toda jornada, à minha irmã por todo apoio sempre e aos meus amigos.

Agradeço à todos que contribuíram com o fornecimento dos dados necessários para o presente estudo, sem eles, nada disso seria possível.

O presente trabalho foi realizado com apoio da Coordenação de Aperfeiçoamento de Pessoal de Nível Superior - Brasil (CAPES) - Código de Financiamento 001. 
"A ciência pode nos divertir e fascinar, mas é a engenharia que muda o mundo"

(Isaac Asimov). 


\section{RESUMO}

O progresso em tecnologias da informação em saúde oferece novas oportunidades, bem como novos cenários de aplicação, trazendo benefícios em qualidade dos serviços médicos e redução dos custos de saúde. As organizações de saúde, consideram a aplicação da Tecnologia da Informação como uma chave fundamental para melhorar a gestão de saúde, porém poucos trabalhos analisam o impacto de sistemas de informação em termos econômicos e de qualidade dos cuidados aos pacientes, além da escassez de estudos que considerarem as características da tecnologia da informação em saúde e as relações que vinculam a informação ao seu ambiente para tomada de decisão. A literatura relacionada com a Avaliação da Tecnologia da Informação em saúde parece ser ainda muito dispersa e fragmentada, demandando novos estudos. Assim, o objetivo geral deste trabalho consiste em propor um framework de avaliação de tecnologia da informação em saúde na perspectiva do custo efetividade, combinando diferentes modelos de adoção de tecnologia. A pesquisa buscou preencher a lacuna e examinar um modelo de avaliação abrangente e documentar o seu impacto sobre o processo decisório dos hospitais em adotar tecnologias em saúde e de fato alavancar resultados tanto para o paciente como uma forma de melhorar a gestão. Para o desenvolvimento do estudo foi aplicado o método Design Science Research (DSR) e avaliação do framework foi feito através de três estudos de caso realizados em hospitais público e público-privado. Os resultados indicam que a avaliação da tecnologia em saúde demanda um framework abrangente, sendo necessário abordar problemas de tecnologia, humanos, organização e aspecto econômico (custo-efetividade).

Palavras-chave: Tecnologia da Informação. Modelos de Adoção de Tecnologia. Custo Efetividade. 


\begin{abstract}
Progress in health information technologies offers new opportunities as well as new application scenarios, bringing benefits in quality of medical services and reduced health costs. Health organizations consider the application of Information Technology as a key to improve health management, but few studies analyze the impact of information systems in terms of economic and quality of patient care, and the scarcity of studies that consider the characteristics of health information technology and the relationships that link information to its environment for decision making. The literature related to the Health Information Technology Assessment seems to be still very scattered and fragmented, requiring further studies. Thus, the general objective of this paper is to propose a health information technology assessment framework from the perspective of cost effectiveness, combining different technology adoption models. The research sought to bridge the gap and examine a comprehensive assessment model and document its impact on hospital decision-making in adopting health technologies and in fact leveraging outcomes for both the patient and a way to improve management. For the development of the study the Design Science Research (DSR) method was applied and the framework evaluation was made through three case studies carried out in public and publicprivate hospitals. The results indicate that health technology assessment requires a comprehensive framework, and it is necessary to address technology, human, organization and economic issues (cost-effectiveness).
\end{abstract}

Keywords: Information Technology. Technology Adoption Models. Cost effectiveness. 


\section{LISTA DE GRÁFICOS}

Gráfico 1 - Comparação da taxa de mortalidade ................................................................. 70

Gráfico 2 - Comparação do tempo médio de internação em horas. ......................................... 70 


\section{LISTA DE ILUSTRAÇÕES}

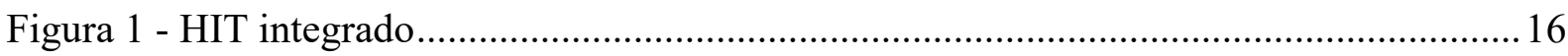

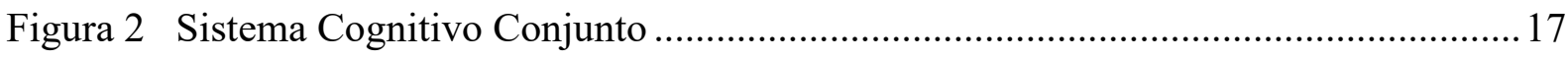

Figura 3 - Os cinco espaços que compõem um sistema cognitivo conjunto e funções............ 18

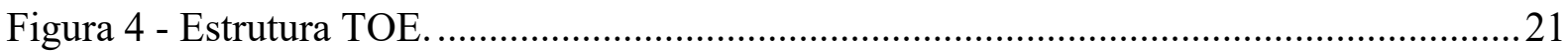

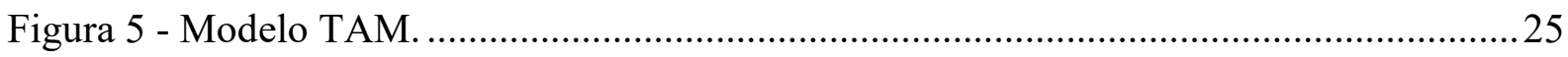

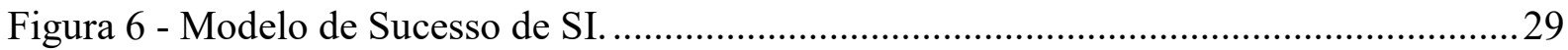

Figura 7 - Modelo de ajuste de organização de TI. ..............................................................2 29

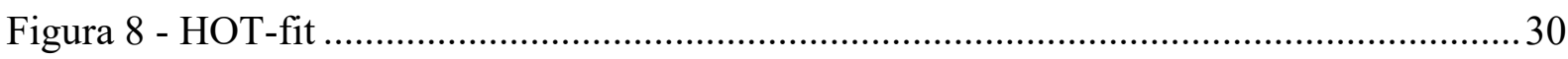

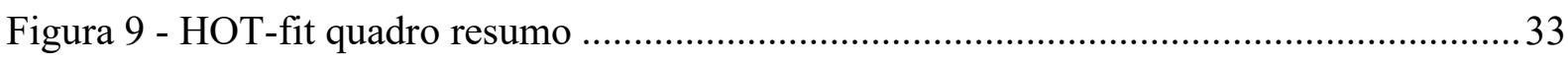

Figura 10 - Comparação dos frameworks HOT-fit e TOE ...................................................... 34

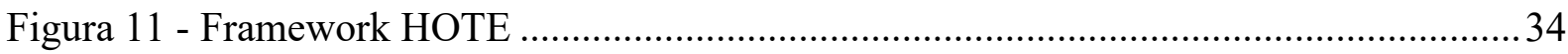

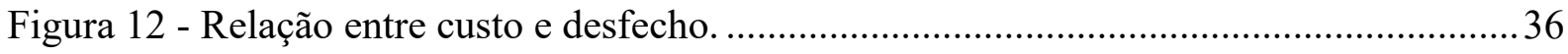

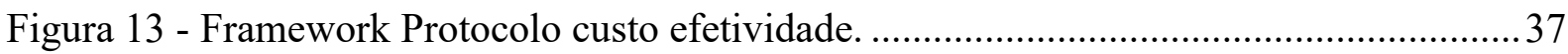

Figura 14 - Framework conceitual de tecnologias de informação em saúde............................ 39

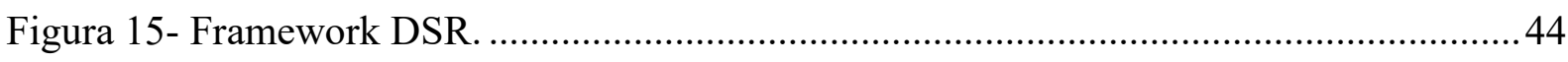

Figura 16 - Questões mapeadas para três ciclos de pesquisa de design ................................ 45

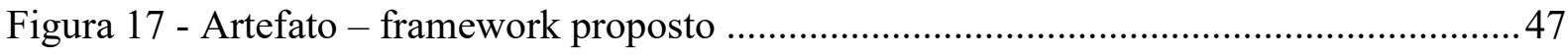

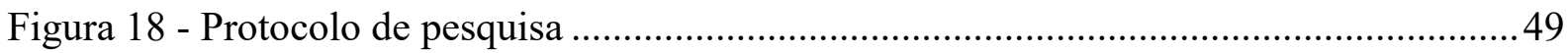

Figura 19 - Assimilação da tecnologia LIDCO no hospital. .................................................56

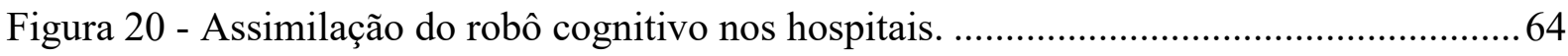

Figura 21 - Comparação do tempo médio de inserção de dados no prontuário eletrônico.......65

Figura 22 - Comparação do tempo médio de prescrição da primeira dose do antimicrobiano 66 


\section{LISTA DE TABELAS}

Tabela 1 - Compilação dos modelos de avaliação HIT ........................................................... 40

Tabela 2 - Diferenciação dos métodos de pesquisa............................................................... 42

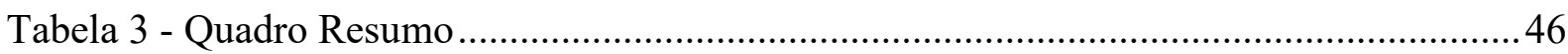

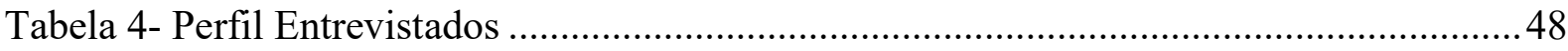

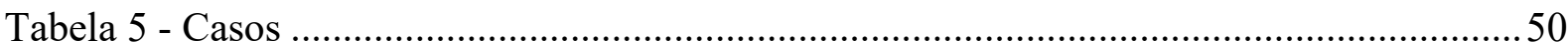

Tabela 6 - Comparação de tempo de internação, medicamentos e exames dos grupos ............58

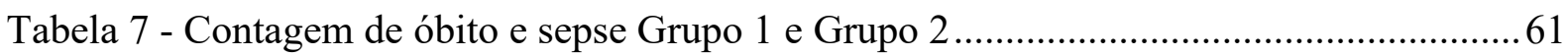

Tabela 8 - Dados período 1 e período 2 utilizados para simulação de Monte Carlo .................66

Tabela 9 - Relatório 1: Previsão da relação TMA/TMP............................................................66

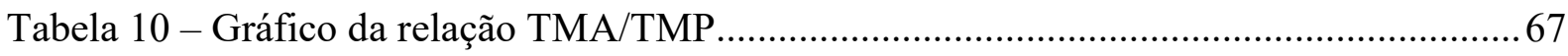

Tabela 11 - Relatório Estatístico da Previsão Relação TMA/TMP .......................................... 67

Tabela 12 - Diminuição dos dias de internação com nível de certeza de 73,64\%....................68

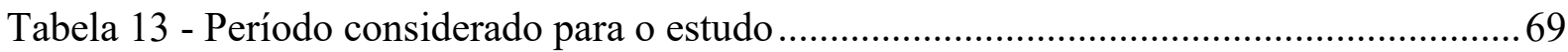

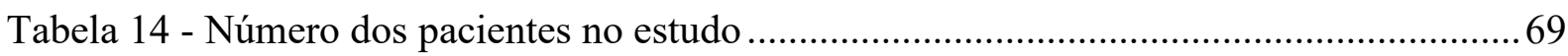




\section{LISTA DE ABREVIATURAS E SIGLAS}

ACA Affordable Care Act

ACE Análise de custo efetividade

ATS Avaliação de tecnologias em saúde

CITL Centro de Informação Technology Leadership

DOI Diffusion of innovation

DSR Design Science Research

EMRs Registros Médicos Eletrônicos

ENEGEP Encontro Nacional de Engenharia de Produção

HIT Health information technology

RCEI Razão de custo efetividade incremental

SUS Sistema Único de Saúde.

TAM Technology acceptance model

TAM2 Technology acceptance model 2

TGM Terapia de Ressuscitação Hemodinâmica Guiada por Metas

TI Tecnologia da Informação

TMA Tempo médio de atendimento

TOE Technology, organization and enviroment

TPB Theory of planned behaviour

UTAUT Uunified theory of acceptance and use of technology

UTI Unidade de Terapia Intensiva 


\section{SUMÁRIO}

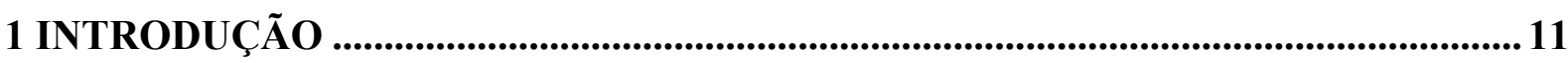

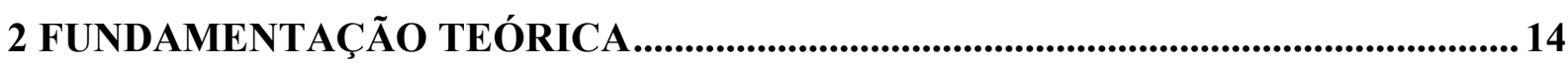

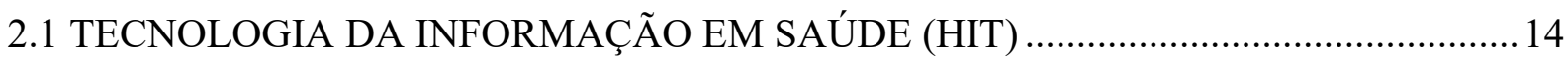

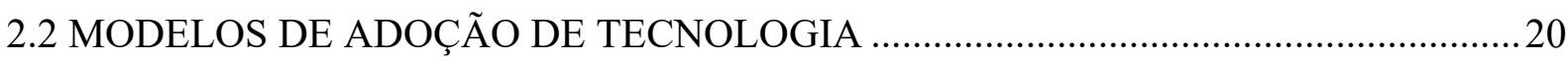

2.2.1 Framework TOE (Technology-Organization-Environment) ...................................21

2.2.2 Framework TPB - (Theory of Planned Behavior) .................................................23

2.2.3 Framework TAM e TAM2 - (Technology Acceptance Model) ......................................24

2.2.4 Framework DOI - (Diffusion of Innovation) ...................................................................26

2.2.5 Framework UTAUT - (Unified Theory of Acceptance and use of Technology) ........26

2.3 MODELOS DE AVALIAÇÃO DA TECNOLOGIA DA INFORMAÇÃO EM SAÚDE 27

2.3.1 Framework HOT-fit e HOTE........................................................................2

2.3.2 Framework Protocolo Custo Efetividade................................................................34

2.3.3 Framework Assimilação De Tecnologia ..................................................................38

2.3.4 Quadro Resumo Modelos de Avaliação Tecnologia da Informação em Saúde ....... 40

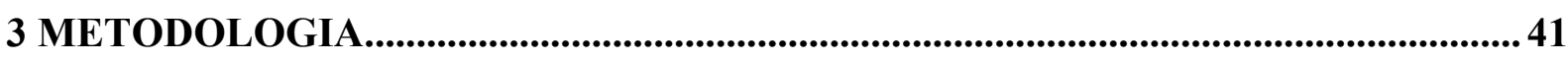

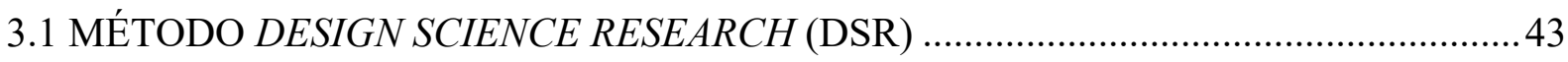

3.2 DESENVOLVIMENTO DO ARTEFATO - FRAMEWORK PROPOSTO........................45

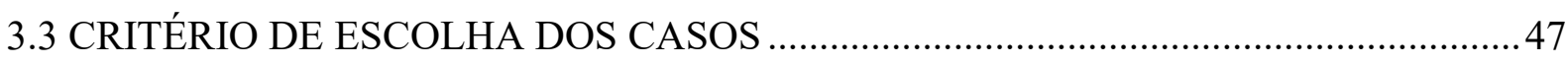

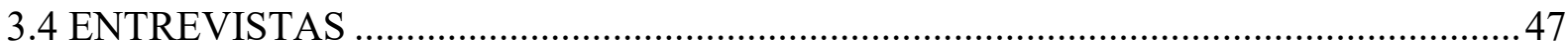

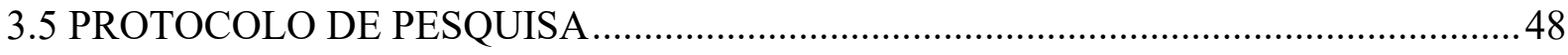

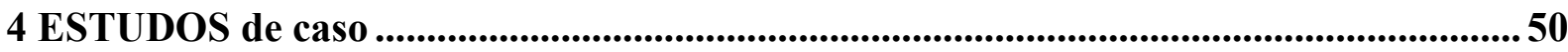

4.1 DESCRIÇÃO DA ORGANIZAÇÃO E TECNOLOGIA DA INFORMAÇÃO.................50

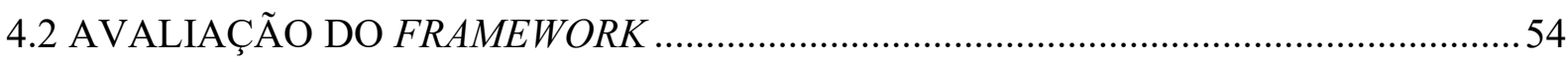

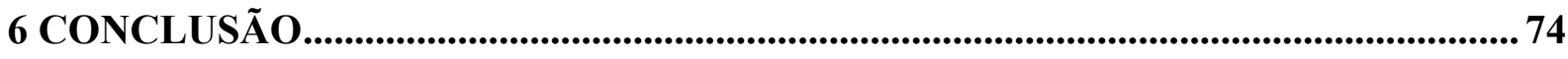

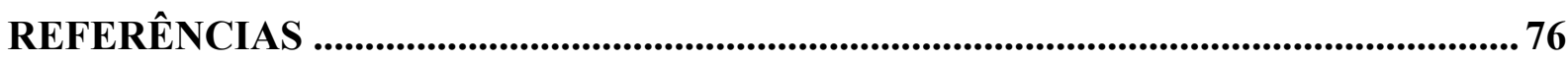

APÊNDICE A- LISTA DE VERIFICAÇÃO DSR ..........................................................82

APÊNDICE B- CHECKLIST FRAMEWORK TOE E TAM ............................................. 84

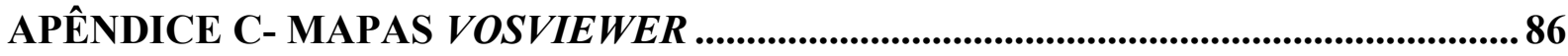




\section{INTRODUÇÃO}

De acordo com Leslie e Paradis (2018), o Affordable Care Act (ACA) encorajou, em 2009, o uso da Tecnologia da Informação em Saúde (ou Health information technology - HIT) para alcançar melhorias na saúde. O uso racional de tecnologias, implica a seleção de tecnologias a serem financiadas e a identificação das condições ou subgrupos em que elas deverão ser utilizadas, no sentido de tornar o sistema de saúde mais eficiente para o objetivo de proteger e recuperar a saúde da população. Marin (2010) menciona que os sistemas de tecnologia da informação são definidos como um conjunto de componentes que se relacionam, capazes de coletar, processar, armazenar e distribuir a informação para apoiar o processo de tomada de decisão e auxiliar no controle das organizações de saúde, dessa forma, os sistemas de tecnologia de informação em saúde incorporam um conjunto de dados, informações e conhecimento utilizados na área de saúde para sustentar o planejamento, o aperfeiçoamento e o processo decisório dos múltiplos profissionais da área da saúde envolvidos no atendimento aos pacientes e usuários do sistema de saúde.

Dobrzykowski et al. (2015), mencionam que, como finalidades principais, um sistema de tecnologia da informação deve servir para gerenciar a informação que os profissionais de saúde precisam para desempenhar as atividades com efetividade e eficiência, facilitar a comunicação, integrar a informação e coordenar as ações entre os múltiplos membros da equipe profissional de atendimento, fornecendo recursos para apoio financeiro e administrativo, além disso, também afirmam que a coordenação ou a troca de informações no hospital constitui um desafio, pois os processos são intensivos em informação, complexos e exigem várias interações, podendo ter um importante papel como meio de promover melhorias no processo de saúde. Elliott (2014) tem um estudo convergente, mencionando que existem poucas pesquisas que relacionem tecnologia da informação unida ao custo efetividade em setores individuais hospitalares (UTI por exemplo), ou procedimentos médicos, Rejeb, et al. (2017) argumentam que muitas organizações de saúde, consideram a aplicação da Tecnologia da Informação como uma chave fundamental para melhorar a gestão de saúde, porém poucos trabalhos analisam o impacto de sistemas de informação em termos econômicos e de qualidade dos cuidados aos pacientes, além disso também existem poucos estudos que considerem as características da tecnologia informação em saúde e as relações que vinculam a informação ao seu ambiente para tomada de decisão (Sedig, Naimi, Haggerty, 2017).

Segundo Leslie e Paradis (2018), os principais objetivos da adoção da tecnologia da informação em saúde são para alcançar a melhoria da saúde e qualidade de cuidados de saúde, 
segurança e comunicação entre todos os membros da equipe de cuidados, surgindo então, ao longo dos anos, a necessidade de mensurar tais aspectos, sendo assim, foram criadas técnicas de análises que objetivam mensurar o impacto de sua adoção.

A fim de entender se as tecnologias foram bem adotadas pela organização de saúde, Yusof, M. et al (2008), Wickramasinghe and Schaffer (2010), Lilford et al. (2014) e Sulaiman e Wickramasinghe (2014), elaboraram modelos que buscam avaliar HITs, para que possam ser usadas em sua totalidade, gerando os resultados esperados pela organização. Porém, de acordo com os autores, um estudo focado especificamente nos modelos de avaliação de tecnologias em saúde, tem sido até o momento bastante limitado. O foco nos modelos de avaliação de HITs deve ser destacado, já que a importância dessas tecnologias nas organizações de saúde hoje é reconhecida como um facilitador-chave para auxiliar a entrega de um melhor resultado de saúde.

Para Krauss (2003), afim de auxiliar na decisão quanto ao uso racional das tecnologias em saúde adotadas, no sentido de tornar o sistema de saúde eficiente para promover, proteger e recuperar a saúde da população, surge a metodologia de análise do custo efetividade (ACE), que é responsável pela elaboração de uma avaliação microeconômica, constituindo uma análise comparativa de cursos alternativos de ação tanto em termos de custos como de consequências: a diferença de custos (variável monetária) é comparada com a diferença de consequências (variável não monetária). Com isso, segundo Lilford et al. (2014), é possível fazer uma relação entre as tecnologias de informação em saúde hospitalar e custo efetividade para entender de que maneira o uso dessas tecnologias traz de benefício para o setor hospitalar sendo possível, avaliar a implementação, adoção, assimilação e eficácia dos sistemas de publicação eletrônica à medida que são introduzidos em hospitais.

Partindo do contexto discutido pelos autores como Rejeb, Pilet, Hamana, \& Durand, (2017), Dobrzykowski, (2015), Elliot (2014) e Lilfordet al. (2014) formulou-se a seguinte pergunta de pesquisa:

Como avaliar a adoção das tecnologias da informação em saúde a partir do modelo integrado TOE e TAM considerando a perspectiva do custo efetividade?

Partindo desta pergunta de pesquisa, o objetivo geral do presente trabalho consiste em estabelecer um estudo de avaliação de tecnologia da informação em saúde sob a perspectiva do custo efetividade, que consiste em elaborar um framework que combine diferentes modelos de adoção de tecnologia. Para desenvolvimento do estudo foi aplicado o método Design Science Research (DSR) e avaliação do framework foi feita através de três estudos de caso realizados em hospitais público e público-privado. 
A metodologia DSR é uma ciência responsável por propor a construção de artefatos (como por exemplo, modelos, frameworks, algoritmos) para solucionar problemas já existentes (Simon, 1996). A DSR é definida por Vaishnavi e Kuechler (2009) como um conjunto de técnicas analíticas que permitem o desenvolvimento de pesquisas nas diversas áreas, em particular na engenharia, constituindo um processo de projetar artefatos para resolver problemas, avaliar o que foi projetado ou o que está funcionando, e comunicar os resultados obtidos. 


\section{FUNDAMENTAÇÃO TEÓRICA}

A adoção de Sistemas de Informação em Saúde (SIS) demanda uma avaliação rigorosa onde torna-se necessário abordar problemas de tecnologia, humanos e organização (Yusof, M. M.et al.,2008). Segundo Baker (2011), existem inúmeros modelos de adoção de tecnologia (TOE, TPB, DOI, TAM, TAM2, UTAUT - serão detalhados posteriormente), responsáveis por análises à nível organizacional e à nível dos indivíduos, afirmam Oliveira e Martins (2011). Porém, para que haja sucesso na adoção da tecnologia, a implantação do sistema deverá se tornar uma rotina, ou seja, se transformar em parte importante das atividades da organização, essa definição refere-se a assimilação da tecnologia (Sulaiman E Wickramasinghe, 2014). De acordo com Sincak et. al. (2014) a tecnologia em saúde tem evoluído, e a principal contribuição consiste em reduzir a necessidade de cuidados humanos e envolvimento nos processos de controle e adaptação de rotina, passando a ter um papel de observador e tomador de decisão, no que diz respeito à saúde. Os sistemas focam na construção de princípios de decisão clínica automatizados auxiliando os médicos a fazerem previsões mais precisas. Ao serem adotadas, o uso racional das tecnologias em saúde pode ser mensurado através do custo efetividade, sendo uma ferramenta que faz uso de dados monetários e não monetários a fim de auxiliar a tomada de decisão (KRAUSS, 2003), mas a avaliação da tecnologia da informação em saúde constitui um desafio, pois constitui uma análise multidisciplinar demandando uma avaliação abrangente.

\subsection{TECNOLOGIA DA INFORMAÇÃO EM SAÚDE (HIT)}

Ammenwerth Elske et al (2012) e Sedig, Naimi, Haggerty (2017) concordam que nos últimos anos a tecnologia de informação em saúde sofreu um grande crescimento, desempenhando um papel fundamental, de forma a garantir eficácia e segurança ao ser usada em ambientes de cuidados de saúde, sendo ferramentas capazes de gerar e/ou sintetizar evidências; integrar evidências de várias fontes; apoiar a decisão para incorporar protocolos baseados em evidências clínicas; garantir a compreensão entre os sistemas através de vocabulários clínicos; facilitar a comunicação médico-paciente através de plataformas ligadas a web; construção de bases tecnológicas para o aprendizado e melhoria institucional.

HIT pode ser classificado em três tipos, de acordo com Hannah, Ball, Edwards (2009):

O primeiro é composto de sistemas limitados quanto ao objetivo e ao escopo. O mais comum é o sistema isolado (stand-alone) direcionado a uma área específica de aplicação, como exemplo, são aqueles dedicados para calcular a carga horária dos enfermeiros que vários 
hospitais possuem. Nos hospitais, os sistemas incluídos nesse grupo são direcionados a laboratórios, controle financeiro, radiologia, eletrocardiografia, controle de funções pulmonares, sistema de farmácia e nutrição. $\mathrm{Na}$ área da saúde pública, os sistemas de imunização podem ser considerados como outro bom exemplo dessa categoria (HANNAH, BALL, EDWARDS, 2009).

O segundo tipo é composto de sistema de informação hospitalar, que, com frequência, consiste em uma rede de comunicação, um componente clínico e um componente administrativo e financeiro. O componente geral de comunicação integra essas três grandes partes em um sistema de informação mais coeso. Um sistema típico de informação hospitalar nessa categoria possibilita ter terminais de computadores em cada posto de enfermagem, assim como terminais que estão ou podem ser acessados em cada área do hospital. Os terminais são unidos por meio de um ou mais computadores de grande porte, que podem estar no local ou fora dele. Em geral, são direcionados para a prestação de cuidado intensivo e organizados de acordo com as funções dos departamentos (HANNAH, BALL, EDWARDS, 2009).

O uso do terceiro tipo, sistemas corporativos de informação em saúde, está em expansão nos ambientes de saúde. Tais sistemas capturam e armazenam informações mais completas, provenientes da assistência à saúde contínua realizada por diferentes organizações, usando um modelo integrado de prestação de serviços. Esses registros são capturados e depositados em diversos tipos de mídia, incluindo som, imagem, animação e impressão. Os registros podem ser armazenados de modo central, em um formato total e abstrato, usando sistemas que realizam tratamento de dados armazenados. Como alternativa, esses registros podem ser fisicamente armazenados no ponto de captura e ligados a um registro virtual, que será unido somente quando for solicitado para atender à demanda dos cuidados. Esses sistemas são caracterizados por focar o paciente que está recebendo o cuidado, em diversos setores (por exemplo, ambulatório, unidade de tratamento intensivo, internação de longa permanência), com uma estrutura comum e organizada (HANNAH, BALL, EDWARDS, 2009).

A figura 1 apresenta exemplo de tecnologias de informação na área da saúde. 
Figura 1 - HIT integrado

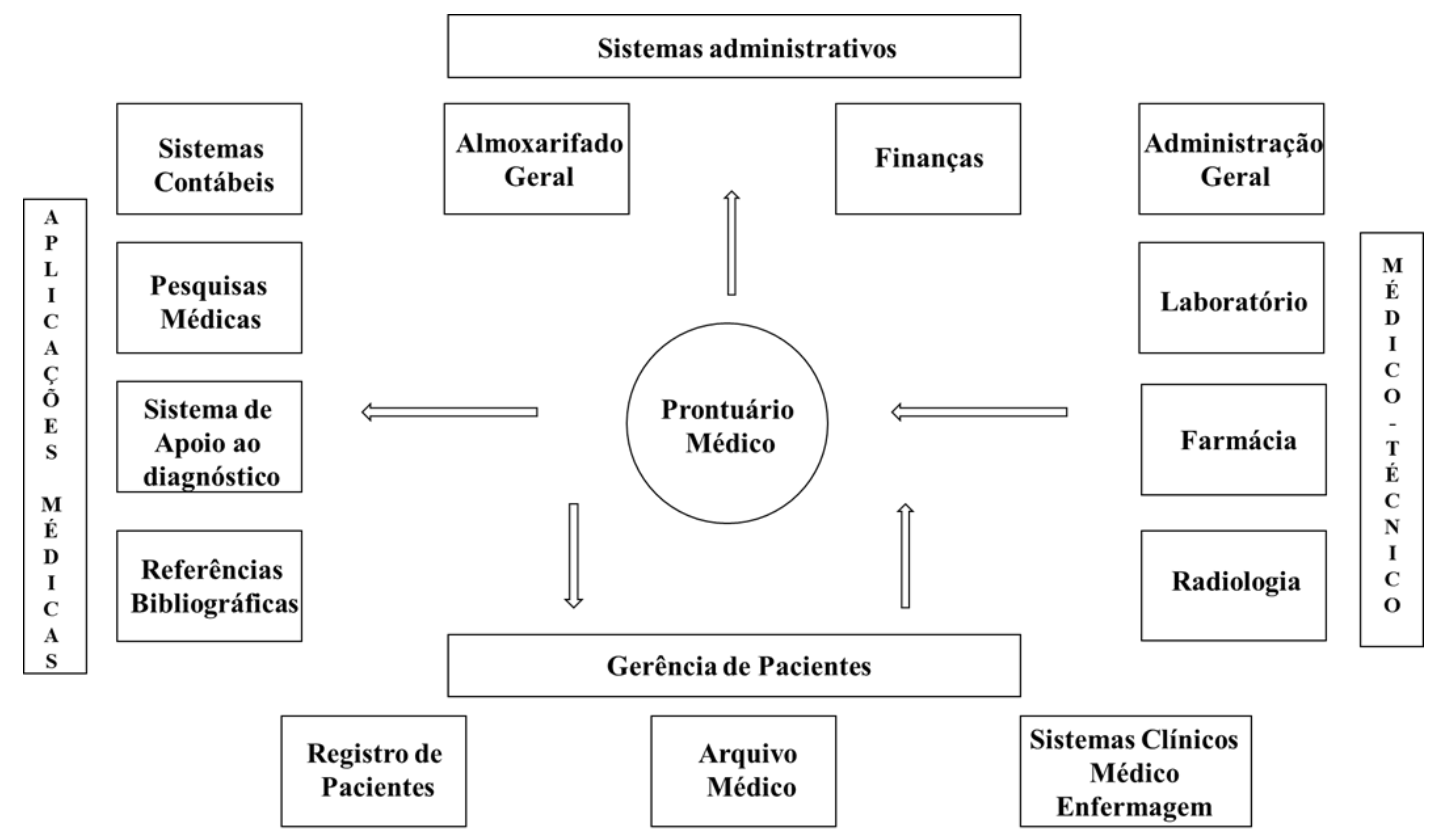

Fonte: Autor, adaptado de Rodrigues, 2001

Outro aspecto levantado por Moen e Knudsen (2013), Barrett (2014) e Sedig, Naimi, Haggerty (2017) para as atividades de cuidado com saúde, se trata das contribuições do uso das tecnologias de informação em saúde, de forma que podem ser divididas em quatro tipos mais comuns:

1 - A tecnologia pode ser categorizada de forma centrada no sistema, por exemplo, eles podem ser classificados em termos das especificações do sistema, hardware ou software;

2 - Categorizar o uso de acordo com o contexto operacional ou disciplinar em que são utilizados, exemplo, informática clínica, informática de saúde pública, informática de enfermagem, informática de imagem ou informática de saúde do paciente;

3 - Categorizar em termos de capacidade de funcionalidade, que, de acordo com Faraj (2012), as definições centradas na funcionalidade tratam os HITs em termos de tipo de objetivos operacionais ou tarefas que eles pretendem apoiar;

4 - Categorizar os HITs de acordo com os processos de conhecimento que eles suportam, por exemplo, categorizar informações de sistemas em termos de suporte para criação, armazenamento, transferência ou aplicação de conhecimento. Esse enquadramento de HITs classificaria, por exemplo, o protocolo eletrônico como dispositivos de armazenamento de 
conhecimento, sistemas de suporte em termos de aplicação do conhecimento e sistemas de entrada de pedidos em termos de transferência de conhecimento.

Portanto, Sedig, Naimi, Haggerty, (2017) sugerem que o uso da tecnologia de informação em saúde não pode ser definido e projetado independentemente dos ambientes em que são utilizados, com isso, é importante que, para fazer de forma correta o uso das tecnologias de informação em saúde de forma que elas sirvam na tomada de decisão, alguns itens devem estar presentes, são eles:

(I) a informação deve estar correta para cada atividade,

(II) a informação pode ser processada e analisada de forma que apoie nas atividades necessárias, (III) a informação deve estar adequadamente representada e exibida para atender as atividades, (IV) as informações devem interagir de forma correta entre si permitindo o seu uso de forma assertiva.

Partindo deste pressuposto, Ash et. al. (2004) adiciona que para apoiar essas atividades é necessário o uso das tecnologias de informação, formando um conjunto de sistemas cognitivos que se trata de uma unidade de análise consistindo em:

(a) HIT e suas propriedades e características;

(b) um profissional do cuidado em saúde e suas características e necessidades; e

(c) a relação entre os dois subsistemas a partir dos quais as tarefas e atividades do cuidado em saúde emergem.

O sistema cognitivo conjunto é apresentado na figura 2 como uma unidade de análise que inclui a tecnologia da informação de saúde, usuários e a relação que os liga

Figura 2 Sistema Cognitivo Conjunto

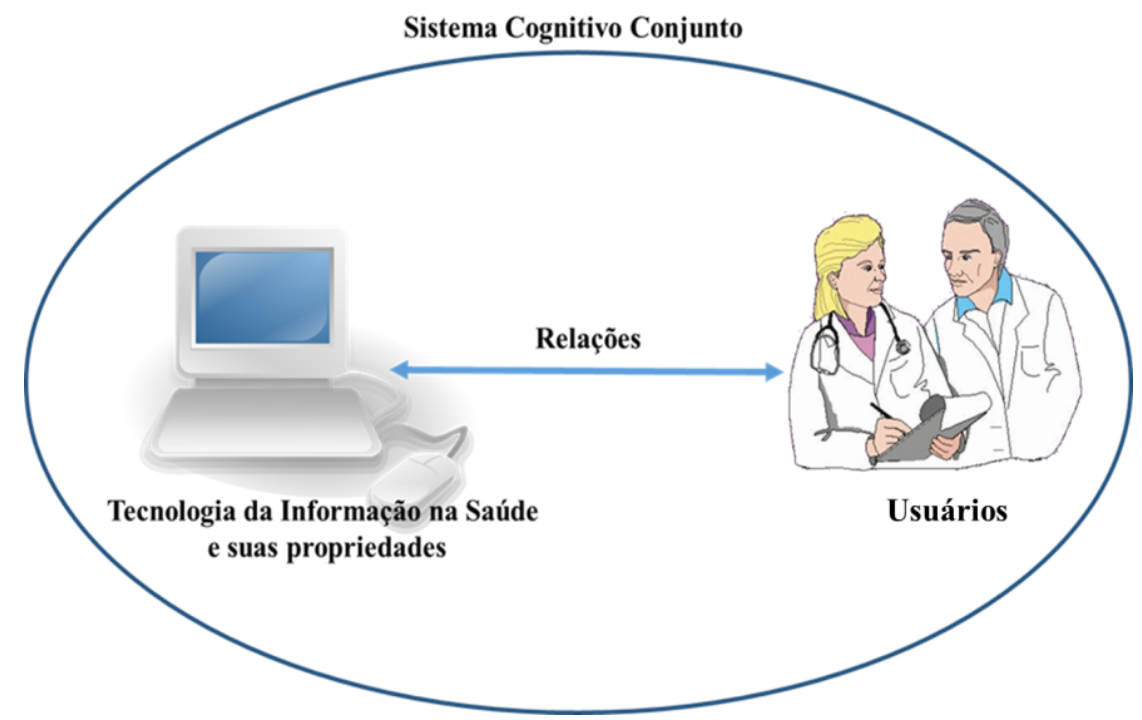

Fonte: Autor, adaptado de Sedig, Naimi, Haggerty, 2017 
Para facilitar o fluxo de informação dentro de um sistema cognitivo conjunto, o sistema pode ser dividido em cinco subsistemas ou espaços, cada um dos quais opera com informações em formas distintas, porém interdependentes, dando importância e distribuindo a prioridade de cada atividade. Os cinco subsistemas são: (I) o espaço de informação, (II) o espaço de computação, (III) o espaço de representação, (IV) o espaço de interação e (V) o espaço mental (Sedig, Parsons \& Babanski, 2012; Parsons \& Sedig, 2013; Sedig \& Parsons, 2013). A Figura 3 exibe cada um desses espaços separadamente, bem como os processos de informação que ocorrem dentro deles

Figura 3 - Os cinco espaços que compõem um sistema cognitivo conjunto e funções.

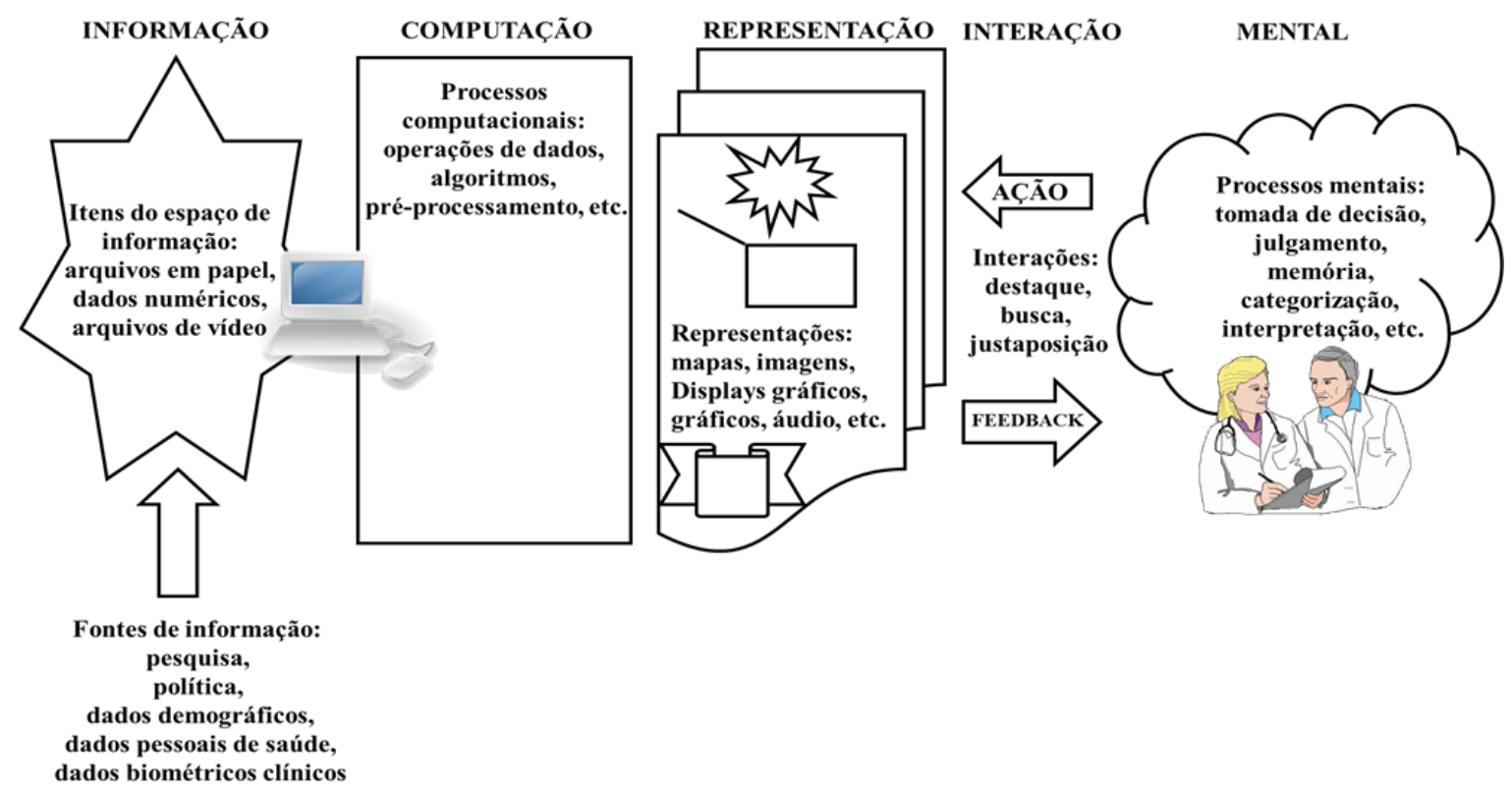

Fonte: Autor adaptado de Sedig, Naimi, Haggerty, 2017

O espaço de informação, possui uma área de depósito de informações realizadas por profissionais interessados para realizar as atividades dos cuidados em saúde (Sedig, Parsons, 2013). O conteúdo desse espaço pode ser real ou possível, ou seja, já pode estar lá ou pode ser gerado de forma contínua, como no caso de algoritmos ou outros processos computacionais. É possível combinar e manter informações (quantitativa ou qualitativa) de diferentes fontes ou ambientes dentro de uma única área, permitindo a análise.

O espaço de computação, de acordo com Sedig, Naimi, Haggerty (2017), os dados do espaço de informações são processados tornando-os útil para as análises dos cuidados em saúde. Esses processos computacionais podem executar funções que vão desde a limpeza e préprocessamento de dados (transformando dados brutos em bancos de dados utilizáveis). Por 
exemplo, através de técnicas computacionais os HITs podem descobrir padrões dentro dos dados de resposta ao medicamento e integrá-los com dados genômicos.

O espaço de representação, os conteúdos do espaço de informações e processados através do espaço computacional são codificados de forma a deixar as informações mais claras para o profissional interessado, já que os dados desses dois espaços anteriores nunca são diretamente acessíveis aos profissionais, portanto, o espaço de representação desempenha o papel crucial de apresentar as respostas pretendidas através de diagramas, mapas, imagens, textos, vídeos, sons ou outros (Sedig, Naimi, Haggerty, 2017).

O espaço de interação contém todas as ações e o intervalo de reações subsequentes que são possíveis dentro de uma HIT. Nesse espaço encontra-se como os usuários atuam sobre as possibilidades oferecidas no sistema, reações subsequentes ou feedback, permitindo aos profissionais explorar, transformar e usar melhor as informações de forma dinâmica. As possibilidades de interação (ação e reação) que existem dentro de um sistema conjunto são a base para a tomada de decisão dos profissionais com informações, o que, por sua vez, permitem a descoberta de novas aplicações e perspectivas sobre a informação. Por exemplo, um médico que encontra um paciente com uma condição genética pouco conhecida, se a doença é desconhecida do médico, ele pode procurar um diagnóstico em um bancos de dados correlacionando aspectos do caso clínico com os detalhados no resultados de pesquisa que ela coleciona (Demelo, Parsons, \& Sedig, 2017; Parsons et al., 2015).

E por fim, ainda de acordo com Sedig, Naimi, Haggerty (2017), o espaço mental, referese à mente dos profissionais, que é a localização dos processos cognitivos que contribuem para atividades emergentes de cuidados em saúde.

Dessa forma, Sedig e Parsons (2013) e Sedig, Naimi, Haggerty (2017) concordam que cada espaço contribui de maneira essencial, seja como apresentação, representação ou processo na transformação de dados de conhecimento brutos em resultados utilizáveis e adequadamente aplicados, os espaços não existem ou operam isoladamente um do outro; cada um contribui de forma indispensável para o fluxo de informações necessário para as atividades do cuidados em saúde, então, cada espaço deve ser projetado para cumprir seu papel específico e trabalhar em conjunto com os outros, permitindo que a informação flua entre os espaços para atingir metas bem definidas. 


\subsection{MODELOS DE ADOÇÃO DE TECNOLOGIA}

A literatura indica uma relação entre HIT e a adoção da tecnologia, conforme evidenciado pelos mapas preparados através do VosViewer (Apêndice C). Nesse contexto, Lilford et al. (2014) mencionam que a partir da avaliação tecnológica é possível fazer uma relação entre as tecnologias de informação em saúde hospitalar e de que maneira o uso dessas tecnologias traz de benefício para o setor hospitalar sendo possível, avaliar a implementação, adoção, eficácia dos sistemas de publicação eletrônica à medida que são introduzidos em hospitais. A busca por maior eficiência na gestão de saúde levou a inúmeras propostas para aumentar a adoção de TI em saúde. Dois estudos realizados, um pelo RAND Corporation e outro pelo Centro de Informação Technology Leadership (CITL), estimaram que cerca de US\$ 80 bilhões em economia anual líquida é potencialmente atribuída à essa tecnologia (Orzag, 2008).

Freedman et al. (2018) discutiram em seu estudo os impactos relacionados com a adoção de tecnologia da informação em saúde como os registros médicos eletrônicos (EMRs). A pesquisa teve como foco analisar os indicadores de segurança do paciente. Os autores mencionam evidências que $E M R$ s reduzem a probabilidade de eventos adversos relacionados com a segurança do paciente, particularmente para pacientes menos complexos. Além disso, outro ponto discutido pelos autores sugere o desempenho financeiro positivo, com base em estimativas de savings obtidos com a adoção de tecnologias como EMRs.

Segundo Sedig, Naimi, Haggerty (2017), nos últimos anos a adoção das HIT teve um crescimento considerável, contribuindo para a comunicação médico-paciente, bases tecnológicas para o aprendizado e melhoria institucional. Este tipo de tecnologia traz muitos desafios e, portanto, compreender a sua adoção torna-se um fator importante para alavancar o potencial de resultados na gestão da saúde.

Um meio de compreender a adoção de novas tecnologias e os seus fatores críticos é através dos modelos de adoção de tecnologias da informação em organizações, Oliveira e Martins (2011), afirmam que dentre as muitas teorias usadas na área de sistemas de informação, as mais usadas para análise da adoção de tecnologia da informação (TI) são:

i. TOE (technology, organization and enviroment - tecnologia-informação-ambiente) (Tornatzky e do Fleischer (1990);

ii. TPB (theory of planned behaviour - teoria do comportamento planejado) (Ajzen 1985, 1991); 
iii. TAM (technology acceptance model -modelo de aceitação de tecnologia) (Davis 1989; Davis et al. 1989);

iv. TAM2 (technology acceptance model 2 - versão mais recente de TAM conhecido como TAM2) (Venkatesh e Davis 2000);

v. UTAUT (unified theory of acceptance and use of technology - teoria unificada de aceitação e uso de tecnologia) (Venkatesh et al. 2003);

vi. $\quad$ DOI (diffusion of innovation - difusão da inovação) (Rogers, 1995).

Entretanto, salientam que apenas os modelos DOI e TOE são para análise em nível organizacional, sendo os demais (TAM, TAM 2, TPB e UTAUT) para análises no nível dos indivíduos (OLIVEIRA E MARTINS, 2011).

\subsubsection{Framework TOE (Technology-Organization-Environment)}

Tornatzky e do Fleischer (1990) propuseram o framework denominado TOE, o qual é visto por grande parte dos estudos de adoção de inovação tecnológica como a estrutura mais adequada para compreender a adoção da tecnologia da informação em um contexto organizacional (Thomas et al., 2008; Chang et al., 2006, Oliveira et al. 2011). O framework TOE explica que três diferentes contextos influenciam nas decisões de adoção de novas tecnologias, sendo eles: contexto tecnológico, organizacional e o ambiente conforme apresentado na figura 4. O framework TOE como originalmente apresentado, e mais tarde adaptado em estudos de adoção de TI, fornece um quadro analítico útil que pode ser usado para estudar a adoção e assimilação de diferentes tipos de inovação de TI.

Figura 4 - Estrutura TOE.

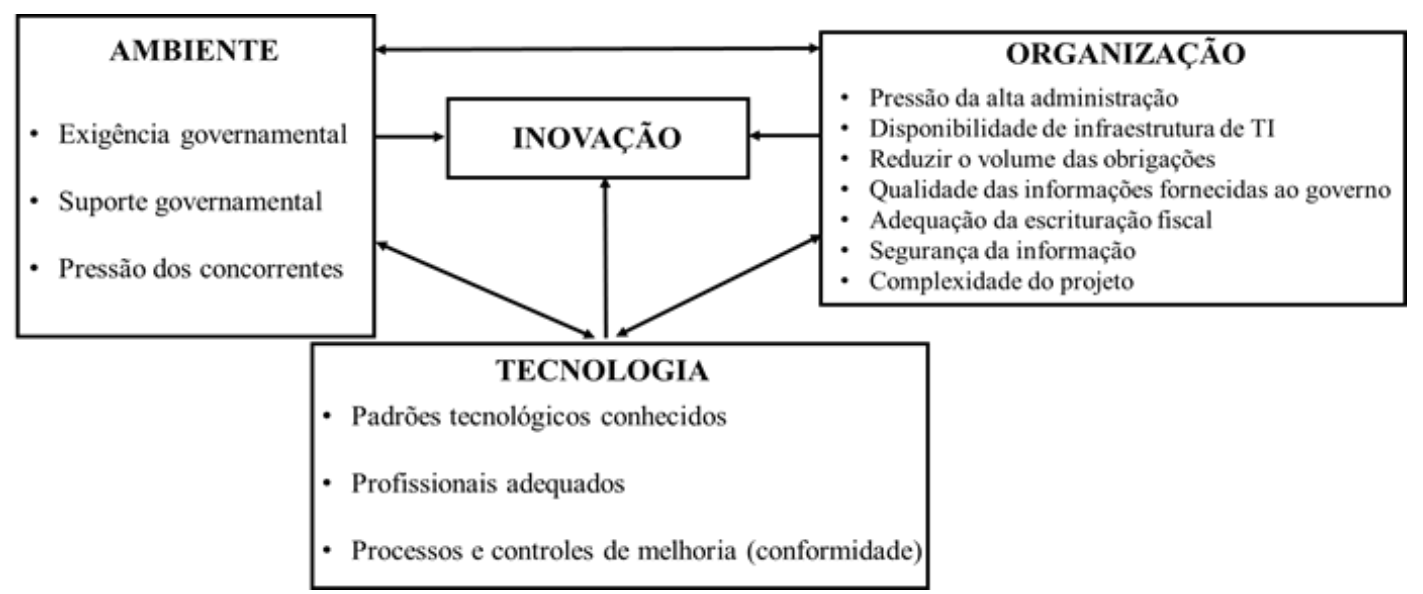

Fonte: Autor adaptado de Baker, 2011. 
Os fatores tecnológicos descrevem as características do ambiente tecnológico, que podem influenciar a difusão dos sistemas na organização, estas características incluem diversas dimensões da tecnologia, desde a vantagem relativa à qualidade da informação do sistema, que aumenta a difusão da tecnologia da informação na organização. Os fatores organizacionais referem-se ao escopo, recursos e tamanho da organização, e a dimensão ambiente refere-se ao contexto em que a empresa desenvolve a sua indústria, concorrentes e relações com o governo (Tornatzky e Fleischer ,1990).

De acordo com Handayani et al. (2017) a gestão hospitalar e os desenvolvedores de TI devem ter mais compreensão sobre os fatores não-tecnológicos para melhor planejar sua implementação. $\mathrm{O}$ envolvimento da gestão é fundamental para assegurar que sua implementação tenha impacto e proporcione benefícios para os usuários, bem como os hospitais.

Alkraiji et al. (2016) utilizaram o framework TOE e efetuaram uma pesquisa em organizações de saúde e identificaram dezessete fatores relacionados com a adoção de tecnologia da informação em saúde relacionada com dados de saúde. Os resultados demonstraram uma lista de fatores-chave de diferentes aspectos que afetam adoção decisão de padrões de dados de saúde nas organizações. Os fatores tecnológicos são: complexidade e compatibilidade dos padrões de dados de saúde, infraestrutura de TI, incertezas em relação aos custos, integração de sistemas e aprimoramento do uso de sistemas avançados. Os principais fatores organizacionais são: a falta de políticas e procedimentos adequados e plano de gestão da informação, resistência a mudança, análise de dados, enquanto os principais fatores ambientais são: a falta de regulador nacional e um plano de troca de dados, sistema nacional de saúde e carência de profissionais.

Angst e Agarwal (2009) mencionam que no contexto emergente de digitalização de saúde, registros eletrônicos constituem um avanço tecnológico significativo da forma que a informação médica é armazenada, comunicada e processada pelas várias partes envolvidas na entrega dos cuidados de saúde e esta característica gera desafios relacionados com sua adoção por parte das organizações de saúde, sendo portanto muito pertinente as aplicações de frameworks como o TOE para melhor compreensão da adoção de novas tecnologias na área de saúde. 


\subsubsection{Framework TPB - (Theory of Planned Behavior)}

Ajzen (2002) definiu a Teoria do Comportamento Planejado (TPB - theory of planned behavior) que é baseada no pressuposto de que os indivíduos tomam suas decisões de forma eminentemente racional e utilizam sistematicamente as informações que estão disponíveis, considerando as implicações de suas ações antes de decidirem se devem ou não se comportar de determinada forma.

Ajzen (2002) defende que o comportamento humano é guiado por três tipos de crenças: comportamentais, normativas e de controle. As crenças comportamentais produzem uma atitude favorável ou desfavorável em relação ao comportamento, as crenças normativas resultam de uma pressão social, já as crenças de controle podem facilitar ou impedir a performance de um comportamento. Assim, atitude em relação ao comportamento, norma subjetiva e percepção se o comportamento está sujeito a vontade, conduzem a formação de uma intenção comportamental. Geralmente, quanto mais favoráveis são as atitudes e a norma subjetiva e maior o controle percebido, maior deve ser a intenção pessoal de realizar o comportamento.

Por fim, dado um suficiente grau de controle do comportamento, as pessoas tendem a realizar suas intenções quando as oportunidades aparecem. Dessa forma, a intenção comportamental é considerada o antecessor imediato do comportamento. Ainda segundo Ajzen (2002), para modificar o comportamento, intervenções podem ser direcionadas a um ou mais de seus três determinantes: atitudes, normas subjetivas ou controle percebido. Uma vez que os indivíduos tenham verdadeiro controle sobre o comportamento, novas intenções comportamentais podem ser produzidas e convertidas em comportamento real.

Armitage (2003) e Ajzen (2002) concordam que os três antecedentes das intenções comportamentais se baseiam em crenças, portanto, torna-se importante conhecer as que são mais preponderantes na memória, para que sejam medidas. Dado que as crenças preponderantes tenham sido identificadas, um questionário padrão de TPB pode ser elaborado, incluindo as diversas medidas dos constructos que incluem crenças, atitudes, normas subjetivas, percepções de controle comportamental, intenções e comportamento real. Por meio de técnicas estatísticas tais como análise de regressão múltipla e metodologias recentes mais sofisticadas como equações estruturais, pode-se determinar, com um certo grau de certeza, a contribuição relativa de atitudes, normas subjetivas e percepções de controle comportamental para prever as intenções, assim como as relativas contribuições de intenções e percepções de controle para a previsão com comportamento efetivo. 
Para Ajzen (2002), as crenças fornecem uma fotografia da fundamentação cognitiva do comportamento de uma dada população num determinado momento, possibilitando entender por que as pessoas têm certas atitudes, normas subjetivas ou percepções de controle comportamental. Vale afirmar que a TPB é, hoje, o modelo dominante das relações atitudecomportamento, possibilitando a previsão acurada das intenções comportamentais, a partir de um conjunto reduzido de variáveis antecedentes - atitude relativa ao comportamento, norma subjetiva e controle percebido do comportamento (ARMITAGE; CHRISTIAN, 2003).

\subsubsection{Framework TAM e TAM2 - (Technology Acceptance Model)}

De acordo com SILVA et. al. (2008), as pesquisas associadas à adoção de tecnologias da informação, bem como a avaliação dos seus impactos, são atividades importantes na investigação de sistemas de informação, quer se trate de contextos organizacionais, quer se trate da sociedade. Consequentemente, as companhias e a sociedade necessitam desenvolver, não apenas uma cultura geralmente favorável, mas características culturais específicas que maximize o uso da tecnologia ao desempenho de seus empregados e no seu dia-a-dia.

O pesquisador em sistemas de informação F. D. Davis iniciou os estudos baseados na problemática de uso em sistemas de forma a propor um modelo que auxiliasse e previsse o uso dos sistemas, desenvolvendo o Technology Acceptance Model (TAM), modelo de aceitação de tecnologia, como afirma Bueno et al (2004).

O modelo TAM foi projetado para compreender a relação causal entre variáveis externas de aceitação dos usuários e o uso real do computador, buscando entender o comportamento deste usuário através do conhecimento da utilidade e da facilidade de utilização percebida por ele (SILVA et. al., 2008).

Silva et. al. (2008) apresenta que Davis (1989) propunha que as pessoas tendem a usar ou não uma tecnologia com o objetivo de melhorar seu desempenho no trabalho - utilidade percebida. Porém, mesmo que essa pessoa entenda que uma determinada tecnologia é útil, sua utilização poderá ser prejudicada se o uso for muito complicado, de modo que o esforço não compense o uso - facilidade percebida.

A figura 5 sugere que os indivíduos usarão a tecnologia se acreditarem que este uso fornecerá resultados positivos, focalizando-se na facilidade de uso percebida e na utilidade percebida. Assim, o TAM normalmente é utilizado para entender a razão pela qual o usuário aceita ou rejeita a tecnologia de informação e como melhorar a aceitação, oferecendo, desse modo, um suporte para prever e explicar a aceitação. 
Figura 5 - Modelo TAM.

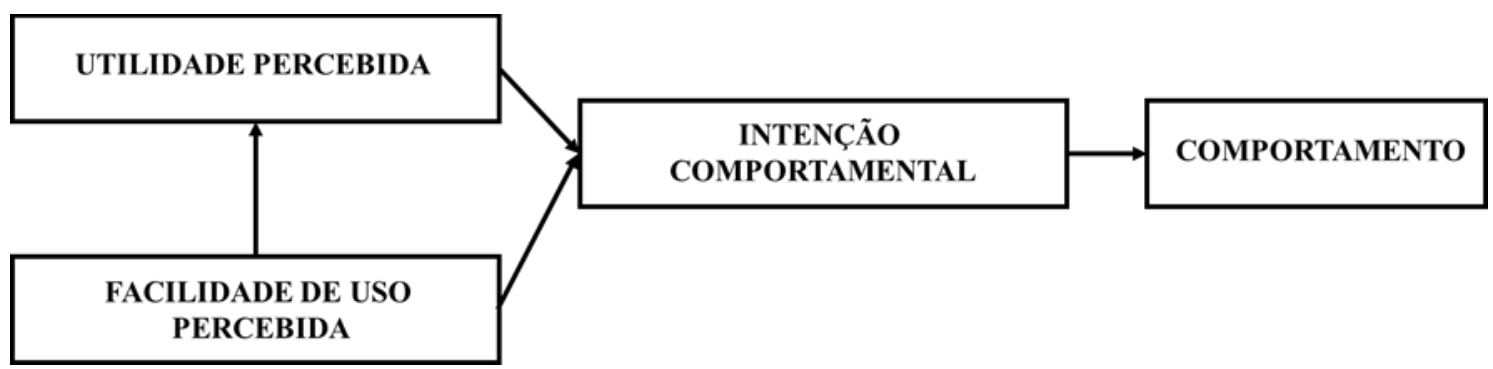

Fonte: Autor adaptado de Silva et. al. 2008

A teoria do TAM aborda que uma intenção comportamental do indivíduo, para usar um sistema, é determinada por duas crenças, facilidade percebida de uso e utilidade percebida, sendo que ambas medem completamente os efeitos das variáveis externas, como características do sistema, processo de desenvolvimento, treinamento, na intenção de uso (DAVIS, 1989).

Segundo Dias et al (2003) alguns autores abordam o comportamento dos usuários em relação à não aceitação da tecnologia como uma questão de resistência às mudanças, sem entender, contudo os motivos de tal resistência. Porém conforme explica Maia e Cedón (2005) existem outros fatores que também comprometem o comportamento do usuário, como por exemplo, a habilidade técnica especifica desse usuário, influenciando diretamente na utilização dos sistemas, assim como, o contexto e o espaço onde a pessoa desenvolve o uso.

Silva et. al. (2008) afirmam que apesar do importante corpo de investigação associado à adoção de tecnologias da informação, ela ainda não consegue explicar todos os fenômenos associados. Tal fato se deve pela complexidade dos processos de adoção, principalmente porque envolvem pessoas e interferem com as suas percepções de natureza cognitiva, as quais nem sempre se regem por interesses organizacionais (antes são afetados por questões de natureza individual e cultural) e, por outro, à natureza fortemente dinâmica e evolutiva das tecnologias da informação, mudando muito rapidamente os paradigmas tecnológicos e criando novos campos de investigação.

Após a criação o modelo TAM, foi proposto o modelo TAM2, considerado como a evolução do TAM, onde aparecem adicionados a este novo modelo: influência social, imagem, relevância do trabalho, qualidade e demonstrabilidade do resultado que a tecnologia fornece. 


\subsubsection{Framework DOI - (Diffusion of Innovation)}

De acordo com Oliveira e Martins (2011), a DOI analisa a inovação organizacional a partir da influência das seguintes variáveis: características individuais, relacionadas à atitude dos líderes para mudança; características internas da estrutura organizacional, incluindo aspectos como centralização, complexidade, formalização e tamanho e características externas da organização, relacionadas ao entendimento da mesma como um sistema aberto, sendo que esta teoria tem sido aplicada e adaptada em pesquisas na área de sistemas de informação.

De acordo com Rogers (2003), é uma teoria que procura explicar como, por que e em que proporção novas ideias e tecnologias se disseminam. Rogers (2003) argumenta que a difusão é o processo pelo qual uma inovação é comunicada ao longo do tempo entre os participantes de um sistema social. As origens da difusão da teoria das inovações são variadas e abrangem múltiplas disciplinas. Rogers (2003) propõe que quatro elementos principais influenciam a disseminação de uma nova ideia: a própria inovação, os canais de comunicação, o tempo e um sistema social. A inovação deve ser amplamente adotada para se sustentar. Dentro da taxa de adoção, há um ponto em que uma inovação atinge a massa crítica, que também pode ser entendida como a curva da adoção.

As categorias dos adotantes são: os inovadores, primeiros adeptos, maioria inicial, maioria tardia e retardatários. A difusão se manifesta de diferentes maneiras e é altamente sujeita ao tipo de adotantes e ao processo de tomada de decisão da inovação. O critério para a categorização do adotante é a qualidade de ser inovador, definida como o grau em que um indivíduo adota uma nova ideia.

\subsubsection{Framework UTAUT - (Unified Theory of Acceptance and use of Technology)}

Venkatesh et al. (2003) tinham o intuito de unificar os modelos anteriores e gerar um ainda mais completo, que abrangesse os principais construtos relacionados à aceitação da TI, contribuindo significativamente para os estudos na área dos Sistemas de Informação (Raaij \& Schepers, 2008). Apesar de algumas teorias não estarem diretamente ligadas com a área da TI, elas contribuíram significativamente para a construção do modelo.

O modelo consiste em quatro construtos determinantes da intenção e do uso da TI e quatro moderadores que foram extraídos dos oito modelos anteriormente. Os determinantes são: expectativa de desempenho (grau em que o indivíduo acredita que, usando o sistema, terá ganhos de desempenho no trabalho); expectativa de esforço (onde o indivíduo relaciona o grau 
de facilidade associado ao uso da tecnologia); a influência social (grau de percepção do indivíduo em relação aos demais quanto à crença destes para com a necessidade de uma nova tecnologia ser usada ou não); e as condições facilitadoras (grau pelo qual o indivíduo acredita que existe uma infraestrutura organizacional e técnica para suportar o uso do sistema) (Venkatesh et al., 2003). Os construtos moderadores da intenção e uso da TI são: gênero, idade, experiência do indivíduo e voluntariedade do uso - o quanto o uso da tecnologia é voluntário, livre e não obrigatório (Venkatesh et al., 2003).

\subsection{MODELOS DE AVALIAÇÃO DA TECNOLOGIA DA INFORMAÇÃO EM SAÚDE}

A avaliação de tecnologias em saúde (ATS) é definida como um campo multidisciplinar que estuda as implicações clínicas, sociais, éticas e econômicas do desenvolvimento, difusão e uso da tecnologia em saúde.

Com isso, pesquisadores como Yusof, M. et al (2008), Sulaiman e Wickramasinghe, (2014) e Lilford et al. (2014), por exemplo, foram responsáveis por elaborar modelos que auxiliassem na avaliação das tecnologias em saúde, cada um analisando aspectos diferentes e buscando apoiar as decisões relacionadas ao impacto da HIT, sendo eles: framework HOTE e HOT-fit, framework protocolo custo efetividade e framework assimilação de HIT, apresentados a seguir.

\subsubsection{Framework HOT-fit e HOTE}

De acordo com Yusof et al. (2008), a adoção de HIT demanda uma avaliação rigorosa sendo necessário abordar problemas de tecnologia, humanos e organização. Os métodos de avaliação atuais avaliam diferentes aspectos do HIT e podem ser melhorados, com isso, surgiu o HOT-fit, uma nova estrutura de avaliação humana, organizacional e de adequação à tecnologia, desenvolvida após uma avaliação crítica dos resultados dos estudos de avaliação HIT existentes.

Yusof et al. (2008) também menciona que o HOT-fit foi baseado em modelos anteriores de avaliação de TI, principalmente no "Modelo de Sucesso de SI" e o "Modelo de Ajuste de Organização de TI", sendo que o primeiro modelo tem seu sistema organizado em seis dimensões, sendo elas: qualidade do sistema (as medidas do processamento da informação - é o próprio sistema), qualidade da informação (as medidas de saída TI), qualidade de serviço (as medidas de suporte técnico ou serviço), uso da informação (consumo de quem recebe a 
informação de TI), satisfação do usuário (resposta de quem recebeu/usou a informação de TI) e benefícios (o impacto geral da TI), ao analisar o modelo é possível concluir que ele leva à direções positivas e negativas, se houver o uso efetivo do sistema, maior será o benefício causando um uso mais intensivo do sistema, em contraste, o uso insuficiente do sistema resultará em resultados irrelevantes.

Já o modelo de Ajuste de Organização de TI trabalha com análise de elementos organizacionais internos e externos, onde os componentes internos incluem estratégia de negócios, estrutura organizacional, processos de gerenciamento e funções e habilidades. $\mathrm{O}$ ajuste externo é conseguido através da formulação de uma estratégia organizacional baseada em tendências e mudanças ambientais, como mercado, indústria e tecnologia. Sendo assim, espera-se que a TI afete o processo de gerenciamento, impactando, assim, no desempenho organizacional e, até certo ponto, em sua estratégia.

Os benefícios trazidos pela adoção da TI serão notados em sua totalidade, principalmente se três pré-requisitos forem levados em consideração:

(I) Os membros da organização precisam ter clara a visão organizacional e as razões por trás dessa adoção, para prepará-los para mudanças organizacionais e, portanto, reduzir os desafios presentes na adoção da tecnologia;

(II) A estratégia da organização (negócios e TI), a tecnologia da informação e as dimensões organizacionais devem estar alinhadas entre si;

(III)A organização deve se equipar de uma infraestrutura de TI de qualidade, como uma rede eletrônica e os padrões alinhados

A união dos três pré-requisitos e da análise dos ajustes internos e externos auxiliam na identificação dos problemas de implementação de TI.

O autor conclui que os modelos apresentados são capazes de se completar, pois fatores de análise que faltam em um modelo estão presentes no outro, por exemplo: as dimensões e medidas de avaliação específicas que faltam no "Modelo de Ajuste de Organização de TI" estão presentes no "Modelo de Sucesso de SI", sendo assim o autor consegue apresentar o HOT-fit como uma nova estrutura de avaliação, composta pela junção dos dois modelos e adicionadas as medidas necessárias. As figuras 6,7 e 8 apresentam as estruturas do "Modelo de Sucesso de SI", "Modelo de Ajuste de Organização de TI" e Modelo HOT-fit. 
Figura 6 - Modelo de Sucesso de SI.

\section{MODELO DE SUCESSO DE SI}

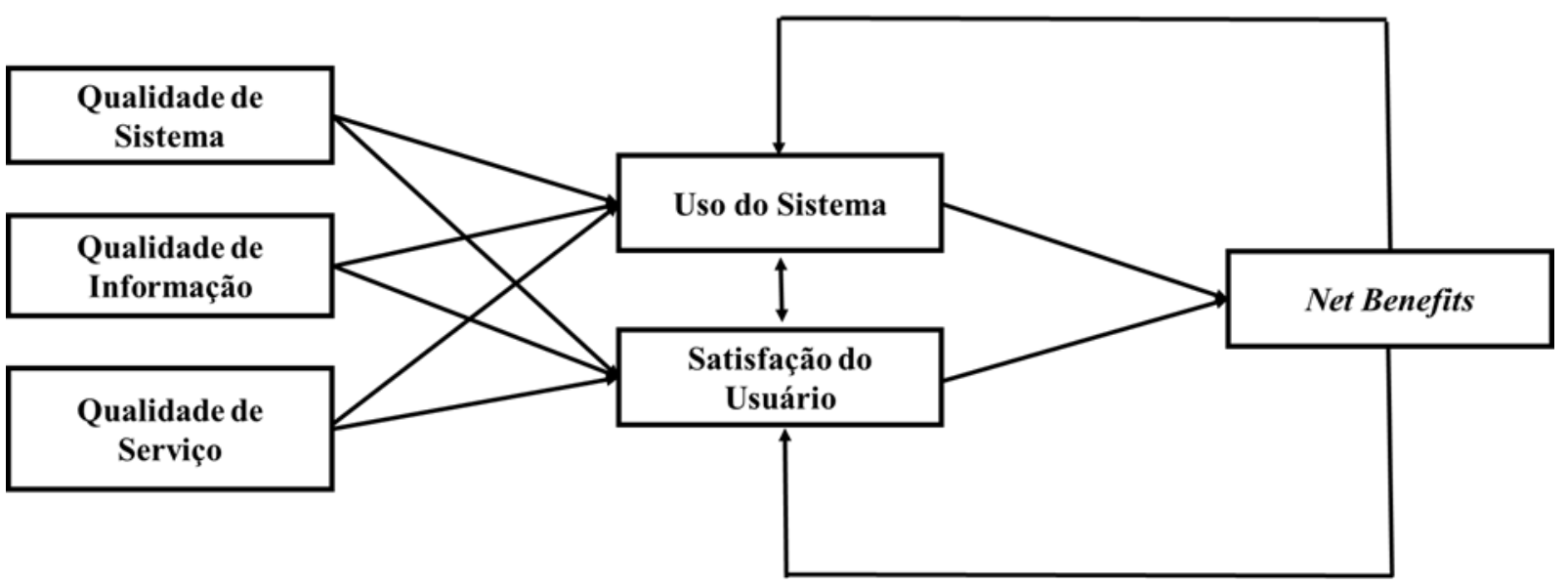

Fonte: Autor adaptado de Yusof et al. 2008

Figura 7 - Modelo de ajuste de organização de TI.

\section{MODELO DE AJUSTE DE ORGANIZAÇÃO DE TI}

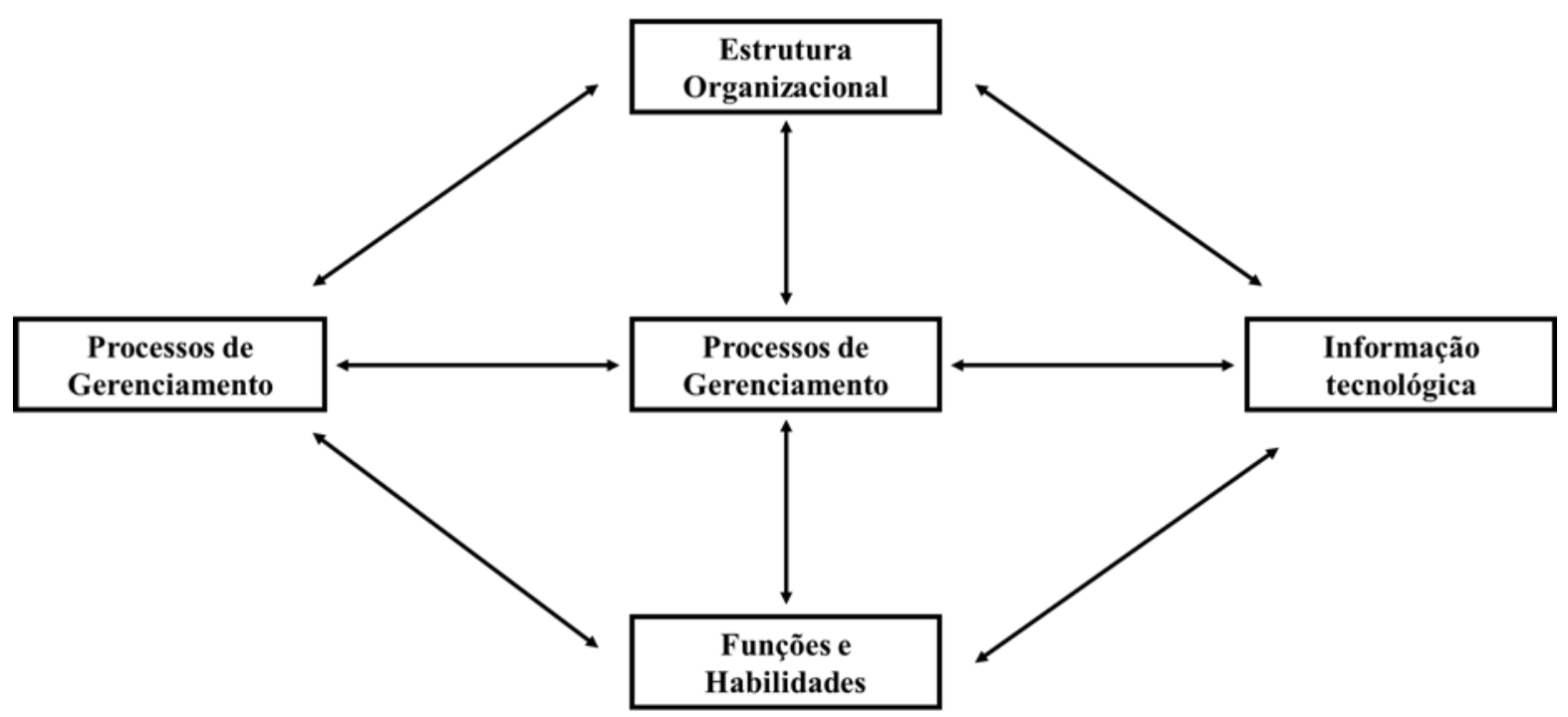

Fonte: Autor adaptado de Yusof et al. 2008 
Figura 8 - HOT-fit

\section{HOT-fit}

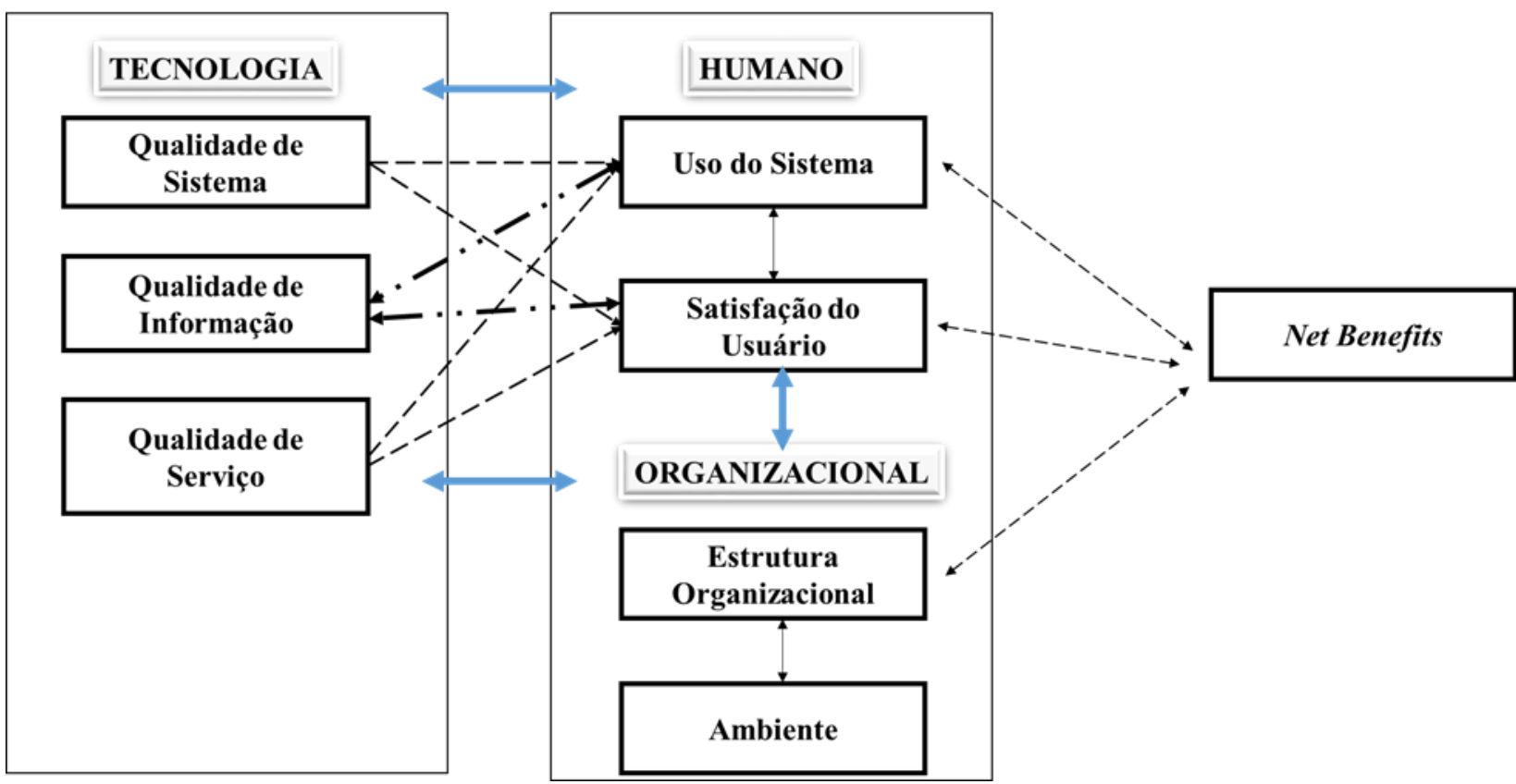

Fonte: Autor adaptado de Yusof et al. 2008

Dessa forma, o HOT-fit se preocupa com aspectos como: a capacidade do HIT, com o ser humano (ou seja, usuários em geral do HIT e práticas clínicas) e da definição de alinhamento entre si, podendo então medir e analisá-lo através dos chamados fatores de avaliação: humanos, organização e tecnologia (humano-organização, tecnologia-humano, organização-tecnologia) usando uma série de medidas definidas desses três fatores, incluindo flexibilidade do sistema, facilidade de uso do sistema utilidade, relevância da informação, atitude do usuário, treinamento do usuário, satisfação do usuário, cultura organizacional, planejamento, estratégia, gestão e comunicação.

Trazendo para a área da saúde, o HOT-fit pode ser usado para avaliar desempenho, eficácia (capacidade da organização de assistência médica atingir as metas usando recursos necessários dentro de um determinado tempo) e impacto de HIT, esses três fatores de avaliação podem ser analisados em todo o ciclo de vida do desenvolvimento do sistema, isto é, planejamento, análise, projeto, implementação, operação e manutenção, já os benefícios podem ser analisados antes e/ou depois da implementação. A seguir foram detalhados os fatores de avaliação com suas dimensões e medidas focando também na área da saúde. 


\section{Tecnologia}

A dimensão "qualidade do sistema" está associada ao desempenho do sistema e interface do usuário, tendo como medidas na área da saúde:

i. Facilidade de uso, avalia se os profissionais de saúde considerar o HIT como satisfatório, conveniente e agradável usar,

ii. Facilidade de aprendizado,

iii. Tempo de resposta,

iv. Utilidade,

v. Disponibilidade, tempo de atividade do HIT

vi. Confiabilidade,

vii. Integridade,

viii. Flexibilidade do sistema capacidade da HIT de se adaptar a uma configuração e integração com outros sistemas

ix. Segurança.

É importante salientar que um sistema deve atender à necessidade dos usuários, ser conveniente e fácil de usar, encaixar nos padrões de trabalho dos profissionais e do sistema geral de saúde.

A dimensão "qualidade da Informação" tem medidas focadas na informação gerada pelo HIT (registros de pacientes, relatórios, imagens e prescrições), porém, tais medidas tendem a ser um tanto quanto subjetivas, pois são derivadas da perspectiva do usuário, no entanto, existem critérios que podem ser analisados para definir a qualidade da informação, são eles: informações completas, precisão, legibilidade, pontualidade, disponibilidade, relevância, consistência e confiabilidade.

Por fim, a dimensão "qualidade de serviço" preocupa-se com o suporte prestado pelo provedor de serviços de HIT, a medida desta dimensão é o suporte técnico, a resposta rápida, a garantia, a empatia e o acompanhamento do serviço.

\section{Humano}

O HOT-fit une os fatores humanos dos modelos citados anteriormente, incluindo então, o uso do sistema e satisfação do usuário e as funções e habilidades, além de outros fatores de fatores humanos característicos do modelo HOT-fit.

Dessa forma, a dimensão "uso do sistema" tem como uma de suas medidas mais usadas as informações, como relatórios, portanto essa dimensão é tida como sucesso quando o usuário faz o uso de maneira voluntária e não obrigatória. Sendo importante salientar que o uso do 
sistema está relacionado ao usuário, ou seja, os níveis de uso, treinamento, conhecimento, crença, expectativa e aceitação ou resistência.

A dimensão "satisfação do usuário" mede o sucesso do sistema, sendo completamente subjetiva, pois é a avaliação geral da experiência de um usuário no uso do sistema e o impacto potencial do sistema, podendo estar relacionada à utilidade e às atitudes percebidas pelo usuário em relação ao HIT.

\section{Organização}

Faz parte do fator de avaliação "organização" as dimensões "estrutura" e "ambiente", responsáveis por examinar a natureza de uma instituição de saúde, onde a estrutura organizacional inclui o tipo e tamanho (número de leitos), cultura, política, hierarquia, autonomia, planejamento e sistemas de controle, estratégia, gestão e comunicação, além disso medidas como liderança, o apoio da alta gerência e o patrocínio da equipe médica também fazem parte das medidas do presente fator. Enquanto a dimensão "ambiente" tem como medidas sua fonte de financiamento, governo, política, localização, tipo de população atendida, concorrência, relacionamento interorganizacional e comunicação.

\section{Benefícios}

Por fim, o fator de avaliação "benefícios" é responsável por analisar se o sistema é capaz de beneficiar um único usuário, um grupo de usuários, uma organização ou um setor inteiro, capturando os impactos positivos e negativos sobre o usuário (corpo clínico, gerentes e TI, funcionários, desenvolvedores de sistemas, hospitais ou todo o setor de saúde). Algumas das possíveis medições quantitativas são: efeitos do trabalho, eficiência, eficácia, qualidade da decisão e redução de erros, além disso, os resultados também podem ser usados como um meio de medição, por exemplo: redução de custos, melhoria da eficiência na prestação de cuidados aos pacientes. Os resultados clínicos também são medidos através de dois critérios: morbidade (taxa de incidência de uma doença) e mortalidade (taxa de mortalidade). Medidas qualitativas tem como exemplo: qualidade do atendimento, impacto no atendimento ao paciente e comunicação (mudança no estilo de comunicação e facilitação do acesso à informação). 


\section{HOT-fit Quadro Resumo}

Figura 9 - HOT-fit quadro resumo

\begin{tabular}{|c|c|c|c|c|}
\hline & & $\begin{array}{l}\text { HOT- fit DETALHADO - } \\
\text { QUADRO RESUMO }\end{array}$ & & \\
\hline \multicolumn{5}{|l|}{ FATORES DE AVALIAÇÃO } \\
\hline \multirow[t]{2}{*}{ TECNOLOGIA } & DIMENSŐES & QUALIDADE DE SISTEMA & QUALIDADE DE INFORMAÇÃO & QUALIDADE DE SERVIÇO \\
\hline & MEDIDAS & $\begin{array}{l}\text { Facilidade de uso; } \\
\text { Facilidade de aprendizado; } \\
\text { Tempo de resposta; } \\
\text { Utilidade; } \\
\text { Disponibilidade; } \\
\text { Confiabilidade; } \\
\text { Integridade; } \\
\text { Flexibilidade do sistema; } \\
\text { Segurança; }\end{array}$ & $\begin{array}{l}\text { Informações completas; } \\
\text { Precisão; } \\
\text { Legibilidade; } \\
\text { Pontualidade; } \\
\text { Disponibilidade; } \\
\text { Relevância; } \\
\text { Consistência; } \\
\text { Confiabilidade }\end{array}$ & $\begin{array}{l}\text { Suporte técnico; } \\
\text { Resposta rápida; } \\
\text { Garantia; } \\
\text { Empatia; } \\
\text { Acompanhamento serviço. }\end{array}$ \\
\hline \multirow[t]{2}{*}{ ORGANIZACIONAL } & DIMENSŌES & ESTRUTURA & AMBIENTE & \\
\hline & MEDIDAS & $\begin{array}{l}\text { Tipo e tamanho (número de } \\
\text { leitos); } \\
\text { Cultura; } \\
\text { Politica; } \\
\text { Hierarquia; } \\
\text { Autonomia; } \\
\text { Planejamento e sistemas de } \\
\text { controle; } \\
\text { Estratégia; } \\
\text { Gestão; } \\
\text { Comunicação; }\end{array}$ & $\begin{array}{l}\text { Fonte de financiamento; } \\
\text { Governo; } \\
\text { Localização; } \\
\text { Tipo de população atendida; } \\
\text { Concorrência; } \\
\text { Relacionamento } \\
\text { interorganizacional; } \\
\text { Liderança; } \\
\text { Apoio da alta gerência; } \\
\text { Patrocinio da equipe médica }\end{array}$ & \\
\hline \multirow[t]{2}{*}{ HUMANO } & DIMENSŐES & USO DO SISTEMA & SATISFAÇÃO DO USUÁRIO & \\
\hline & MEDIDAS & $\begin{array}{l}\text { Uso de informações } \\
\text { (relatórios); } \\
\text { Uso real do sistema: uso } \\
\text { voluntário em vez do } \\
\text { obrigatório; } \\
\text { Se relaciona com a pessoa } \\
\text { que o utiliza, seus níveis de } \\
\text { uso, treinamento, } \\
\text { conhecimento, crença, } \\
\text { expectativa e aceitação ou } \\
\text { resistência; }\end{array}$ & $\begin{array}{l}\text { Frequentemente usada para } \\
\text { medir o sucesso do sistema; } \\
\text { Depende as satisfação de cada } \\
\text { usuário; } \\
\text { Relacionada à utilidade e às } \\
\text { atitudes percebidas pelo } \\
\text { usuário em relação ao SIS; }\end{array}$ & \\
\hline
\end{tabular}

Fonte: Autor, 2019

Portanto, é possível concluir que o HOT-fit, elaborado por Yusof et al. (2008), se trata de uma estrutura baseada em humanos, organização e ajuste de tecnologia, após conduzir uma avaliação crítica dos resultados de estudos de avaliação de HIT existentes.

No entanto, de acordo com Marques et al. (2010), há também uma série de estudos que apontam a importância do contexto ambiental com a adoção da tecnologia da informação, onde exploraram os fatores ambientais como determinantes para a adoção do EMR, sendo assim, os autores propõem adicionar o fator ambiental no framework HOT-fit, criando, portanto, a estrutura HOTE, que pode ser definida como a junção do framework HOT-fit (Yusof et al. 2008) e do framework TOE (Tornatsky and Fleischer, 1990), a figura 10 apresenta os frameworks HOT-fit e TOE e a figura 11 apresenta o framework HOTE. 
Figura 10 - Comparação dos frameworks HOT-fit e TOE
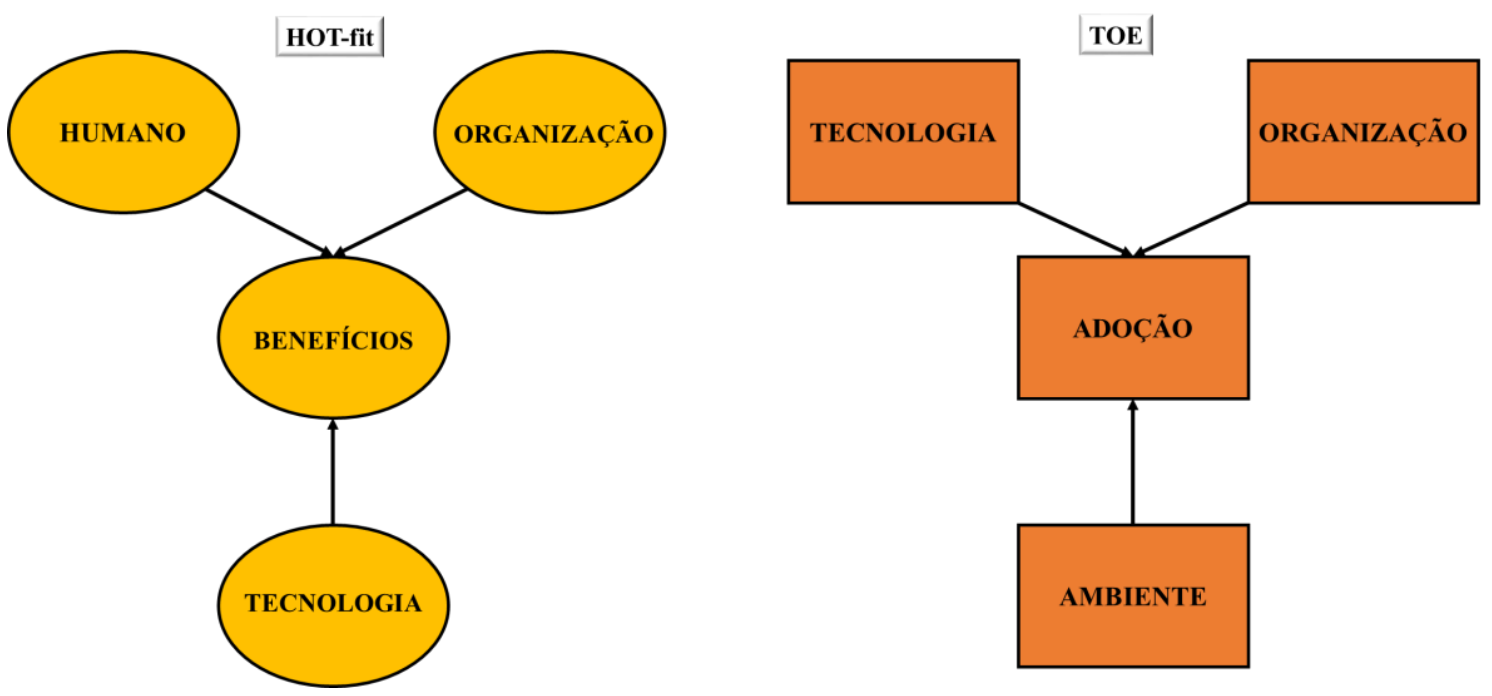

Fonte: Autor adaptado de Marques et al. 2010

Figura 11 - Framework HOTE

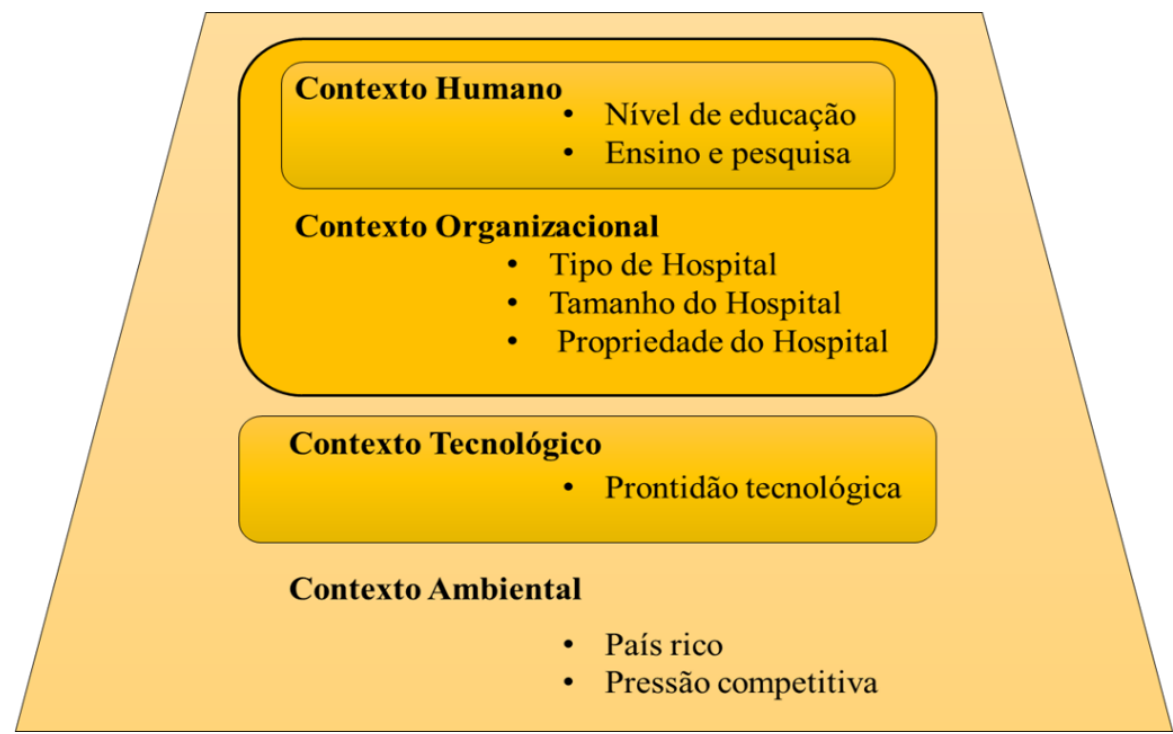

Fonte: Autor adaptado de Marques et al. 2010

\subsubsection{Framework Protocolo Custo Efetividade}

O uso da Análise de Custo-efetividade (ACE) vem crescendo intensamente a fim de avaliar os custos e os efeitos de intervenções específicas em saúde, tais estudos são realizados para comparar novas intervenções com as já existentes (WHO, 2003).

A ACE ajuda a definir e esclarecer o custo de oportunidade de cada escolha: os benefícios de saúde perdidos porque uma alternativa, também relevante, não foi selecionada. Pode-se utilizar dados de custo contábil para fazer avaliações econômicas, mas com frequência, eles não são suficientemente detalhados ou são insuficientes de outra forma, sendo importante 
utilizar outros métodos como o custeio $\mathrm{ABC}$ para uma tomada de decisão com eficácia (SOUZA, 2011).

Os impactos são medidos considerando o efeito natural mais adequado ou as unidades físicas, e a unidade de medida deve ser aquela com o impacto relevante para a análise (BRASIL, 2008). Os benefícios são medidos em unidades naturais, exemplos, anos de vida ganhos, casos de câncer detectados, infartos evitados.

A principal vantagem da abordagem da ACE é que os desfechos (anos de vida, qualidade de vida e eventos clínicos) podem ser quantificados, dessa forma, os desfechos são melhor entendidos pelos profissionais da saúde, já que essas unidades fazem parte da rotina na prática clínica (RASCATI, 2010).

A interpretação dos resultados está relacionada ao fato de que existem possíveis e importantes resultados de uma ACE. O primeiro panorama refere-se à nova tecnologia quando comparada à existente, apresentando um custo menor e uma maior efetividade, é chamado cenário dominante, ou seja, a nova tecnologia deve ser adotada. No segundo panorama, a nova tecnologia tem custo mais elevado quando comparado a já existente com menor efetividade, chamado então de cenário dominado e a nova tecnologia deve ser rejeitada. No terceiro panorama, a nova tecnologia proporciona custo maior, e com uma maior efetividade, nessa condição deve-se analisar a razão de custo efetividade incremental (RCEI), para avaliar se a nova tecnologia é custo-efetiva (ARAÚJO, V., \& BAHIA, 2010).

$$
\mathrm{ACE}=\frac{\text { Diferença entre custos }(\text { Procedimento A-Procedimento B })}{\text { Diferença entre benefícios }(\text { Procedimento A-Procedimento B })}
$$

Segundo Souza (2011), pode-se dizer então que o custo efetividade mensura o custo em unidades monetárias dividido por uma unidade não monetária ou desfecho, chamada unidade natural: anos de sobrevida; sequelas evitadas após vacinação da população; dias ganhos sem sintomas; casos prevenidos; pacientes melhorados; AVCs evitados, recidivas evitadas, fraturas evitadas, como apresentado na figura 12. 
Figura 12 - Relação entre custo e desfecho.

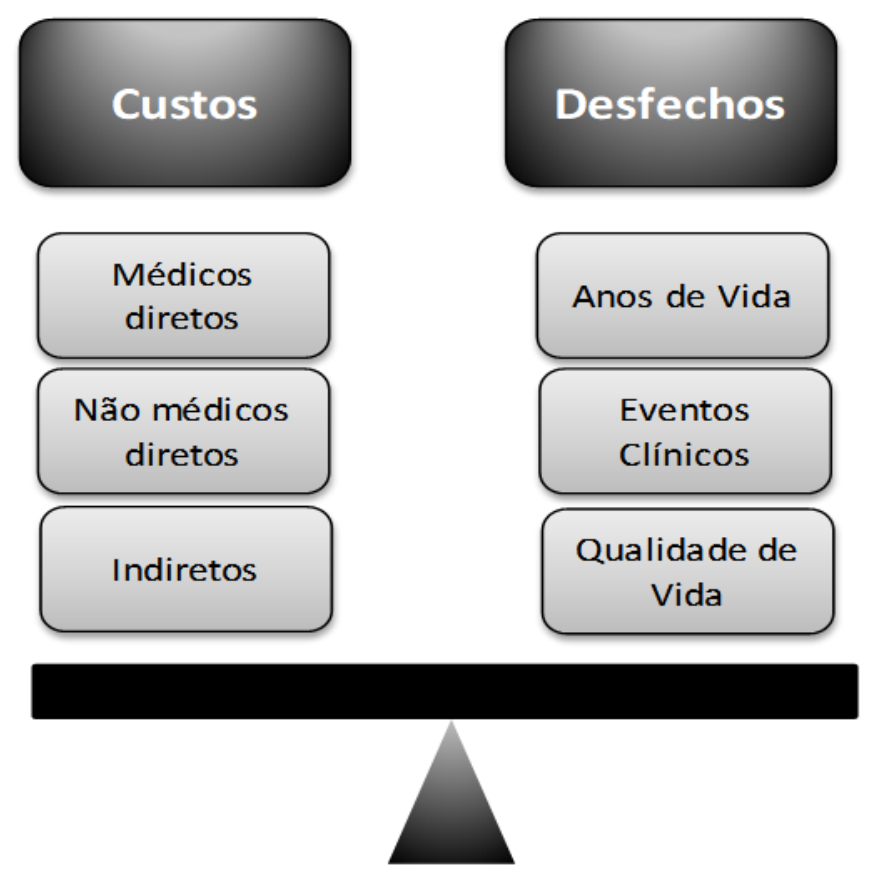

Fonte: Autor adaptado de Souza, 2011.

O protocoloco custo efetividade é um método de avaliação elaborado por Lilford et al (2014), o qual faz referência à análise do custo efetividade em atividades da organização de saúde. Para iniciar a pesquisa, os autores definiram, juntamente com o corpo diretivo do hospital, quais eram os pontos chaves relacionados a efetividade e posteriormente escolheram os pontos chaves passíveis de investigação e favoráveis para o desenvolvimento do estudo, sendo eles:

1. Qualidade de vida;

2. Taxas de eventos adversos (incluindo mortalidade);

3. Taxas de erro;

4. Triggers (para erros ou eventos adversos).

Os autores escolheram para trabalhar o modelo as variáveis taxas de eventos adversos e taxas de erro, pois são medidas que trazem mais confiabilidade para o estudo. A figura 13 apresenta o framework. 
Figura 13 - Framework Protocolo custo efetividade.

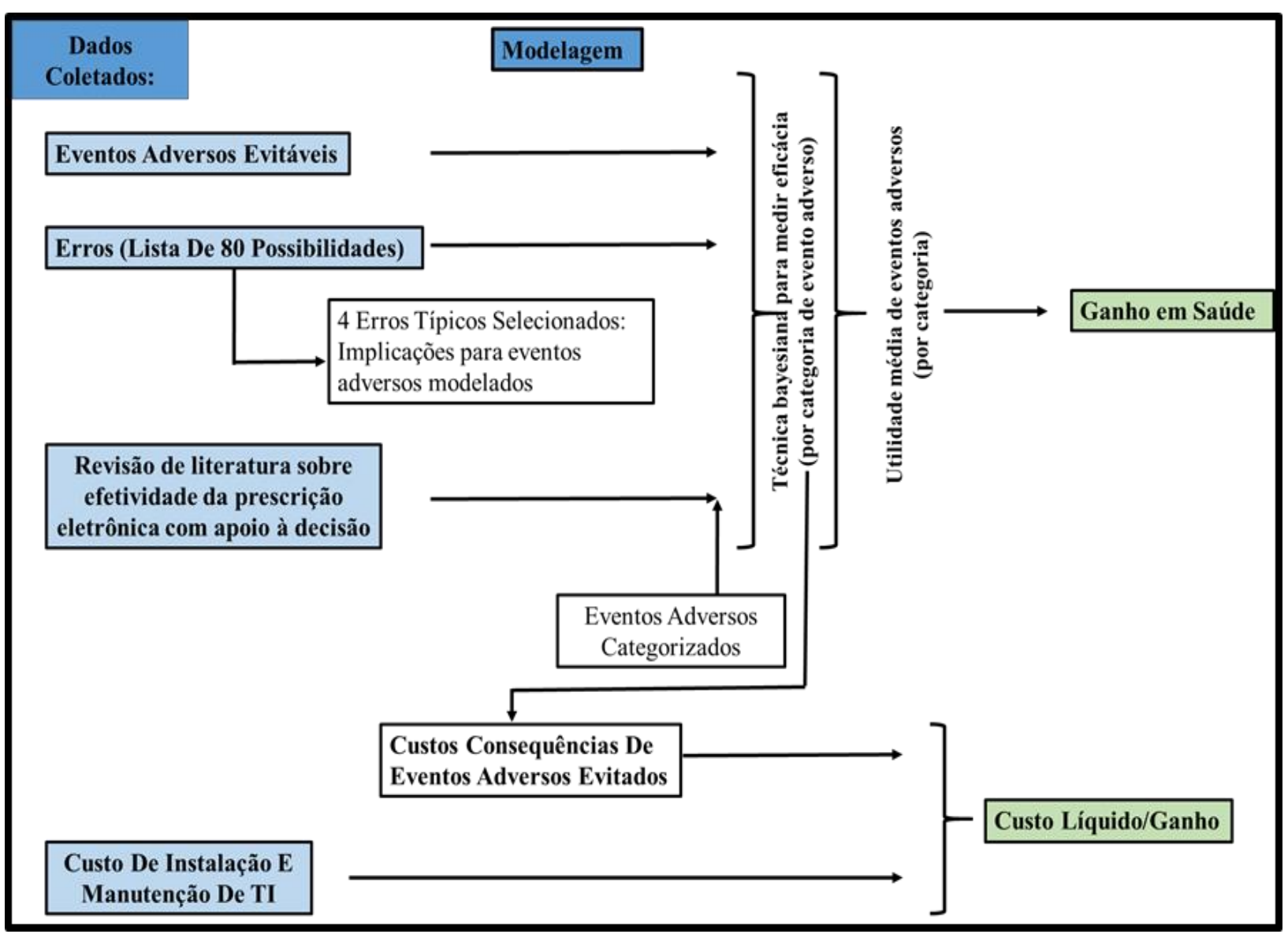

Fonte: Autor adaptado de Lilford, 2014

Os autores apresentam um método para o momento em que as intervenções genéricas e complexas de prestação de serviços devem ser avaliadas quanto à relação custo-benefício, o método inclui a montagem de informações relevantes sobre múltiplos pontos chaves e fatores contextuais de dentro e de fora de um estudo, no lugar de usar essas informações para informar diretamente uma decisão, ela é usada para gerar densidades de probabilidade bayesiana para os parâmetros de interesse - no caso do estudo, reduções em eventos adversos, por categoria, resultantes da implantação de TI. Segue-se um processo de diálogos deliberativos, para que os especialistas possam refazer suas estimativas subjetivas de probabilidade estando assegurados de possíveis fatores negligenciados.

Ou seja, o modelo apresentado pelos autores possui etapas de:

i) definição dos pontos chaves da organização;

ii) revisão da literatura;

iii) levantamento dos custos de instalação e manutenção de TI

Realizadas as etapas anteriores, tem início à modelagem, onde os autores definiram para cálculo, ideias bayesianas (é um ramo da estatística que usa o termo probabilidade como uma 
medida condicional da incerteza associada com a ocorrência de um evento) como um guia, ao invés de um método matemático, para atualizar uma densidade de probabilidade prévia, para os eventos adversos, resultando então, em seus custos. Unindo então aos custos de TI estimados, e aplicando a técnica do custo efetividade, tem-se como resultado os ganhos monetários e em saúde.

\subsubsection{Framework Assimilação De Tecnologia}

A assimilação pode ser definida como uma série de etapas a partir da avaliação inicial do potencial do sistema da organização a ser usado para sua adoção formal, onde a implantação do sistema se tornará uma rotina, criando uma parte importante das atividades da cadeia de valor (Sulaiman e Wickramasinghe, 2014).

Muitas literaturas de implementação de HIT citam a necessidade da assimilação da inovação. Um estudo apresentado por Littlejohns, Wyatt \& Garvican (2003) sobre a implementação de tecnologias de informação de saúde, onde o HIT foi avaliado, três quartos falharam sem nenhuma evidência de que o sistema realmente melhorou a produtividade do profissional de saúde. Os hospitais afetados, sem dúvida, sofreram com uma grave falha de assimilação durante a sua implementação e operação. Milhões foram gastos em todo o processo de implementação da tecnologia de informação, no entanto, devido à má gestão da assimilação da nova tecnologia para o pessoal de saúde, a HIT não conseguiu apresentar seus benefícios, (Sulaiman e Wickramasinghe, 2014).

Outra pesquisa realizada por Sulaiman e Wickramasinghe (2014), aborda a importância da adoção e assimilação em um hospital, onde criaram um framework conceitual do HIT, figura 14, que foi derivado de uma combinação de trabalhos anteriores por eles pesquisados, para apresentar como um enfoque sistemático na assimilação facilita a manutenção do uso dos HIT nos hospitais. Além disso, o framework também identifica os estágios de assimilação e os diferentes componentes de adoção: tecnologia, organização e ambiente que atuam como facilitadores para o sucesso da assimilação de inovação HIT. 
Figura 14 - Framework conceitual de tecnologias de informação em saúde.

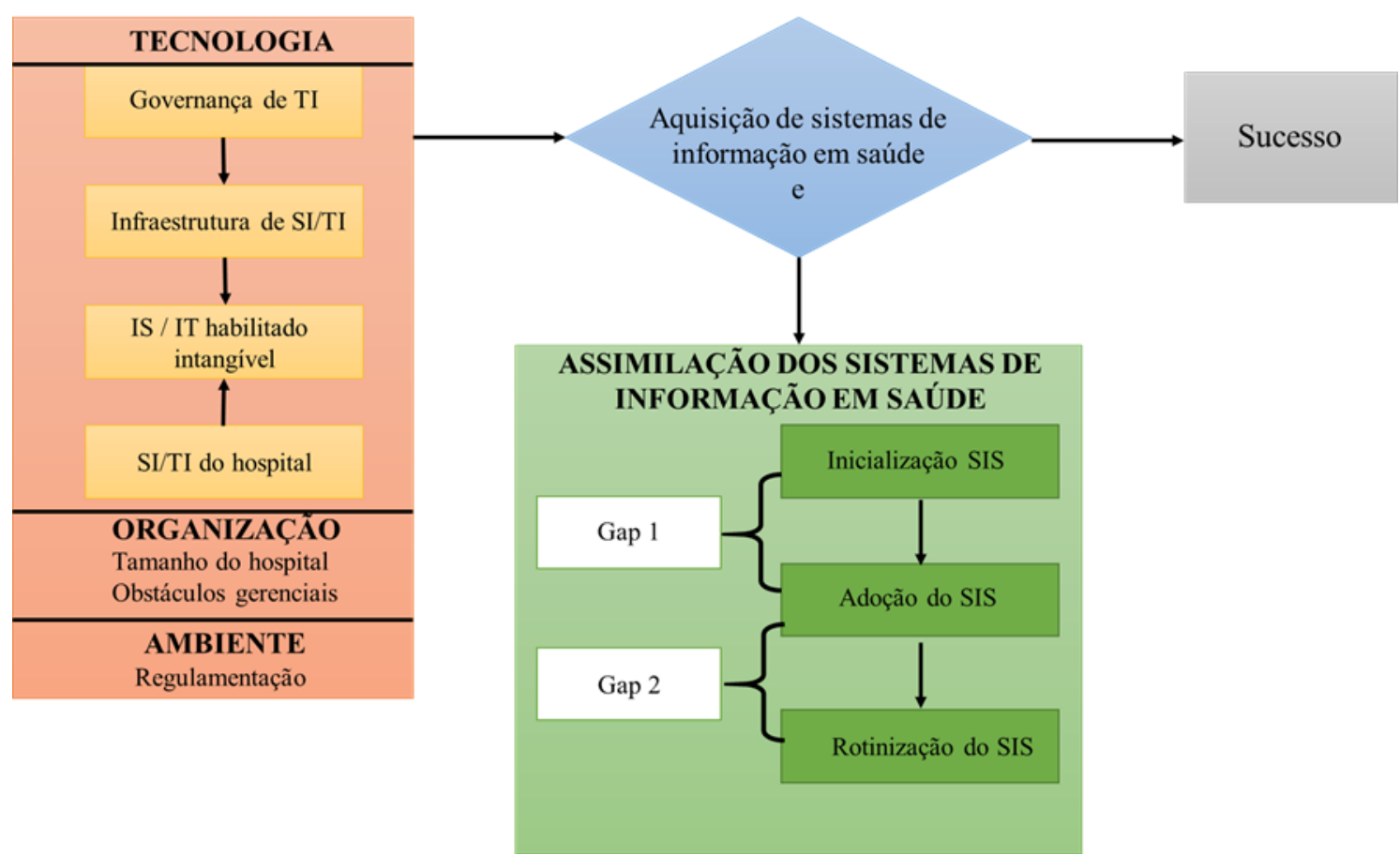

Fonte: Autor adaptado de Sulaiman e Wickramasinghe, 2014

Greenhalgh et al (2007) e Sulaiman e Wickramasinghe (2014) afirmam que a assimilação das tecnologias de informação em saúde com sucesso é considerada extremamente importante na resolução dos problemas de adoção e institucionalização do HIT nas organizações, explorando fatores como: a possibilidade da assimilação dos HIT resultar no bom uso dessas tecnologias nas unidades de saúde, as atividades diárias do médico clínico e não clínico, alinhadas com o objetivo das aplicações HIT, pois o nível de entusiasmo entre os profissionais de saúde deve permanecer durante todo o processo de assimilação, já que o HIT é institucionalizado como parte dos processos de negócios da organização de assistência médica.

Além disso, quando uma inovação é adquirida pela organização, não necessariamente ela vem seguida por uma implantação generalizada e plena utilização, pois existe um intervalo de assimilação entre a taxa de aquisição e implantação, onde certas barreiras alegam ter retardado o processo de difusão da inovação e causado um impacto negativo na implantação quando comparado com a aquisição (SULAIMAN E WICKRAMASINGHE, 2014).

Zhu, Kraemer e Xu (2003) identificaram três estágios de assimilação de HIT, envolvendo iniciação, adoção e rotinização, que abrangem a maioria dos aspectos das etapas de assimilação da inovação tecnológica, onde consideram a "iniciação" como a primeira etapa do estágio de assimilação, o estágio de envolve o uso bem-sucedido da tecnologia adquirida e, por fim, a rotinização, que refere-se ao estágio final da difusão da inovação a um ponto em que o 
uso do HIT torna-se parte dos processos de negócios da organização e dos sistemas gerenciais, pois, uma vez adotada a inovação, nem sempre indica que a tecnologia tem sido amplamente utilizada na organização.

\subsubsection{Quadro Resumo Modelos de Avaliação Tecnologia da Informação em Saúde}

A tabela 1 mostra uma compilação dos modelos de avaliação da tecnologia da informação em saúde citadas anteriormente, apresentando um resumo de suas respectivas definições.

Tabela 1 - Compilação dos modelos de avaliação HIT

\begin{tabular}{|c|c|c|}
\hline $\begin{array}{c}\text { MODELO DE } \\
\text { A VALIAÇÃO DE HIT }\end{array}$ & DEFINIÇÃO & REFERÊNCIA \\
\hline HOT-fit & $\begin{array}{l}\text { Trata de uma estrutura baseada em humanos, } \\
\text { organização e ajuste de tecnologia, após conduzir uma } \\
\text { avaliação crítica dos resultados de estudos de avaliação } \\
\text { de HIT existentes. }\end{array}$ & $\begin{array}{l}\text { Yusof et al. } \\
\text { (2008) }\end{array}$ \\
\hline HOTE & $\begin{array}{l}\text { HOTE é definido como a junção do framework HOT-fit } \\
\text { (Yusof et al. 2008) e do framework TOE (Tornatsky and } \\
\text { Fleischer, 1990), de forma que adiciona o contexto } \\
\text { ambiental à análise, passando a avaliar fatores humanos, } \\
\text { tecnológicos, organizacionais e ambientais. }\end{array}$ & $\begin{array}{l}\text { Marques et al. } \\
\text { (2010) }\end{array}$ \\
\hline $\begin{array}{l}\text { ASSIMILAÇÃO DA } \\
\text { TECNOLOGIA }\end{array}$ & $\begin{array}{l}\text { A assimilação pode ser definida como uma série de } \\
\text { etapas a partir da avaliação inicial do potencial do } \\
\text { sistema da organização a ser usado para sua adoção } \\
\text { formal, onde a implantação do sistema se tornará uma } \\
\text { rotina, criando uma parte importante das atividades da } \\
\text { cadeia de valor }\end{array}$ & $\begin{array}{l}\text { Sulaiman e } \\
\text { Wickramasinghe } \\
\qquad(2014)\end{array}$ \\
\hline $\begin{array}{l}\text { PROCOTOLO CUSTO } \\
\text { EFETIVIDADE }\end{array}$ & $\begin{array}{l}\text { Os autores apresentam um método para o momento } \\
\text { em que as intervenções genéricas e complexas de } \\
\text { prestação de serviços devem ser avaliadas quanto à } \\
\text { relação custo-benefício, }\end{array}$ & Lilford, 2014 \\
\hline
\end{tabular}

Fonte: Autor 


\section{METODOLOGIA}

Através de um estudo sobre métodos de pesquisa adotados no âmbito dos principais periódicos internacionais da área de gestão de operações, Lacerda et. al. (2013) concluiu que há predominância do paradigma positivista, seguido por pesquisas baseadas em modelagem/simulação e, por fim, pesquisas interpretativistas. No Brasil, através de uma varredura nos anais do ENEGEP (Encontro Nacional de Engenharia de Produção), Lacerda et. al. (2013) encontrou a predominância dos estudos de caso seguido por estudos empíricos, baixa participação das surveys e poucos estudos de modelagem e da simulação.

Lacerda (2013), sustentado por Miguel (2007) e Mello et al (2011), afirma que é importante, ao definir o método de pesquisa, que este permita:

i) responder ao problema de pesquisa formulado;

ii) ser avaliado pela comunidade científica;

iii) evidenciar procedimentos que robusteçam os resultados da pesquisa.

Diante disso, torna-se válido diferenciar três métodos de pesquisas (Tabela 2), a fim de apresentar o método que melhor se enquadra ao presente estudo, são eles: estudo de caso, pesquisa-ação e design research.

De acordo com Taylor (2009) e Nakano (2010), as pesquisas realizadas na área de engenharia de produção têm tipicamente considerado como referência os objetivos e práticas de pesquisa das ciências naturais e sociais, de fato a maior parte das pesquisas em gestão é fundamentada na noção de que o objetivo da ciência é descrever, entender, explicar e, se possível, predizer. Por consequência, Proença et al (2015) concorda que, seu principal foco é desenvolver pesquisas que permitam a construção de teorias que descrevam, expliquem e predigam como a realidade e os processos empresariais funcionam, dessa forma, e buscando maior confiabilidade das teorias propostas, faz-se necessário avançar o rigor metodológico, principalmente em questões de validade. Porém, de acordo com Lacerda (2013), essa forma de construção do conhecimento científico, com foco em teorias descritivas, dificulta a elaboração de estudos que abram novas perspectivas em termos de pesquisas futuras, sendo assim o autor, apoiado em Gouvêa da Costa e Pinheiro de Lima (2011), afirma que a engenharia se preocupa com a utilização do conhecimento científico com o objetivo de projetar e construir artefatos para a solução dos problemas.

Dessa forma, Simon (1996) expõe a necessidade de criar uma ciência responsável por propor como construir artefatos que possuam certas propriedades desejadas, ou seja, como projetá-los. Sendo assim, surge a Design Research, que tem como missão principal desenvolver 
conhecimento para a concepção e desenvolvimento de artefatos, surgindo então, um novo foco de pesquisa: pesquisas efetivamente direcionadas ao projeto de artefatos que sustentem melhores soluções para os problemas existentes. Com isso, para Romme (2003) os estudos relacionados às organizações devem incluir a Design Science Research, como um dos principais modos de conceber o conhecimento e de realizar pesquisas científicas. Portanto, dentre os três métodos de pesquisa apresentados, o que melhor se enquadra no presente trabalho é a Design Science Research.

Tabela 2 - Diferenciação dos métodos de pesquisa.

\begin{tabular}{|c|c|c|c|}
\hline Características & Design Science Research & $\begin{array}{l}\text { Estudo de Caso } \\
\text { Tradicional }\end{array}$ & Pesquisa-ação tradicional \\
\hline Objetivos & $\begin{array}{l}\text { - Desenvolver artefatos que } \\
\text { permitam soluções satisfatórias } \\
\text { aos problemas práticos; } \\
\text { - Prescrever e projetar. }\end{array}$ & $\begin{array}{l}\text { Auxiliar na compreensão de } \\
\text { fenômenos sociais complexos; } \\
\text { - Explorar, descreve e explicar. }\end{array}$ & $\begin{array}{l}\text { Resolver ou explicar problemas } \\
\text { de um determinado sistema } \\
\text { gerando conhecimento para a } \\
\text { prática e para a teoria; } \\
\text { - Explorar, descrever e explicar }\end{array}$ \\
\hline Principais Atividades & $\begin{array}{l}\text { - Conscientizar } \\
\text { - Sugerir } \\
\text { - Desenvolver } \\
\text { - Avaliar } \\
\text { - Concluir }\end{array}$ & $\begin{array}{l}\text { - Definir estrutura conceitual } \\
\text { - Planejar os casos } \\
\text { - Conduzir piloto } \\
\text { - Coletar dados } \\
\text { - Analisar dados } \\
\text { - Gerar relatório }\end{array}$ & $\begin{array}{l}\text { - Planejar a ação } \\
\text { - Coletar dados } \\
\text { - Analisar dados e planejar } \\
\text { ações } \\
\text { - Implementar ações } \\
\text { - Avaliar resultados } \\
\text { - Monitorar (contínuo) }\end{array}$ \\
\hline Resultados & $\begin{array}{l}\text { Artefatos (constructos, modelos, } \\
\text { métodos, instanciações) }\end{array}$ & $\begin{array}{ll}\text { - } & \text { Constructos } \\
\text { - } & \text { Hipóteses } \\
\text { - } & \text { Descrições } \\
\text { - } & \text { Explicações }\end{array}$ & $\begin{array}{l}\text { - Constructos } \\
\text { - Hipóteses } \\
\text { - Descrições } \\
\text { - Explicações } \\
\text { - Ações }\end{array}$ \\
\hline Tipo de conhecimento & Como as coisas deveriam ser & $\begin{array}{l}\text { Como as coisas são ou como se } \\
\text { comportam }\end{array}$ & $\begin{array}{l}\text { Como as coisas são ou como se } \\
\text { comportam }\end{array}$ \\
\hline Papel do pesquisador & $\begin{array}{l}\text { Construtor e Avaliador do } \\
\text { Artefato }\end{array}$ & Observador & $\begin{array}{l}\text { Múltiplo, em função do tipo de } \\
\text { pesquisa-ação }\end{array}$ \\
\hline Base Empírica & Não obrigatória & Obrigatória & Obrigatória \\
\hline $\begin{array}{c}\text { Colaboração do } \\
\text { pesquisador-pesquisado }\end{array}$ & Não obrigatória & Não obrigatória & Obrigatória \\
\hline Implementação & Não obrigatória & Não se aplica & Obrigatória \\
\hline Avaliação dos Resultados & $\begin{array}{l}\text { - Aplicações } \\
\text { - Simulações } \\
\text { - Experimentos }\end{array}$ & Confronto com a teoria & Confronto com a teoria \\
\hline Abordagem & Qualitativa e/ou Quantitativa & Qualitativa & Qualitativa \\
\hline
\end{tabular}

Fonte: Autor adaptado de Lacerda. 2013 


\subsection{MÉTODO DESIGN SCIENCE RESEARCH (DSR)}

De acordo com Lacerda (2013), entre os anos de 1969 e 1996, Herbert Simon foi o pioneiro a distinguir os ambientes natural e artificial, a ciência natural trata-se de um conjunto de conhecimentos sobre uma classe de objetos e/ou fenômenos do mundo (suas características, como se comportam e como interagem), sendo tarefa das disciplinas científicas naturais pesquisarem e ensinarem como as coisas são e como elas funcionam, podendo ser aplicado para os fenômenos naturais (biologia, química, física) e sociais (economia, sociologia), enquanto isso, a ciência artificial trata da concepção de artefatos que realizem objetivos, ou seja, como as coisas devem ser para funcionar e atingir determinados objetivos, nesse sentido pode-se dizer, de acordo com Van Aken (2004), que é a ciência que se preocupa em propor como construir/desenvolver conhecimento para a concepção e desenvolvimento de artefatos, criando o termo "design research".

Com surgimento da Design Research, de acordo com Romme (2003), Hevner et al. (2007) e Dresch, Lacerda, Antunes (2015), é evidente que a questão da relevância do conhecimento produzido e a tensão na relação teoria-prática demandem a necessidade de elaborar um novo foco de pesquisa, ou seja, pesquisas efetivamente direcionadas ao projeto de artefatos afim de conceber e validar sistemas que ainda não existem, seja criando, recombinando, alterando produtos/ processos/ softwares/ métodos que sustentem melhores soluções para os problemas existentes.

Os autores Bayazit (2004) e Vaishnavi e Kuechler (2009) concordam que enquanto o termo Design Research é a base do conhecimento dessa nova ciência, a Design Science Research é o método que operacionaliza a construção do conhecimento nesse contexto, sendo um novo conjunto de técnicas analíticas que permitem o desenvolvimento de pesquisas nas diversas áreas, tanto do ponto de vista acadêmico quanto da organização, em particular na engenharia, buscando estudar, pesquisar e investigar o artificial e seu comportamento, avaliando o que foi projetado ou o que está funcionando e comunicando os resultados obtidos.

Hevner et al. (2004), ao elaborar a DSR, apresenta um dos componentes mais importantes do método: os artefatos, que são criados com bases nas leis naturais e nas teorias comportamentais, são aplicados, testados, modificados e estendidos por meio da experiência, criatividade, intuição e habilidades de resolução de problemas de seus pesquisadores. É possível classificar os artefatos em:

- Construtos (entidades e relações;

- Modelos (abstrações e representações); 
- Métodos (algoritmos e práticas) e

- Instanciações (implementação de sistemas e protótipos).

O que nos faz concluir que os artefatos podem ser desde um software, uma teoria, até descrições informais em linguagem natural. Para os autores, artefatos auxiliam na definição de ideias, práticas, capacidades técnicas e produtos. O conhecimento e a compreensão do problema a ser resolvido são adquiridos durante a construção e o uso dos artefatos, quando são validados e avaliados. Dessa forma, a DSR pode ser vista como uma conjunção de três ciclos reguladores de atividades relacionadas (HEVNER, 2007).

A Figura 15 apresenta o framework DSR para entender, executar e avaliar a metodologia.

Figura 15- Framework DSR.

AMBIENTE

DESIGN SCIENCE RESEARCH

TEORIA

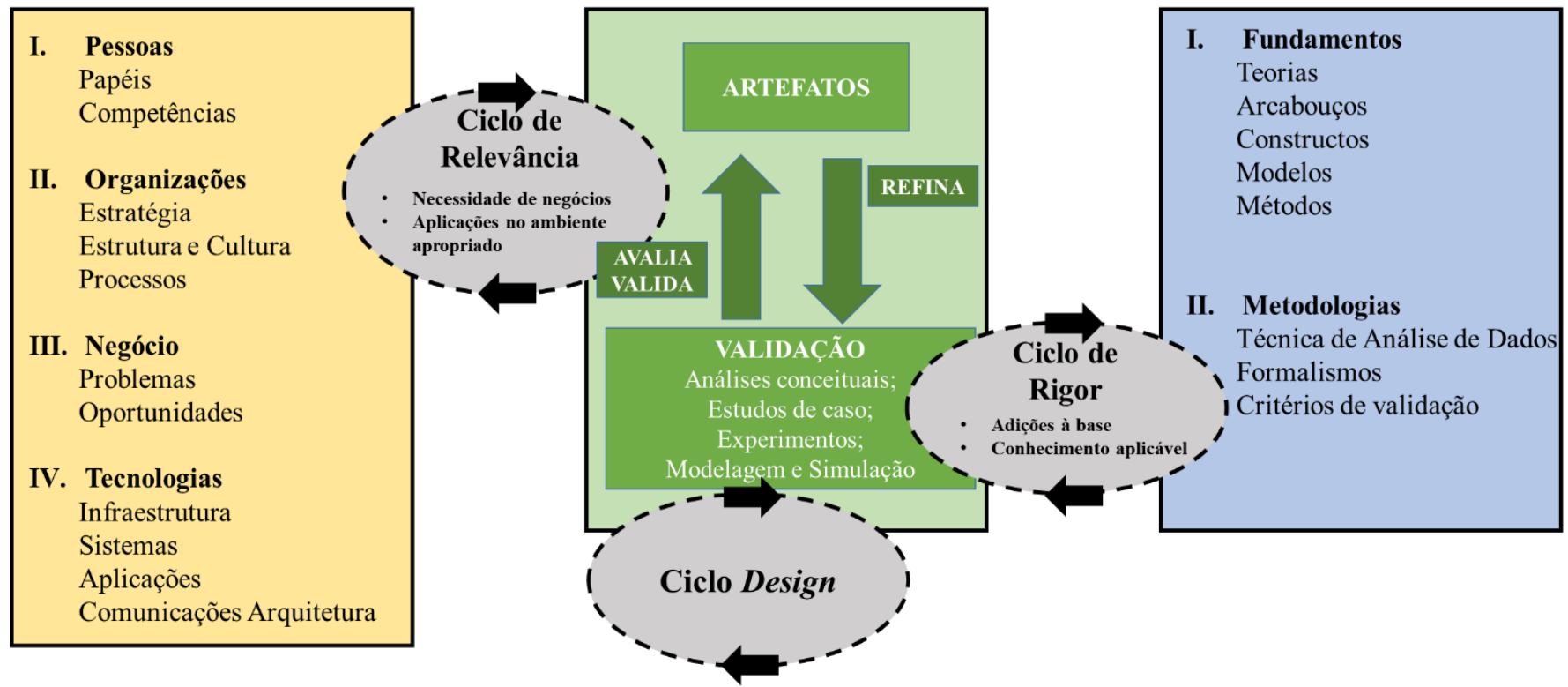

Fonte: Adaptado de Hevner et al. 2004 E Bax, 2015

O "ciclo de relevância" inicia a pesquisa com um contexto de aplicação que fornece como insumo os requisitos para a pesquisa e define os critérios de aceitação para a avaliação dos resultados da investigação.

$\mathrm{O}$ "ciclo de rigor" fornece o conhecimento científico passado ao projeto de pesquisa para assegurar a sua inovação, o pesquisador é responsável pela boa condução deste ciclo, onde deve realizar uma investigação o mais completa possível na base de conhecimento (conjunto das bases de referência da literatura científica da área), fazendo referências aos trabalhos correspondentes, buscando como objetivo garantir que os artefatos produzidos serão 
contribuições de pesquisa efetivas e não projetos de rotina, baseados na aplicação de processos já conhecidos pelos pesquisadores da área. Por fim, o "ciclo design" itera entre as atividades principais de construção e avaliação dos artefatos de design e processos da pesquisa.

Ainda nesta mesma linha de considerações, o autor Hevner (2004) elaborou uma lista de verificação específica (Apêndice A) com perguntas para avaliar um projeto de DSR, sendo uma lista de verificação útil para garantir que os projetos abordem os aspectos-chave da metodologia. Com isso, a fim de demonstrar a relação dessas questões com os três ciclos de pesquisa já discutidos, a figura 16 mapeia as oito questões para o ciclo de pesquisa apropriado.

Figura 16 - Questões mapeadas para três ciclos de pesquisa de design

AMBIENTE

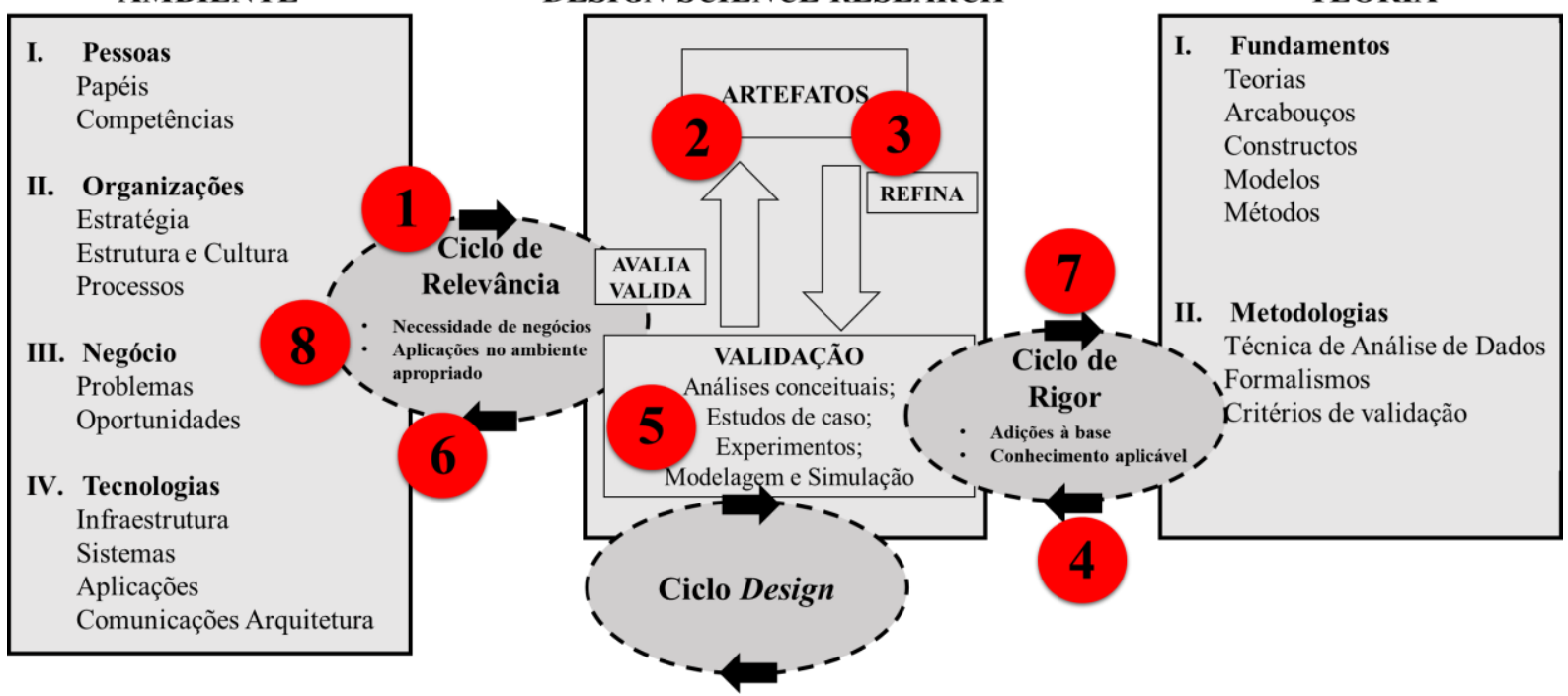

Fonte: Autor adaptado de Hevner, 2004.

\subsection{DESENVOLVIMENTO DO ARTEFATO - FRAMEWORK PROPOSTO}

O presente estudo abordará um framework que reúne as teorias TOE, TAM, assimilação de tecnologia e protocolo custo efetividade, desenvolvido a partir das teorias discutidas nos tópicos anteriores, como método de pesquisa foi definido o método design science research, a tabela 3 apresenta o quadro resumo e figura 17 apresenta o artefato desenvolvido. 
Tabela 3 - Quadro Resumo

\begin{tabular}{|c|c|c|}
\hline TEORIAS & VARIÁVEIS ANALISADAS & REFERÊNCIAS \\
\hline TOE & $\begin{array}{l}\text { T - Infraestrutura de comunicação, } \\
\text { compatibilidade, benefício percebido, } \\
\text { segurança, percepção de redução de } \\
\text { custo, navegação do sistema, } \\
\text { O - Envolvimento da alta direção, } \\
\text { recursos financeiros, competências } \\
\text { tecnológicas. } \\
\text { E - Pressões do ambiente competitivo }\end{array}$ & $\begin{array}{l}\text { Tornatzky e do } \\
\text { Fleischer,1990; Mattos, } \\
2016 .\end{array}$ \\
\hline TAM & $\begin{array}{l}\text { Facilidade de Acesso, } \\
\text { Relacionamento, } \\
\text { Qualidade de informações, } \\
\text { Confiabilidade, } \\
\text { Pontualidade, } \\
\text { Compatibilidade, } \\
\text { Acesso e autorização. }\end{array}$ & $\begin{array}{l}\text { Davis, 1989; } \\
\text { Bueno et al, 2004; } \\
\text { Tolentino, } 2007 \\
\text { Silva et. al, 2008; }\end{array}$ \\
\hline $\begin{array}{l}\text { ASSIMILAÇÃO DE } \\
\text { TECNOLOGIA }\end{array}$ & $\begin{array}{l}\text { - Iniciação, adoção, rotinização. } \\
\text { - Após a adoção da tecnologia onde a } \\
\text { implantação do sistema se tornará uma } \\
\text { rotina }\end{array}$ & $\begin{array}{l}\text { Sulaiman e } \\
\text { Wickramasinghe, } 2014\end{array}$ \\
\hline $\begin{array}{c}\text { PROTOCOLO CUSTO } \\
\text { EFETIVIDADE }\end{array}$ & $\begin{array}{l}\text { - Variáveis não monetárias: qualidade } \\
\text { de vida, óbito, desfechos clínicos, } \\
\text { entre outros; } \\
\text { - Variáveis monetárias: custos }\end{array}$ & Lilford et al, 2014 \\
\hline
\end{tabular}

Fonte: Autor 
Figura 17 - Artefato - framework proposto

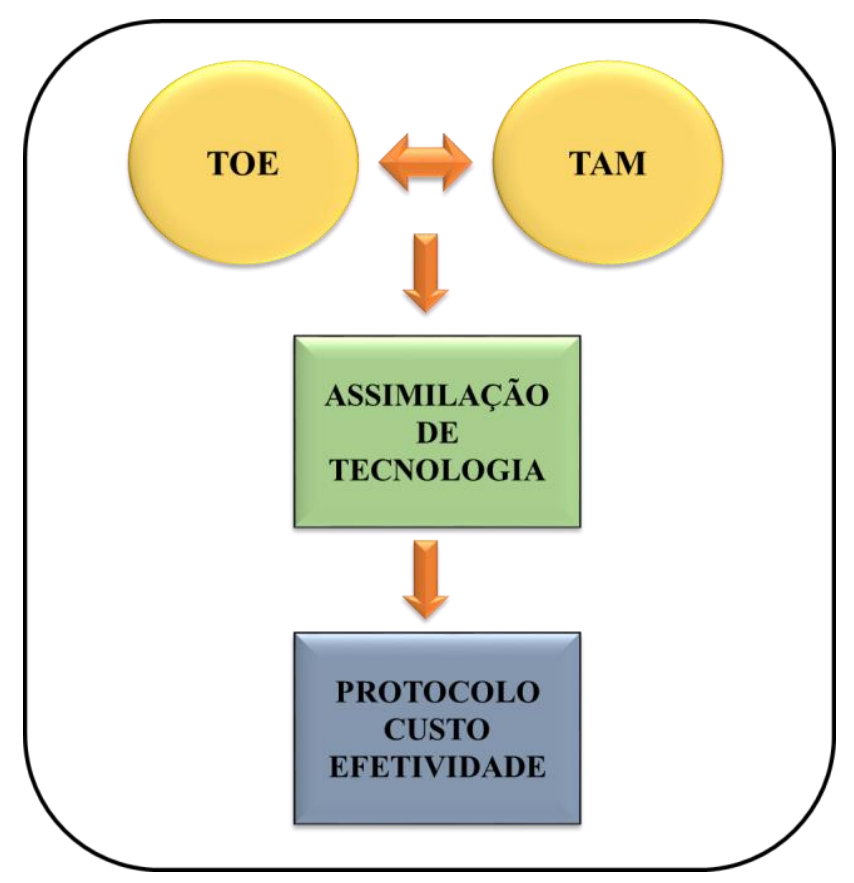

Fonte: Autor.

\subsection{CRITÉRIO DE ESCOLHA DOS CASOS}

A definição da organização para o estudo é de suma importância, e foi baseada nos autores Hannah, Ball, Edwards (2009) e Sedig, Naimi, Haggerty (2017). Foram escolhidas organizações que estão adotando sistemas corporativos de informação em saúde, os quais capturam e armazenam informações mais completas, provenientes da assistência à saúde contínua. Esses sistemas são caracterizados por focar no paciente que está recebendo o cuidado, em diversos setores (por exemplo, ambulatório, unidade de tratamento intensivo, internação de longa permanência), com uma estrutura comum e organizada (HANNAH, BALL, EDWARDS, 2009). Adicionalmente, a escolha dos casos para avaliação do framework proposto também está suportada por Sedig, Naimi, Haggerty (2017) que enfatizam o conjunto sistema cognitivo (unidade de análise que inclui a tecnologia da informação de saúde, usuários e a relação que os liga). Para finalizar os critérios de escolha, buscou hospitais que tenham protocolo de efetividade para acompanhar os resultados das tecnologias em saúde implantadas.

\subsection{ENTREVISTAS}

As entrevistas foram realizadas com usuários dos sistemas utilizados e os gestores envolvidos com a implantação das tecnologias analisadas. Os perfis são colaboradores que participaram desde o início do projeto e ainda estão na organização. O objetivo foi analisar a 
trajetória desde a adoção e verificar o nível de assimilação por parte da organização através de entrevistas semiestruturadas. O roteiro de perguntas (apêndice B) refere-se ao framework TOE e TAM, assimilação de forma combinada, o qual foi aplicado aos profissionais responsáveis pelos projetos implantados (Tabela 4).

Com base nas entrevistas conduzidas com profissionais, relatórios e observações, foi avaliado a aplicação do framework TOE, TAM e Protocolo de efetividade de forma combinada como ferramenta de gestão de avaliação de tecnologias em saúde.

Tabela 4- Perfil Entrevistados

\begin{tabular}{|c|l|}
\hline CASO & \multicolumn{1}{|l}{ PERFIL DOS ENTREVISTADOS / USUÁRIOS DA TECNOLOGIA } \\
\hline A & $\begin{array}{l}\text { Médico anestesista } \\
\text { Enfermeira Padrão } \\
\text { Enfermeira (técnica) } \\
\text { Médico / Pesquisador Plataforma de Gestão Sepse } \\
\text { Enfermeira / Pesquisadora Plataforma de Gestão Sepse }\end{array}$ \\
\hline B & $\begin{array}{l}\text { Médico / Pesquisador Plataforma de Gestão Sepse } \\
\text { Enfermeira / Pesquisadora Plataforma de Gestão Sepse }\end{array}$ \\
\hline C &
\end{tabular}

Fonte: Autor.

\subsection{PROTOCOLO DE PESQUISA}

Yin (2004) relata que é indispensável elaborar um protocolo para o estudo com a finalidade de estabelecer a relação do pesquisador com o ambiente a ser pesquisado. $\mathrm{O}$ protocolo é mais que um instrumento, pois contém os procedimentos e regras que deverão ser seguidas para o desenvolvimento desta pesquisa. A figura 18 apresenta o protocolo de pesquisa do framework proposto seguido pelo estudo de caso realizado a fim de validar a pesquisa. 
Figura 18 - Protocolo de pesquisa

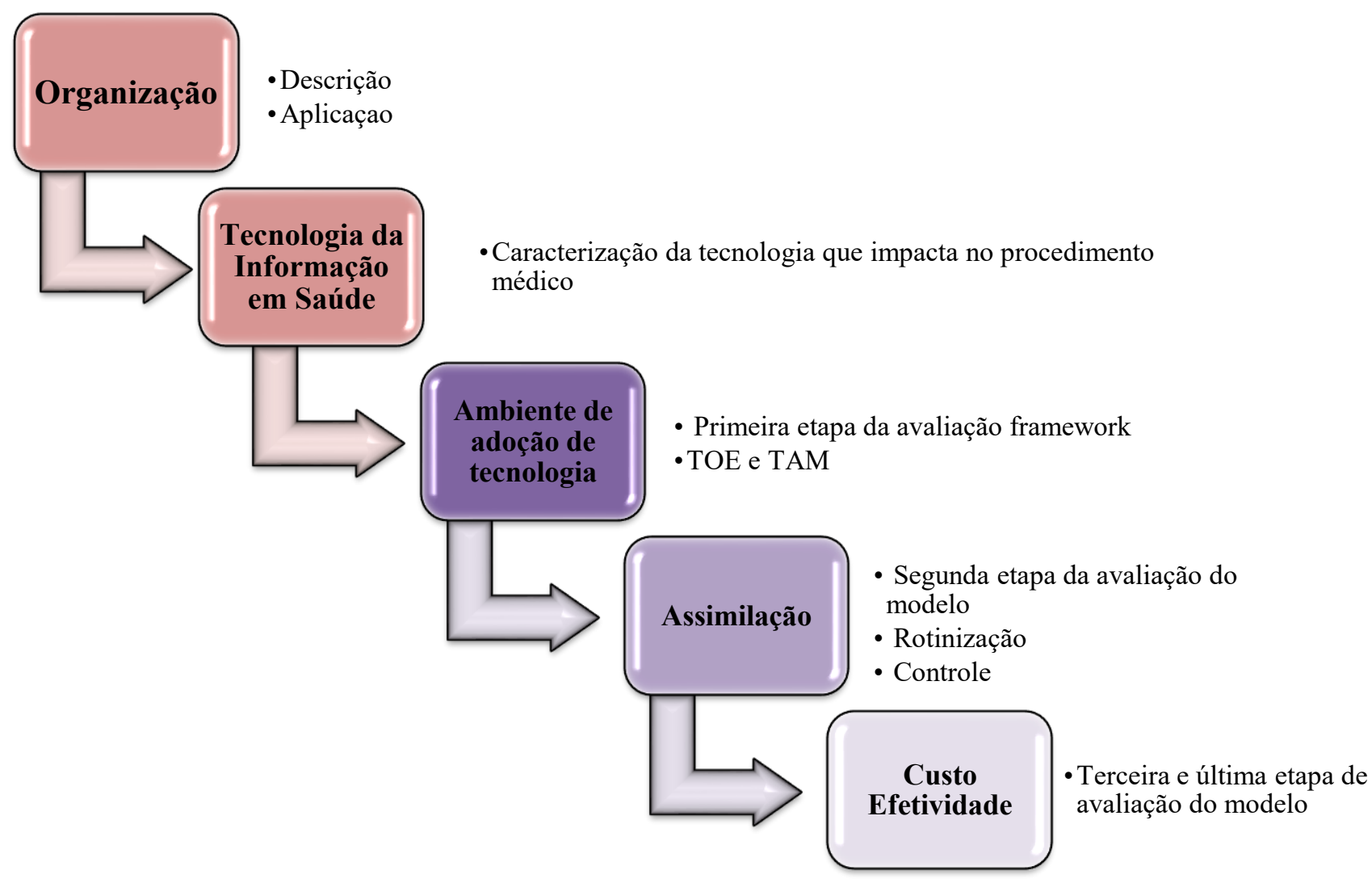

Fonte: Autor 


\section{ESTUDOS DE CASO}

\section{Avaliação do framework proposto}

A tabela 5 apresenta os casos que fizeram parte do estudo, os quais foram definidos através dos critérios de escolha da organização, defendidos por Hannah, Ball, Edwards (2009) e Sedig, Naimi, Haggerty (2017).

Tabela 5 - Casos

\begin{tabular}{|c|c|l|}
\hline CASO & \multicolumn{1}{|c|}{ ORGANIZAÇÃO } & \multicolumn{1}{|c|}{$\begin{array}{l}\text { TIPO DE TECNOLOGIA DA } \\
\text { INFORMAÇÃO EM SAÚDE }\end{array}$} \\
\hline A & Hospital Escola-Pública & Sistema Cognitivo- Plataforma LIDCO \\
\hline B & Hospital Público-Privado & $\begin{array}{l}\text { Sistema Cognitivo - Plataforma de Gestão } \\
\text { Sepse }\end{array}$ \\
\hline C & Hospital Público-Privado & $\begin{array}{l}\text { Sistema Cognitivo - Plataforma de Gestão } \\
\text { Sepse }\end{array}$ \\
\hline
\end{tabular}

Fonte: Autor.

\subsection{DESCRIÇÃO DA ORGANIZAÇÃO E TECNOLOGIA DA INFORMAÇÃO}

Através dos critérios de escolha da organização anteriormente abordados e suportado por Hannah, Ball, Edwards (2009) e, tem início a primeira fase do protocolo de pesquisa que contempla a descrição da organização escolhida para o estudo e a caracterização da tecnologia da informação em saúde que impacta no procedimento médico. A seguir serão apresentados os casos definidos com suas respectivas definições.

\section{CASO A - HOSPITAL ESCOLA-PÚBLICA}

\section{Organização}

O hospital-escola pública de alta complexidade é especializado em cardiologia, pneumologia e cirurgias cardíaca e torácica. Além de ser um polo de atendimento - desde a prevenção até o tratamento - o hospital também se destaca como um grande centro de pesquisa e ensino. Sua missão, portanto, é promover ações de difusão do conhecimento científico, de técnicas e de tecnologias em sua especialidade para o desenvolvimento econômico-social do País e bem-estar de sua população.

Sendo assim, o hospital é caracterizado como uma instituição pública prestadora de serviços de saúde. 
Com relação à infraestrutura, possui $75.000 \mathrm{~m}^{2}$ de área construída em dois prédios (11 andares e 17 andares), 535 leitos distribuídos em sete alas de internação. Desse total, 157 leitos são de UTI's de alta complexidade, 14 salas de cirurgia, 7 salas de hemodinâmica e estudos eletrofisiológicos, 12 salas de diagnóstico de alta complexidade (tomografia, ressonâncias e medicina nuclear), 60 consultórios médicos. Em média, aproximadamente $80 \%$ do atendimento são dedicados a pacientes cujo tratamento é financiado pelo SUS - Sistema Único de Saúde.

O hospital realiza em média por ano 260 mil consultas médicas 37 mil atendimentos multiprofissionais, 13 mil internações, 5 mil cirurgias, 2 milhões de exames de análises clínicas, 330 mil exames de diagnóstico de alta complexidade.

Os procedimentos de Revascularização Miocárdica, Troca Valvar Aórtica e combinados, representam $30 \%$ sobre o total de cirurgias cardíacas realizadas.

\section{Tecnologia da Informação em Saúde - LIDCO}

De acordo com a LiDCO Group PLC, LiDCO é um fornecedor de equipamento hemodinâmico não invasivo e /ou minimamente invasivo para hospitais, são usados para monitorar a quantidade de sangue que flui ao redor do corpo e garantir que os órgãos vitais sejam adequadamente oxigenados. Os produtos da LiDCO facilitam a aplicação de protocolos de otimização hemodinâmica em pacientes de alto risco, tanto em unidades de cuidados intensivos quanto na sala de cirurgia. De acordo com os fundadores, estudos clínicos vêm mostrando que a otimização do estado hemodinâmico em pacientes de alto risco produz melhores resultados e menor tempo de internação hospitalar. A tecnologia baseada em computador da LiDCO, desenvolvida no St Thomas' Hospital em Londres, demonstrou reduzir significativamente a morbidade e as complicações, o tempo de internação e os custos gerais associados à cirurgia de grande porte.

\section{CASO B - HOSPITAL PÚBLICO-PRIVADO}

\section{Organização}

Hospital público-privado de Curitiba - Paraná é um dos maiores centros de saúde do Estado, referência pela qualidade em tratamentos clínicos e cirúrgicos de alta complexidade, como Transplante de Medula Óssea e Hepático. Possui políticas de humanização, responsabilidade social e parceria público-privada, sendo responsável pela administração de mais cinco hospitais que atendem, em sua maioria.

Sobre a estrutura, o hospital possui, entre outras, dez salas de cirurgias, equipadas com tecnologia de ponta. Um dos diferenciais do Centro Cirúrgico é a sala de Cirurgia Inteligente, 
além de tecnologia de ponta em focos e equipamentos, o grande destaque da sala é a interatividade com telas móveis, os cirurgiões conseguem visualizar nas telas o prontuário do paciente, monitorização cardíaca, laudos e exames durante o procedimento, assim como interação com câmeras que ampliam detalhes da cirurgia.

\section{CASO C - HOSPITAL PÚBLICO-PRIVADO}

\section{Organização}

Hospital localizado em Foz do Iguaçu-PR, com 202 leitos, em 24 mil metros quadrados, atendendo planos de saúde, privado e SUS, além disso, o hospital conta com laboratório de análises clínicas 24 horas que garante o máximo de segurança e precisão na realização de diversos exames e destaca-se pela busca em possuir serviços de alta complexidade. O hospital conta com UTI's, diagnóstico por imagens e está equipado com o que há de mais moderno em medicina nuclear.

\section{CASO B e C}

\section{Tecnologia da Informação em Saúde - Plataforma de Gestão Sepse}

De acordo com informações fornecidas pela equipe da Plataforma de gestão Sepse, a tecnologia da informação utilizada é um artefato de inteligência artificial que gerencia os riscos pela aprendizagem autônoma e agnóstica de seus motores, conectados em tempo real com os bancos de dados dos sistemas e equipamentos geradores e gravadores de informações do hospital. Assim, com a conexão ao banco de dados hospitalar, a tecnologia pode, em tempo real, alertar a equipe de cuidados sobre pacientes em risco.

Tal inteligência artificial tem capacidade de atuar em diversas áreas, podendo ser: - Sepse;

- Compliance: Monitora processos, atividades e tarefas visando detectar falhas operacionais em qualquer departamento das organizações;

- Saving: Monitora os recursos das organizações utilizados nas atividades operacionais e administrativas;

- Blood: Monitora o banco de sangue, gerando campanhas de doação direcionadas diretamente aos doadores do tipo sanguíneo necessário;

-Epidemiology: Monitora os exames laboratoriais para contribuir com a Vigilância Epidemiológica, com o fim de detectar a ocorrência de surtos e epidemias em tempo real;

- Medicine: Monitora a biota hospitalar, visando a demonstrar o comportamento das bactérias nos ambientes assistenciais, com objetivo de apresentar um perfil de multirresistência. 
A tecnologia foi conectada à base de dados do prontuário eletrônico do hospital, a tecnologia recebeu os dados necessários de protocolo de sepse em vigência na instituição, o qual utilizava critérios de sinais vitais alterados e disfunções orgânicas para identificação de pacientes em risco, após o período de inserção dos dados necessários à "aprendizagem" de tecnologia, ele foi efetivamente implantado em duas unidades de internação como projeto piloto (unidade oncológica e unidade clínico-cirúrgica).

Com isso, a tecnologia passou a rastrear todos os registros do prontuário eletrônico de pacientes internados a cada 3,8 segundos, analisando a informação sobre os sinais vitais que foram inseridos pela equipe de assistência, juntamente com testes laboratoriais na procura de combinações de risco para sepse.

Quando a tecnologia identifica combinações de risco para uma infecção com base no protocolo de sepse da instituição, um alerta visual é emitido em monitor de vídeo instalado no posto de enfermagem, além disso, um alarme visual também é emitido, caso os dados rotineiramente inseridos pela equipe estiverem ausentes (data missing), e também, mensagens de texto são enviadas para o telefone celular de gestores das unidades de internação, para que os mesmos sejam alertados a verificar as condições do paciente em risco.

A frequência de envio das mensagens pela tecnologia é baseada no tempo médio de atendimento (TMA) calculado de forma autônoma e dinâmica pela tecnologia, esse intervalo representa o tempo médio para a inserção de qualquer tipo de dado no prontuário eletrônico, sejam dados de sinais vitais, prescrições, evoluções ou resultados de testes laboratoriais.

Os dados do estudo são provenientes apenas de pacientes internados na unidade clínico cirúrgica, dentro de um período de seis meses antes e seis meses após a implantação, respectivamente Período 1 e Período 2.

É importante citar que, foram excluídos da amostra do período 1, todos aqueles pacientes que passaram através da sala de emergência imediatamente antes da hospitalização, cujos primeiros sinais identificados da infecção foram detectados imediatamente antes de sua internação. Isso acontece devido à unidade de Pronto Atendimento não possuir um robô instalado e, também, porque durante o período do estudo, ocorreram algumas modificações específicas no processo de assistência que sabidamente impactaram diretamente no intervalo de tempo para a realização da terapia antibiótica, em casos suspeitos de sepse na emergência.

Um total de 974 pacientes foram admitidos na unidade clínico-cirúrgica no Período 1 e no período 2 foram admitidos 1086 pacientes na unidade clínico-cirúrgica, ao todo, 60 desses pacientes foram identificados com suspeita de infecção, (30 pacientes em cada período), através dos métodos de busca ativa habituais da instituição, dos 60 pacientes, 36 (60\%) tiveram 
passagem pelo setor de Pronto Atendimento pré-internação e 24 pacientes (40\%) foram admitidos sem passar por esta unidade.

Os 36 pacientes que passaram pelo setor de Pronto Atendimento pré-internação tiveram a primeira, evidência clínica de sinais de infecção registrada no prontuário eletrônico após seu internamento na unidade clínico-cirúrgica, os quais foram então considerados para a avaliação de perfil e tempo para realização de antimicrobiano nos períodos antes e após a implantação da tecnologia.

Para realização do estudo, este foi dividido em duas partes, sendo:

1) Relacionada à amostra de 36 pacientes internados na unidade clínico-cirúrgica que tiveram o primeiro sinal de infecção a partir da internação;

2) Amostra total de 60 pacientes internados com alguma infecção na unidade clínicocirúrgica, independente se o primeiro sinal da infecção foi no internamento ou no pronto atendimento, para que possa ser feita a análise em relação aos alarmes emitidos pela tecnologia antes e após sua implantação.

\subsection{AVALIAÇÃO DO FRAMEWORK}

A avaliação do framework inicia a segunda fase do protocolo de pesquisa, sendo composto por três etapas: ambiente de adoção da tecnologia (avaliando os frameworks TOE e TAM), assimilação de tecnologia (onde são investigadas atividades de rotinização e controle da tecnologia) e protocolo custo efetividade. A seguir serão apresentados os casos com suas respectivas avaliações.

\section{CASO A - HOSPITAL ESCOLA-PÚBLICA - UTI (CARDIOLOGIA)}

\section{Ambiente de adoção da Tecnologia}

Tem início a primeira etapa de validação do modelo, onde foram elaboradas questões baseadas nos frameworks TOE e TAM para realizar entrevistas com os profissionais da área médica e profissionais responsáveis pela tecnologia, de acordo com as respostas obtidas foi possível analisar entendimento da adoção da tecnologia implantada, sendo útil para examinar os fatores que afetam a segunda etapa de validação do modelo, a assimilação da TI. A adoção da plataforma LIDCO faz parte das estratégias para identificar e aprimorar os cuidados na população de alto risco, com o objetivo de prevenir eventos adversos, para melhorar os resultados dos pacientes clínicos-cirúrgicos. Neste caso, a avaliação da tecnologia, utilizou 
ferramentas de análise econômica para auxiliar nas decisões relativas à utilização das tecnologias em saúde e suas intervenções.

\section{Assimilação de Tecnologia}

A assimilação foi discutida com usuários da tecnologia (médico, médico anestesista, enfermeiras e ecocardigrafista) e eles destacaram como o uso da tecnologia LIDCO se difundiu nos processos de trabalho e tornou-se parte das atividades realizadas pela equipe. É de suma importância destacar que os entrevistados mencionaram a facilidade de uso da tecnologia e a confiança na informação, além disso, os usuários enfatizaram o impacto em suas atividades e melhoria no desempenho do trabalho. No que diz respeito ao entendimento do significado prático para Facilidade de Uso, os usuários definiram como sendo aquela variável que expressa expectativas de que um indivíduo possa ter na diminuição de esforço físico ou mental para o desenvolvimento de suas atividades, enquanto o significado de Utilidade Percebida é o quanto um indivíduo crê que ao usar um determinado sistema, melhora seu desempenho.

Discutindo os detalhes da tecnologia, observou, pelos relatos, que a assimilação também pode ser observada pela amplitude e profundidade do uso de TI nos processos, que refletem quão amplamente e extensivamente a TI é usada no hospital analisado. Observou-se que durante as entrevistas, os usuários percebem os aspectos de facilidade de uso e dos impactos nos processos (antes da implantação da tecnologia LIDCO, havia um responsável pela digitação dos dados sobre o paciente, no caso, um auxiliar administrativo, porém com a tecnologia os dados são armazenados em um cartão e descarregados diretamente no sistema de prontuário eletrônico do hospital).

Os benefícios notados pelos usuários após a implantação da tecnologia dizem respeito a mudança nos procedimentos, os ganhos de tempo, os benefícios em termos de gestão, porém quando se discute a avaliação da tecnologia, o foco fica no protocolo de efetividade em termos de qualidade de vida e óbitos.

Buscando apresentar as etapas para uma assimilação assertiva de tecnologia da informação e suas consequências, foi elaborada a figura 19, que condiz com o caso A. 
Figura 19 - Assimilação da tecnologia LIDCO no hospital.

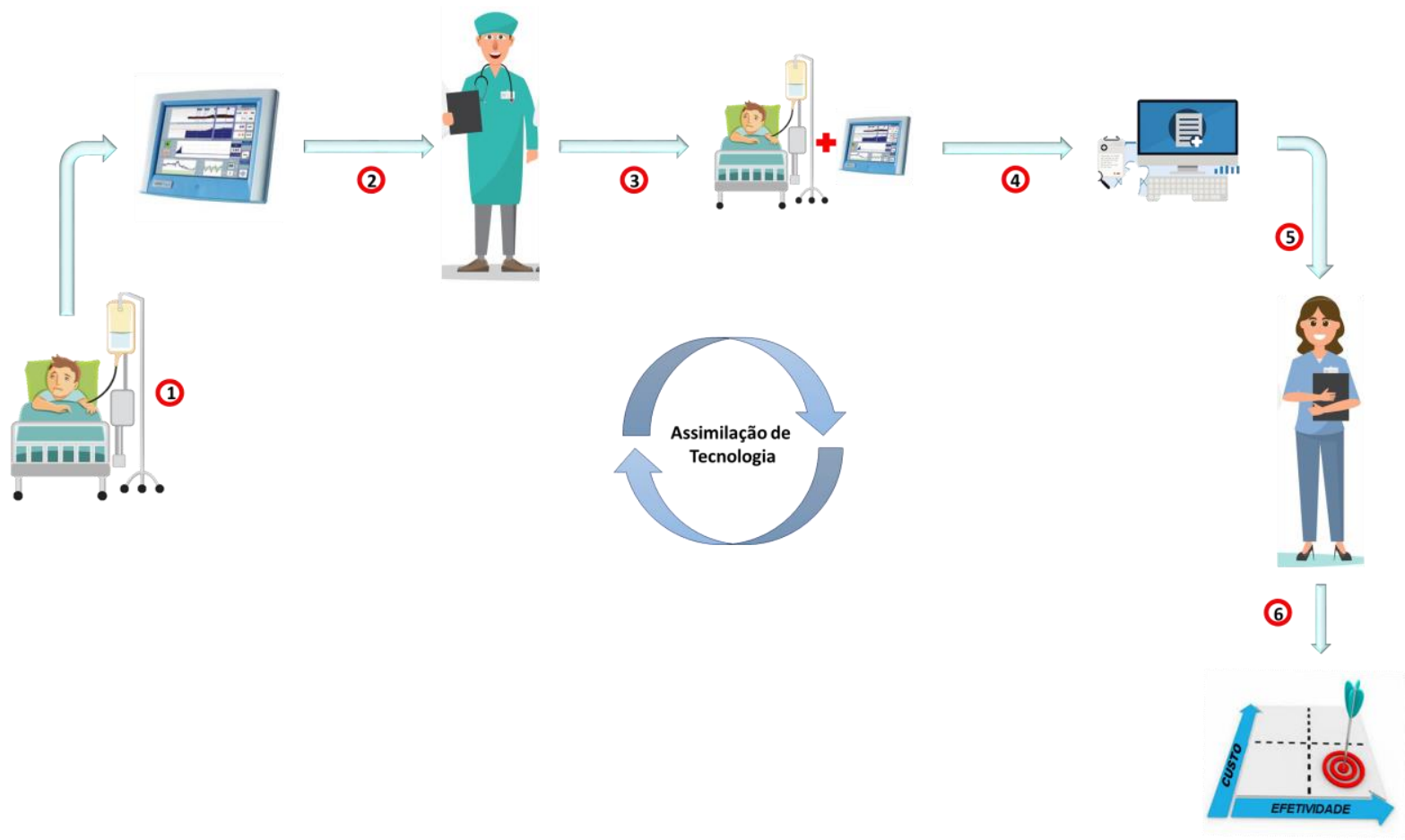

Fonte: Autor

A etapa 1 representa o paciente alocado ao Grupo TGM, ou seja, pacientes tratados através protocolo de Terapia de Ressuscitação Hemodinâmica Guiada por Metas, nesse momento, o paciente se conecta à tecnologia LIDCO para dar início à cirurgia.

A etapa 2 é o momento da cirurgia propriamente dita, e que tem a particularidade de ter um membro a menos na equipe médica, ou seja, com o uso da tecnologia, não é necessária a presença do ecocardiografista, já que o LIDCO cumpre esse trabalho, apresentando todas as informações necessárias sobre o paciente em tempo real. Além disso, a tecnologia é capaz de medir com precisão as quantidades necessárias de medicamentos que o paciente precisa durante (e após) a cirurgia, evitando possíveis erros.

Etapa 3 refere-se à etapa pós-cirúrgica e ida do paciente para UTI, o software permanece conectado ao paciente, monitorando e medicando o paciente de acordo com as necessidades, e envia todas as informações para o protocolo eletrônico do hospital, nesse momento, o uso da tecnologia elimina mais uma fase do processo, já que anteriormente os dados levantados durante a cirurgia eram enviados para um auxiliar administrativo responsável pela digitação de todas essas informações no prontuário eletrônico do hospital.

Etapa 4, o paciente recebe a visita do corpo de enfermagem para checar o monitor, sendo que a quantidade de visitas diminui se comparado ao procedimento sem tecnologia, onde eram 
necessárias aproximadamente 6 visitas de enfermeiros por dia além da visita de um médico responsável.

O cálculo do custo efetividade da implantação do monitor LIDCO nesta instituição já era algo previsto no estudo de análise da tecnologia em saúde, por se tratar da cultura presente na organização e será detalhado a seguir.

\section{Protocolo Custo Efetividade}

O estudo tem como objetivo primário avaliar os custos e a efetividade dos pacientes que foram tratados através protocolo de Terapia de Ressuscitação Hemodinâmica Guiada por Metas (Grupo 1 - Grupo TGM), grupo que fez uso da tecnologia LIDCO, comparados à pacientes tratados por protocolo institucional (Grupo 2 - Grupo controle) na otimização hemodinâmica.

Trata-se de um estudo prospectivo e randomizado, onde foram selecionados 126 pacientes de forma aleatória, sendo 62 tratados por protocolo de Terapia de Ressuscitação Hemodinâmica Guiada por Metas e o outro grupo, composto por 64 pacientes, tratado de forma convencional/protocolo institucional na otimização de variáveis hemodinâmicas em pacientes de alto risco submetidos à procedimentos cardíacos eletivos de Revascularização Miocárdica, Troca Valvar Aórtica e combinadas, durante o período de 13 de dezembro de 2011 a 17 de fevereiro de 2014.

O desfecho do estudo foi mortalidade por todas as causas e/ou complicação maior (isquemia miocárdica, síndrome do baixo débito cardíaco, necessidade de diálise, acidente vascular cerebral, infecção ou reoperação) e sepse em 30 dias.

Para a inclusão e exclusão de pacientes no estudo foram definidos os seguintes critérios institucionais:

Critérios de inclusão:

a) Indicação de cirurgia cardíaca eletiva: revascularização do miocárdio, cirurgia valvar ou combinada.

b) Idade maior ou igual a 18 anos.

c) Pontuação do EuroSCORE aditivo igual ou maior que 6 pontos, fração de ejeção menor que $50 \%$, infarto agudo do miocárdio recente, angina instável de alto risco e doença arterial periférica grave.

Critérios de exclusão:

a) Participação em outro estudo;

b) Gestação; 
c) Diagnóstico atual de endocardite infecciosa;

d) Insuficiência renal crônica dialítica;

e) Diagnóstico de neoplasia;

f) Síndrome do baixo débito cardíaco no pré-operatório;

g) Uso de dobutamina no pré-operatório;

h) Diagnóstico de hipertensão pulmonar;

i) Necessidade de balão intra-aórtico no pré-operatório ou no período de intervenção;

j) Necessidade de Noradrenalina em dose superior a $1 \mathrm{ug} / \mathrm{Kg} / \mathrm{min}$;

k) Recusa em participar do estudo.

De acordo com os dados fornecidos por profissionais do hospital, foi possível elaborar a tabela 6, que compara a média do tempo de internação, medicamentos e exames utilizados pelo Grupo 1 e Grupo 2:

Tabela 6 - Comparação de tempo de internação, medicamentos e exames dos grupos

\begin{tabular}{|c|c|c|c|c|c|}
\hline GRUPO & TEMPO DE INTERNAÇÃO (dias) & MEI & AMENTOS & \multicolumn{2}{|c|}{ EXAMES } \\
\hline 1 & 16,3 & $\mathrm{R} \$$ & $13.746,95$ & $\mathrm{R} \$$ & $1.147,85$ \\
\hline 2 & 21,6 & $\mathrm{R} \$$ & $22.723,91$ & $\mathrm{R} \$$ & $1.618,76$ \\
\hline
\end{tabular}

Fonte: Autor.

Para realizar a análise dos dados, foi utilizado a técnica estatística de teste de diferenças de medianas de duas amostras - Mann-Whitney, que é bastante utilizada no hospital A, para validar se existe diferença significativa para tempo de internação, medicamentos e exames com a utilização da tecnologia, os resultados são apresentados a seguir:

\section{Teste Mann-Whitney para TEMPO DE INTERNAÇÃO (dias) para Grupo 1 e Grupo 2}

\section{Method}

$\eta_{1}:$ median of TEMPO DE INTERNAÇÃO (DIAS) 1

$\eta_{2}:$ median of TEMPO DE INTERNAÇÃO (DIAS) 2

Difference: $\eta_{1}-\eta_{2}$

\section{Descriptive Statistics}




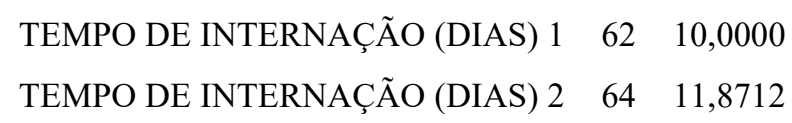

\section{Estimation for Difference}

\begin{tabular}{rcr} 
Difference & $\begin{array}{c}\text { CI for } \\
\text { Difference }\end{array}$ & $\begin{array}{r}\text { Achieved } \\
\text { Confidence }\end{array}$ \\
\hline-1 & $(-3,7 ;-0,0000000)$ & $95,05 \%$
\end{tabular}

Test

\begin{tabular}{lrr}
$\begin{array}{lr}\text { Null hypothesis } \\
\text { Alternative hypothesis }\end{array}$ & \multicolumn{1}{l}{$H_{0}: \eta_{1}-\eta_{1}-\eta_{2}=0$} \\
Method & W-Value & P-Value \\
\hline Not adjusted for ties & 3580,00 & 0,082 \\
Adjusted for ties & 3580,00 & 0,081
\end{tabular}

Análise: Em um nível de significância de 5\% $(0,05)$, a hipótese nula de igualdade de medianas dos tempos de internação entre os dois grupos foi aprovada, porém em um nível de 10\% de significância a hipótese nula não seria aprovada e as medianas dos tempos de internação dos dois grupos seriam consideradas diferentes (hipótese complementar $-\mathrm{H}_{1}$ ).

\section{Teste Mann-Whitney para EXAMES para Grupo 1 e Grupo 2}

$\eta_{1}:$ median of EXAMES 1

$\eta_{2}:$ median of EXAMES 2

Difference: $\eta_{1}-\eta_{2}$

\section{Descriptive Statistics}

\begin{tabular}{rrr} 
Sample & N & Median \\
\hline EXAMES 1 & 62 & 806,72 \\
EXAMES 2 & 64 & 1085,97
\end{tabular}

\section{Estimation for Difference}

\begin{tabular}{ccc} 
Difference & $\begin{array}{c}\text { CI for } \\
\text { Difference }\end{array}$ & $\begin{array}{r}\text { Achieved } \\
\text { Confidence }\end{array}$ \\
\hline$-208,315$ & $(-442,37 ;-26,02)$ & $95,05 \%$
\end{tabular}

\section{Test}

$\begin{array}{ll}\text { Null hypothesis } & H_{0}: \eta_{1}-\eta_{2}=0 \\ \text { Alternative hypothesis } & H_{1}: \eta_{1}-\eta_{2} \neq 0 \\ \text { W-Value P-Value } & \end{array}$


$3478,00 \quad 0,025$

Análise: Em um nível de significância de 5\% $(0,05)$, a hipótese nula de igualdade de medianas dos valores de exames entre os dois grupos não pode ser aprovada, portanto as medianas dos valores de exames entre os dois grupos são consideradas diferentes (hipótese complementar $\left.-\mathrm{H}_{1}\right)$.

\section{Teste Mann-Whitney para MEDICAMENTOS para Grupo 1 e Grupo 2}

$\eta_{1}$ : median of MEDICAMENTOS 1

$\eta_{2}:$ median of MEDICAMENTOS 2

Difference: $\eta_{1}-\eta_{2}$

\section{Descriptive Statistics}

\begin{tabular}{rcc} 
Sample & N & Median \\
\hline MEDICAMENTOS 1 & 62 & 6558,63 \\
MEDICAMENTOS 2 & 64 & 9901,45
\end{tabular}

\section{Estimation for Difference}

\begin{tabular}{rcr} 
Difference & CI for Difference & $\begin{array}{r}\text { Achieved } \\
\text { Confidence }\end{array}$ \\
\hline$-2409,24$ & $(-4805,54 ;-493,05)$ & $95,05 \%$
\end{tabular}

\section{Test}

$\begin{array}{ll}\text { Null hypothesis } & H_{0}: \eta_{1}-\eta_{2}=0 \\ \text { Alternative hypothesis } & H_{1}: \eta_{1}-\eta_{2} \neq 0 \\ \text { W-Value } & \text { P-Value }\end{array}$

Análise: Em um nível de significância de 5\% (0,05), a hipótese nula de igualdade de medianas dos valores de medicamentos entre os dois grupos não pode ser aprovada, portanto as medianas dos valores de medicamentos entre os dois grupos são consideradas diferentes (hipótese complementar $-\mathrm{H}_{1}$ ).

Portanto, para tempo de internação, medicamentos e exames a hipótese nula não é aprovada, o que significa que há diferença significativa entre grupo 1 e grupo 2 . 
Foi realizada análise estatística para os desfechos citados anteriormente: óbito e sepse em 30 dias para avaliar se existe diferença significativa, a tabela 7 apresenta a contagem de óbitos e sepses em ambos os grupos e os resultados são apresentados a seguir:

Tabela 7 - Contagem de óbito e sepse Grupo 1 e Grupo 2

\begin{tabular}{|c|c|c|}
\hline GRUPO & 1 & 2 \\
\hline COM ÓBITO & 3 & 6 \\
\hline NÃO ÓBITO & 39 & 37 \\
\hline COM SEPSE & 33 & 22 \\
\hline NÃO SEPSE & 9 & 21 \\
\hline
\end{tabular}

Fonte: Autor.

\section{Teste Mann-Whitney para ÓBITO para Grupo 1 e Grupo 2}

\section{Method}

$\eta_{1}:$ median of Óbito1

$\eta_{2}:$ median of Óbito2

Difference: $\eta_{1}-\eta_{2}$

\section{Descriptive Statistics}

\begin{tabular}{lrr} 
Sample & N & Median \\
\hline Obito1 & 42 & 0 \\
Obito2 & 43 & 0
\end{tabular}

\section{Estimation for Difference}

\begin{tabular}{rcr} 
Difference & CI for Difference & $\begin{array}{r}\text { Achieved } \\
\text { Confidence }\end{array}$ \\
\hline$-0,0000000$ & $(0,0000000 ;-0,0000000)$ & $95,05 \%$
\end{tabular}

\section{Test}

\begin{tabular}{lrr}
$\begin{array}{l}\text { Null hypothesis } \\
\text { Alternative hypothesis }\end{array}$ & \multicolumn{1}{c}{$\mathrm{H}_{0}: \eta_{1}-\eta_{2}=0$} \\
Method & W-Value & P-Value \\
\hline Not adjusted for ties & 1744,50 & 0,592 \\
Adjusted for ties & 1744,50 & 0,314
\end{tabular}

Análise: Em um nível de significância de 5\% (0,05), a hipótese nula de igualdade de medianas do número de óbitos entre os dois grupos foi aprovada, portanto as medianas do número de óbitos entre os dois grupos são consideradas iguais (hipótese nula $-\mathrm{H}_{0}$ ). 


\section{Teste Mann-Whitney para SEPSE para Grupo 1 e Grupo 2}

\section{Method}

$\eta_{1}:$ median of Infec1

$\eta_{2}:$ median of Infec 2

Difference: $\eta_{1}-\eta_{2}$

\section{Descriptive Statistics}

\begin{tabular}{rrr} 
Sample & N & Median \\
\hline Infec1 & 42 & 0 \\
Infec2 & 43 & 1
\end{tabular}

\section{Estimation for Difference}

\begin{tabular}{ccr} 
Difference & $\begin{array}{c}\text { CI for } \\
\text { Difference }\end{array}$ & $\begin{array}{r}\text { Achieved } \\
\text { Confidence }\end{array}$ \\
\hline$-0,0000000$ & $(-1 ;-0,0000000)$ & $95,05 \%$
\end{tabular}

\section{Test}

\begin{tabular}{lrr}
$\begin{array}{l}\text { Null hypothesis } \\
\text { Alternative hypothesis }\end{array}$ & \multicolumn{1}{c}{$\mathrm{H}_{0}: \eta_{1}-\eta_{1}-\eta_{2}=0$} \\
Method & W-Value & P-Value \\
\hline Not adjusted for ties & 1537,50 & 0,018 \\
Adjusted for ties & 1537,50 & 0,005
\end{tabular}

Análise: Em um nível de significância de 5\% (0,05), a hipótese nula de igualdade de medianas de infecção entre os dois grupos não pode ser aprovada, portanto as medianas de infecção entre os dois grupos são consideradas diferentes (hipótese complementar $-\mathrm{H}_{1}$ ).

Portanto, para o desfecho óbito a hipótese nula foi aprovada, o que significa que não há diferença significativa entre os grupos, já para o desfecho sepse em 30 dias hipótese nula não é aprovada, o que significa que há diferença significativa entre grupo 1 e grupo 2 .

De acordo com o Instituto Latino Americano de Sepse (ILAS) custo diário de um paciente de Sepse nas UTI's brasileiras é de US\$934.

O cálculo do custo efetividade é:

$$
\mathrm{ACE}=\frac{\text { Diferença entre custos }(\text { Procedimento A-Procedimento B })}{\text { Diferença entre benefícios }(\text { Procedimento A-Procedimento B })}
$$




$$
\mathrm{ACE}=\frac{22.723,91-13.746,95}{21-9}
$$

$\mathrm{ACE}=748,08$

Através do estudo foi possível encontrar uma redução média de 21 casos de sepse para 9 após a implantação da tecnologia LiDCO. De forma que o custo efetividade é R\$ 748,08. Ou seja, houve uma diminuição dos gastos com medicamentos além da diminuição dos casos de sepse.

\section{CASO B e C- HOSPITAIS PÚBLICO-PRIVADOS}

\section{Ambiente De Adoção Da Tecnologia}

Tem início a primeira etapa de validação do modelo, onde foram elaboradas questões baseadas nos frameworks TOE e TAM para realizar entrevistas com os profissionais da área médica e profissionais responsáveis pela inteligência artificial (questões apêndice B), de acordo com as respostas obtidas foi possível analisar entendimento da adoção da tecnologia implantada, sendo útil para examinar os fatores que afetam a segunda etapa de validação do modelo, a assimilação da TI.

Os hospitais devem possuir a seguinte infraestrutura para implantar o robô cognitivo: suporte de TI adequado, computador, sistema hospitalar com input de dados de sinais vitais e exames laboratoriais eletrônico e painéis de gestão a vista (televisão). O custo aproximado de aquisição da tecnologia gira em torno de $\mathrm{R} \$ 70.000,00$, e os motivos válidos que levaram tais hospitais a adotar a tecnologia foram a diminuição de mortalidade, custos, casos de sepse e inovação.

O segundo questionário refere-se ao framework TAM, e foi enviado à equipe de enfermagem dos dois casos estudados, de forma que as respostas obtidas serviram para avaliar a adoção com foco no indivíduo.

Em ambos os casos, em um primeiro momento, houve estranhamento por parte dos profissionais que fariam uso frequente da tecnologia, porém, ao passarem pelo treinamento e perceberem facilidade no uso e velocidade de resposta, houve maior aceitação. O TMA (tempo médio para a inserção de qualquer tipo de dado no prontuário eletrônico) melhorou, portanto, conclui-se que há uso frequente da inteligência artificial em ambos os hospitais, além de notar a existência de confiabilidade e satisfação dos profissionais pela tecnologia. 


\section{Assimilação de Tecnologia}

Buscando apresentar as etapas para uma assimilação assertiva de tecnologia da informação e suas consequências, foi elaborada a figura 20, que condiz com os casos B e C. Figura 20 - Assimilação do robô cognitivo nos hospitais.

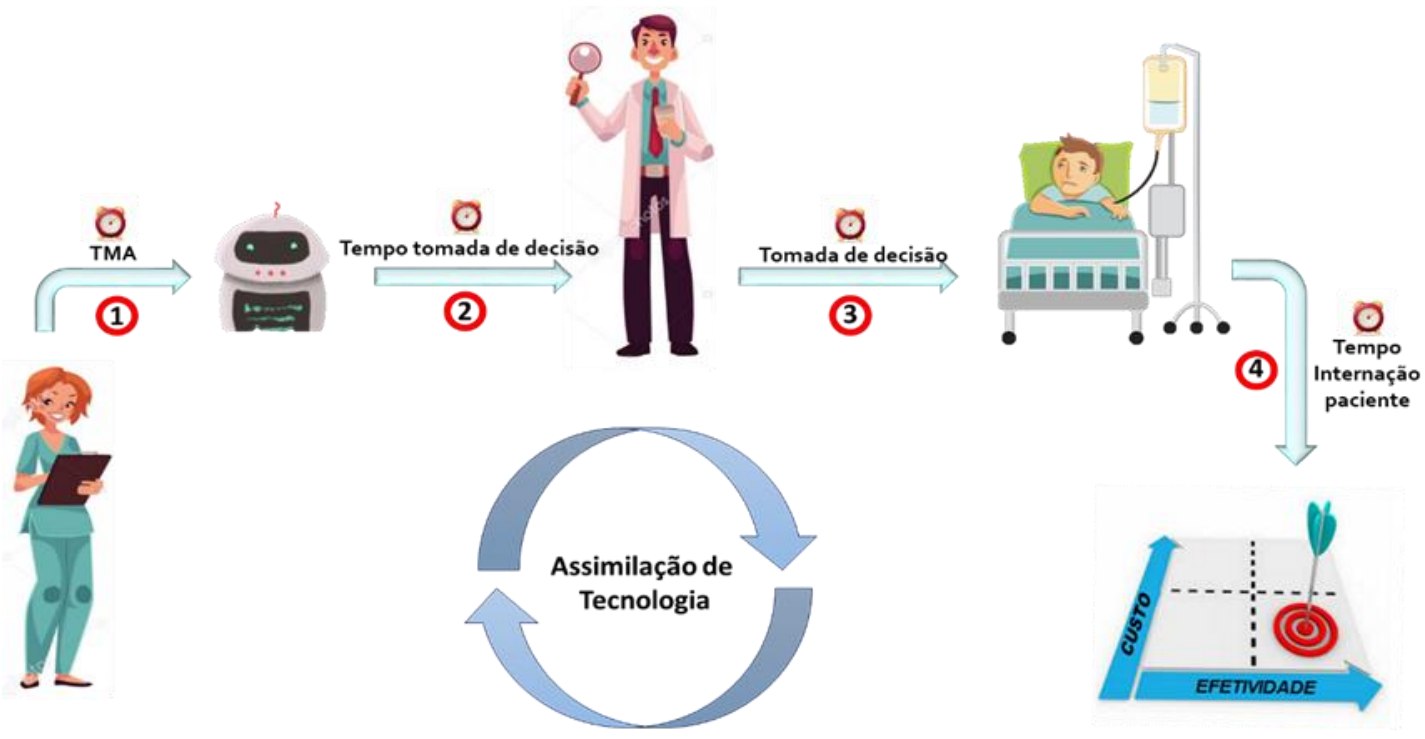

Fonte: Autor.

A etapa 1 representa o tempo médio de atendimento (TMA), ou seja, o tempo médio para a inserção de qualquer tipo de dado no prontuário eletrônico, sejam dados de sinais vitais, prescrições, evoluções ou resultados de testes laboratoriais, quanto menor o TMA, maior quantidade de dados estão sendo inseridas no prontuário eletrônico, melhora a assimilação.

A etapa 2 é o momento em que a tecnologia inicia o rastreamento dos registros do prontuário eletrônico de pacientes internados (essa atividade ocorre a cada 3,8 segundos), analisando a informação sobre os sinais vitais e testes laboratoriais que foram inseridos, caso o robô identifique combinações de risco de infecção um alerta visual é emitido. Além disso, caso a equipe deixe de inserir dados como o habitual, um alarme visual também é emitido.

Etapa 3 refere-se à emissão do alerta, onde a equipe médica realiza a tomada de decisão, ou seja, tem início o tratamento em tempo hábil comparado ao processo anterior (período 1).

Etapa 4, após o alerta, o tempo de tomada de decisão é menor, precipitando o tratamento e a melhora do paciente, consequentemente, diminuindo o tempo de internação e reduzindo o seu custo. Nesse momento, pode-se avaliar o impacto da assimilação da tecnologia no custo efetividade da atividade. 
Portanto, torna-se possível analisar o custo efetividade da implantação da tecnologia sob a perspectiva de assimilação de tecnologia, ou seja, quanto maior o custo efetividade, melhor a assimilação da tecnologia no hospital.

\section{Protocolo Custo Efetividade - CASO B}

A fim de encontrar a relação entre assimilação da tecnologia e custo efetividade, primeiramente foram levantados os dados de TMA (tempo médio para a inserção de qualquer tipo de dado no prontuário eletrônico) e o TMP (tempo médio de prescrição da primeira dose do antimicrobiano) para o período 1 e período 2 como apresentado na Figura 21 e Figura 22.

Figura 21 - Comparação do tempo médio de inserção de dados no prontuário eletrônico

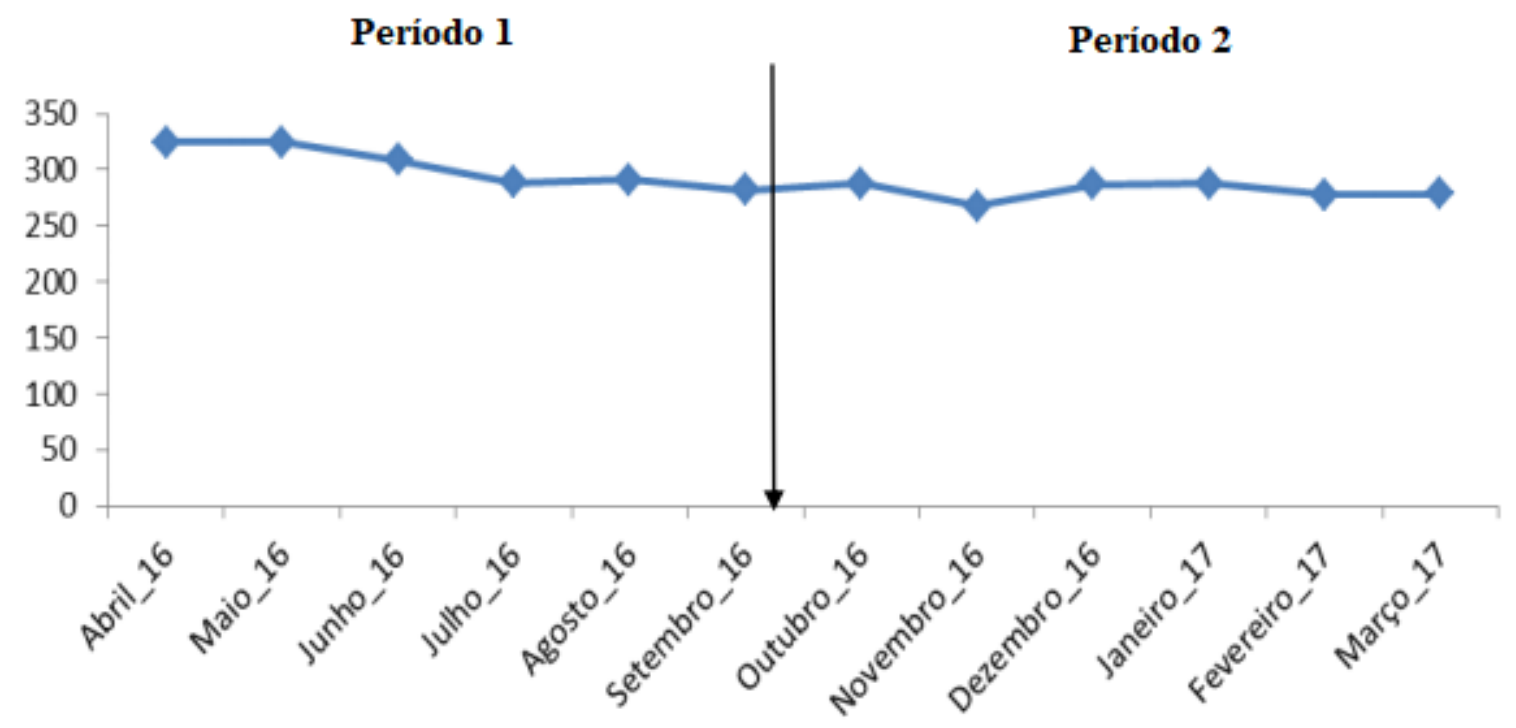

Fonte: Autor, adaptado de Kalil, 2010 
Figura 22 - Comparação do tempo médio de prescrição da primeira dose do antimicrobiano

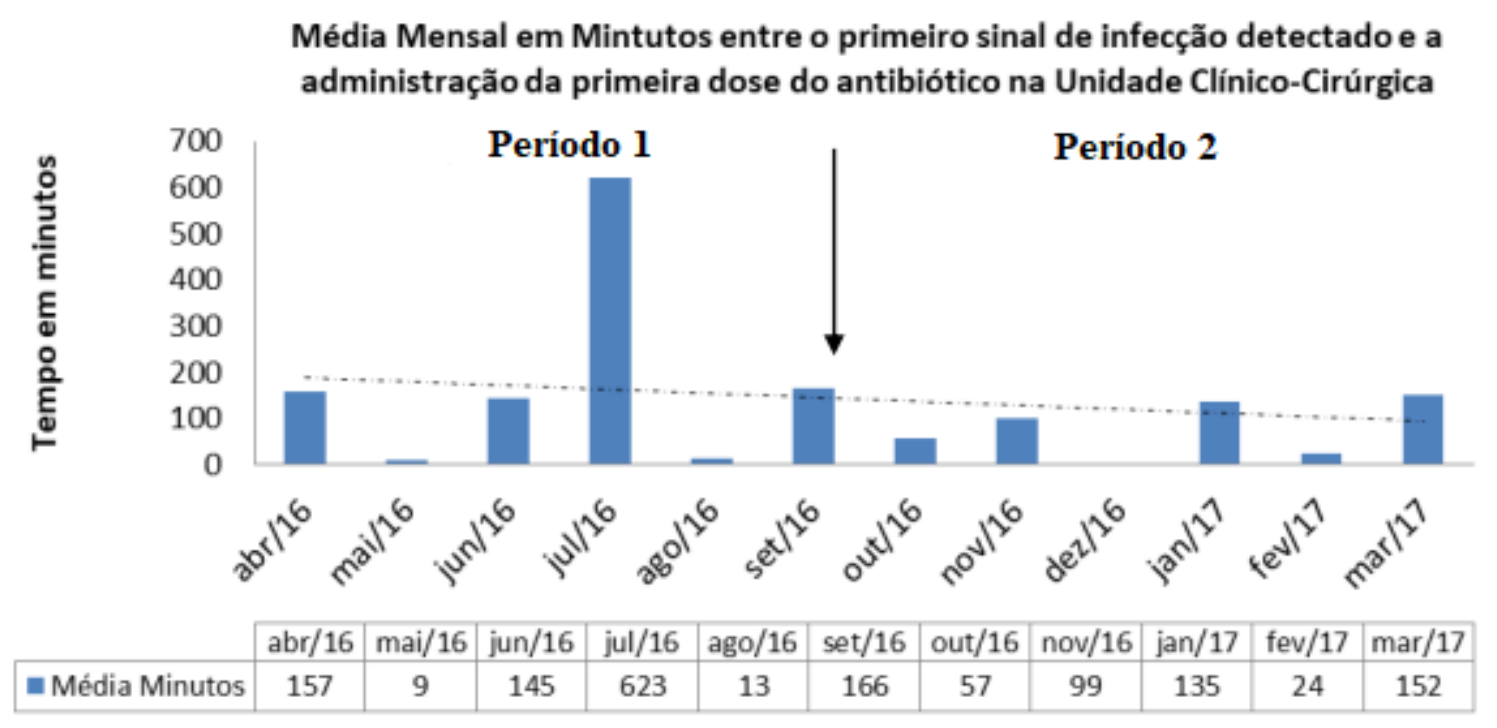

Fonte: Adaptado de Kalil, 2010.

A partir do levantamento de dados foi realizada a simulação de Monte Carlo, e seus relatórios são apresentados a seguir, nas Tabelas 8,9,10 e 11 .

Tabela 8 - Dados período 1 e período 2 utilizados para simulação de Monte Carlo

\begin{tabular}{|c|c|c|c|c|}
\hline & TMA (min) & $\begin{array}{c}\text { TMP } \\
\text { (min) }\end{array}$ & $\begin{array}{c}\text { Média de dias de } \\
\text { internação }\end{array}$ & $\begin{array}{c}\text { Relação } \\
\text { TMA/TMP }\end{array}$ \\
\hline Máximo & 325 & $\mathbf{1 5 7}$ & $\mathbf{2 1}$ & 2,070064 \\
\hline Mais provável & 300 & $\mathbf{5 7}$ & $\mathbf{1 7}$ & 5,263158 \\
\hline Mínimo & 280 & $\mathbf{2 4}$ & $\mathbf{1 5}$ & 11,66667 \\
\hline
\end{tabular}

Fonte: Autor.

A função escolhida para realizar a simulação foi função triangular para TMA e TMP, nível de confiança de $95 \%$.

A relação encontrada através de simulação foi:

Tabela 9 - Relatório 1: Previsão da relação TMA/TMP.

\begin{tabular}{|l|}
\hline \multicolumn{2}{|c|}{ RESUMO: } \\
\hline O nível de certeza é $73,64 \%$ \\
\hline O intervalo de certeza é de 3,00 a 9,06 \\
\hline O intervalo inteiro de 1,89 a 12,67 \\
\hline O caso base é --- \\
\hline Após 5.000 avaliações, o erro padrão da média é 0,02 \\
\hline
\end{tabular}

Fonte: Autor. 
Tabela 10 - Gráfico da relação TMA/TMP

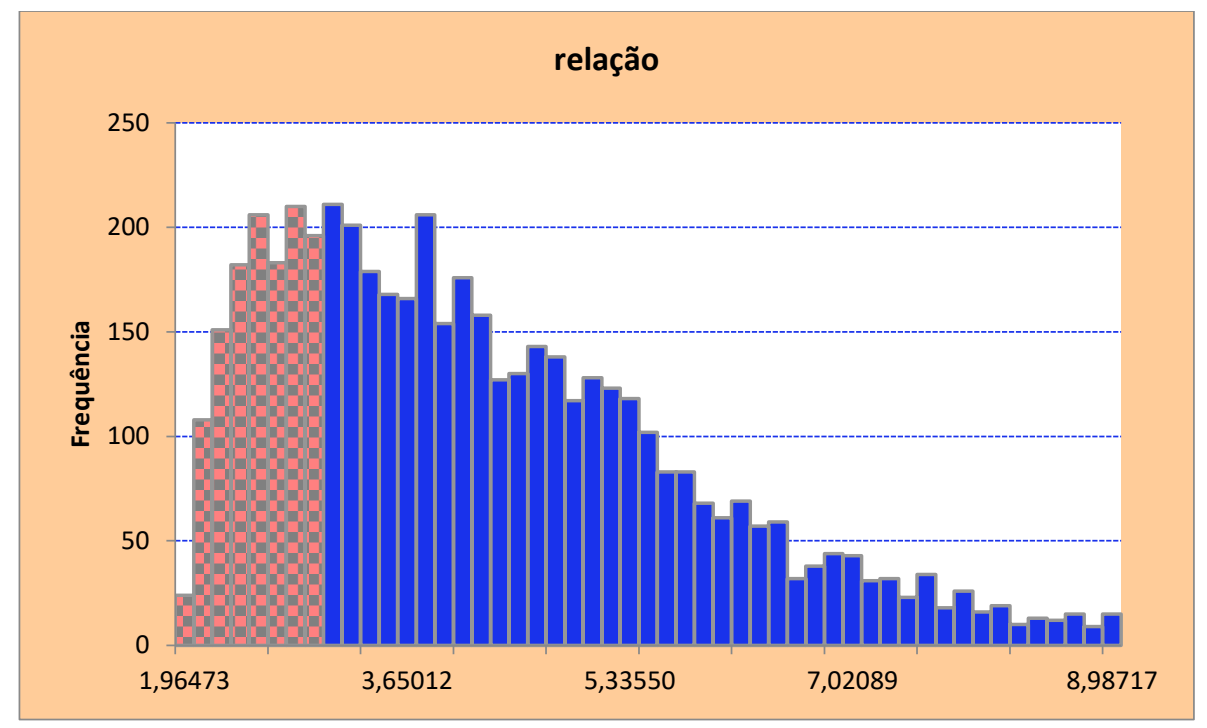

Fonte: Autor.

Tabela 11 - Relatório Estatístico da Previsão Relação TMA/TMP

\begin{tabular}{|l|r|}
\hline & Valores de previsão \\
\hline Avaliações & 5.000 \\
\hline Caso Base & --- \\
\hline Média & 4,31 \\
\hline Mediana & 3,96 \\
\hline Moda & --- \\
\hline Desvio Padrão & 1,69 \\
\hline Variância & 2,87 \\
\hline Obliquidade & 1,16 \\
\hline Curtose & 4,56 \\
\hline Coeficiente de Variação & 0,3929 \\
\hline Mínimo & 1,89 \\
\hline Máximo & 12,67 \\
\hline Largura do Intervalo & 10,78 \\
\hline Erro Padrão Média & 0,02 \\
\hline
\end{tabular}

Fonte: Autor.

Como apresentado na Tabela 4, o intervalo de certeza foi de 3,00 a 9,06 com nível de certeza $73,64 \%$, ou seja, a probabilidade de diminuir o número de número de dias de internação de 21 para 17 dias, após a implantação da tecnologia, ou seja, probabilidade de redução de 4 dias em média (tabela 12). 
Tabela 12 - Diminuição dos dias de internação com nível de certeza de 73,64\%

\begin{tabular}{|c|c|c|c|c|}
\hline & TMA (min) & $\begin{array}{c}\text { TMP } \\
(\mathbf{m i n})\end{array}$ & $\begin{array}{c}\text { Média de dias de } \\
\text { internação }\end{array}$ & Relação TMA/TMP \\
\hline Máximo & $\mathbf{3 2 5}$ & $\mathbf{1 5 7}$ & $\mathbf{2 1}$ & 2,070064 \\
\hline Mais provável & $\mathbf{3 0 0}$ & $\mathbf{5 7}$ & $\mathbf{1 7}$ & 5,263158 \\
\hline & & & & 9,06 \\
\hline Mínimo & $\mathbf{2 8 0}$ & $\mathbf{2 4}$ & $\mathbf{1 5}$ & 11,66667 \\
\hline
\end{tabular}

Fonte: Autor.

Sobre a análise da informação gerada de forma autônoma pelo robô em relação ao TMA (tempo médio de atendimento), que mede o intervalo entre qualquer inserção de dados no sistema de prontuário eletrônico (seja dado vital, prescrição ou exame laboratorial), foi possível verificar que houve uma redução significativa entre as médias no período antes e após a implantação de a tecnologia (325 e 280 minutos respectivamente), evidenciando menor intervalo de tempo entre as inserções de informação pela equipe assistencial no prontuário do paciente, o que significa que houve assimilação da tecnologia implantada pelo hospital.

De acordo com o Instituto Latino Americano de Sepse (ILAS) custo diário de um paciente de Sepse nas UTI's brasileiras é de US\$ 934, com internação média de 9,5 dias.

Através do estudo foi possível encontrar uma redução média de 4 dias de internação de pacientes com sepse após a implantação da tecnologia e da assertiva assimilação da tecnologia pelo hospital. De forma que houve em média uma redução de US\$ 3736, 00 no custo de internação de pacientes com sepse para o hospital. Ou seja, quanto menor o tempo de inserção dos dados na tecnologia por parte dos membros da equipe, maior a assimilação, melhor o desempenho da nova tecnologia, melhores serão os resultados, o tratamento da sepse será realizado mais rápido, com isso, o paciente possivelmente sairá mais rápido do hospital, consequentemente, o custo efetividade aumentará.

\section{Protocolo Custo Efetividade - CASO B e CASO C}

Foi disponibilizado para o estudo, uma comparação entre os casos B e C, com dados referentes à mortalidade, o tempo de internação do paciente e o tempo entre a primeira prescrição de antimicrobiano.

A tabela 13 apresenta o período considerado para o estudo foi: 
Tabela 13 - Período considerado para o estudo

\begin{tabular}{|c|c|c|}
\hline CASO & $\begin{array}{c}\text { PERÍODO ANTES DA } \\
\text { IMPLANTAÇÃO }\end{array}$ & $\begin{array}{c}\text { PERÍODO APÓS A } \\
\text { IMPLANTAÇÃO }\end{array}$ \\
\hline CASO B & de $15 / 09 / 15$ a $15 / 09 / 16$ & de $15 / 09 / 16$ a $15 / 09 / 17$ \\
\hline CASO C & de $05 / 02 / 17$ a $04 / 05 / 18$ & de $05 / 02 / 18$ a $05 / 02 / 19$ \\
\hline
\end{tabular}

Fonte: Plataforma de Gestão Sepse.

A tabela 14 representa o número de pacientes que participaram do estudo em cada período e em cada hospital. Para classificar o paciente entre antes e depois, considerou a data de entrada do paciente.

Tabela 14 - Número dos pacientes no estudo

\begin{tabular}{|c|c|c|}
\hline HOSPITAL & ANTES & DEPOIS \\
\hline CASO B & 3246 & 6006 \\
\hline CASO C & 13809 & 13139 \\
\hline
\end{tabular}

Fonte: Plataforma de Gestão Sepse.

Os gráficos 1 e 2 apresentam as comparações entre os hospitais B e C. No caso da taxa de mortalidade, (gráfico 1) foi apresentado uma visão geral da queda da mortalidade dos dois casos, enquanto o gráfico 2 apresenta a comparação das taxas de mortalidade em cada um dos casos antes e depois da implantação da tecnologia cognitiva, é possível notar que no caso $\mathrm{C}$ a queda foi de 2.27 pontos percentuais (p.p.) ou queda de $119 \%$ na taxa de mortalidade. Sobre o tempo médio de internação em horas, ambos os hospitais reduziram o tempo médio de internação em, aproximadamente, $7 \%$, no caso B, foram nove horas a menos no período antes da implantação em comparação com o período após a implantação e a redução no caso $C$ foi de 6 horas. 
Gráfico 1 - Comparação da taxa de mortalidade

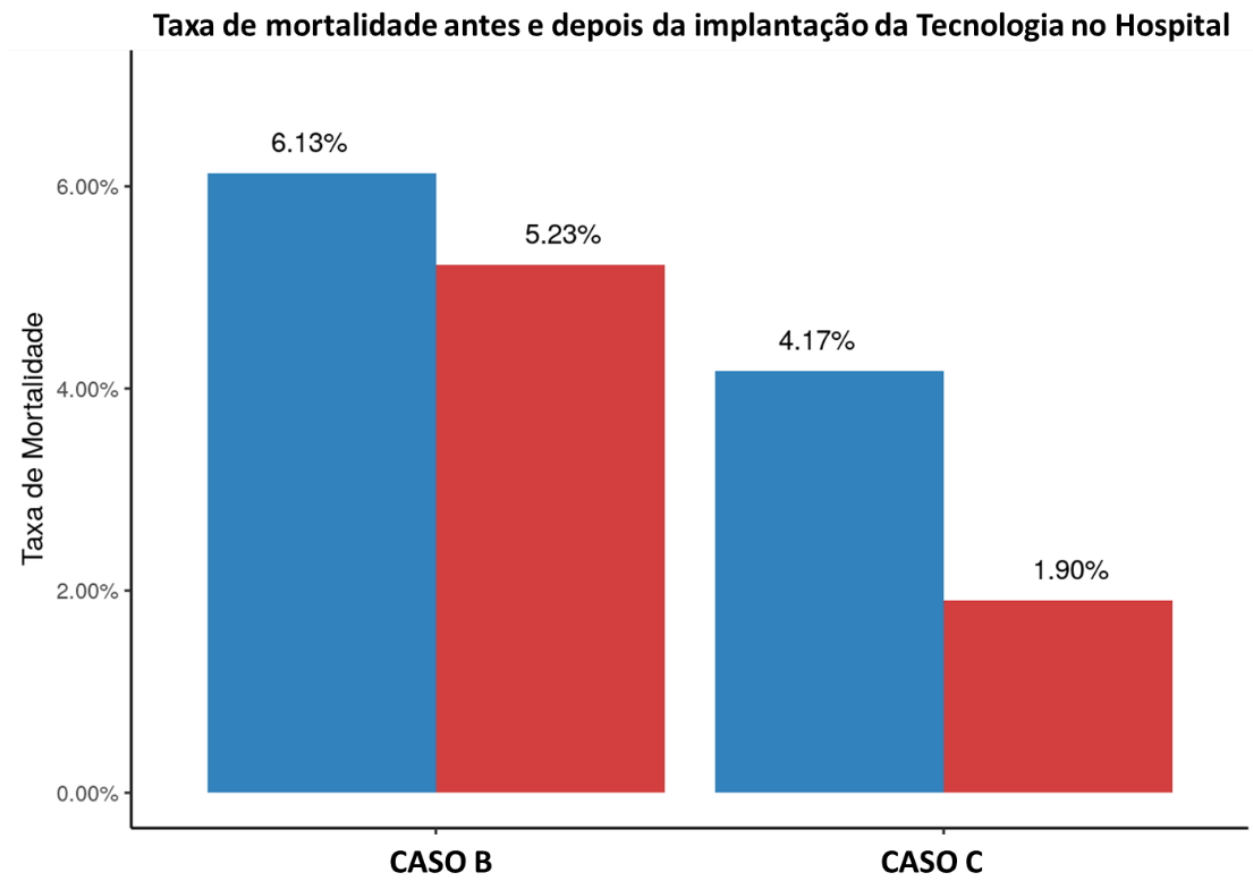

Fonte: Plataforma de Gestão Sepse.

Gráfico 2 - Comparação do tempo médio de internação em horas.

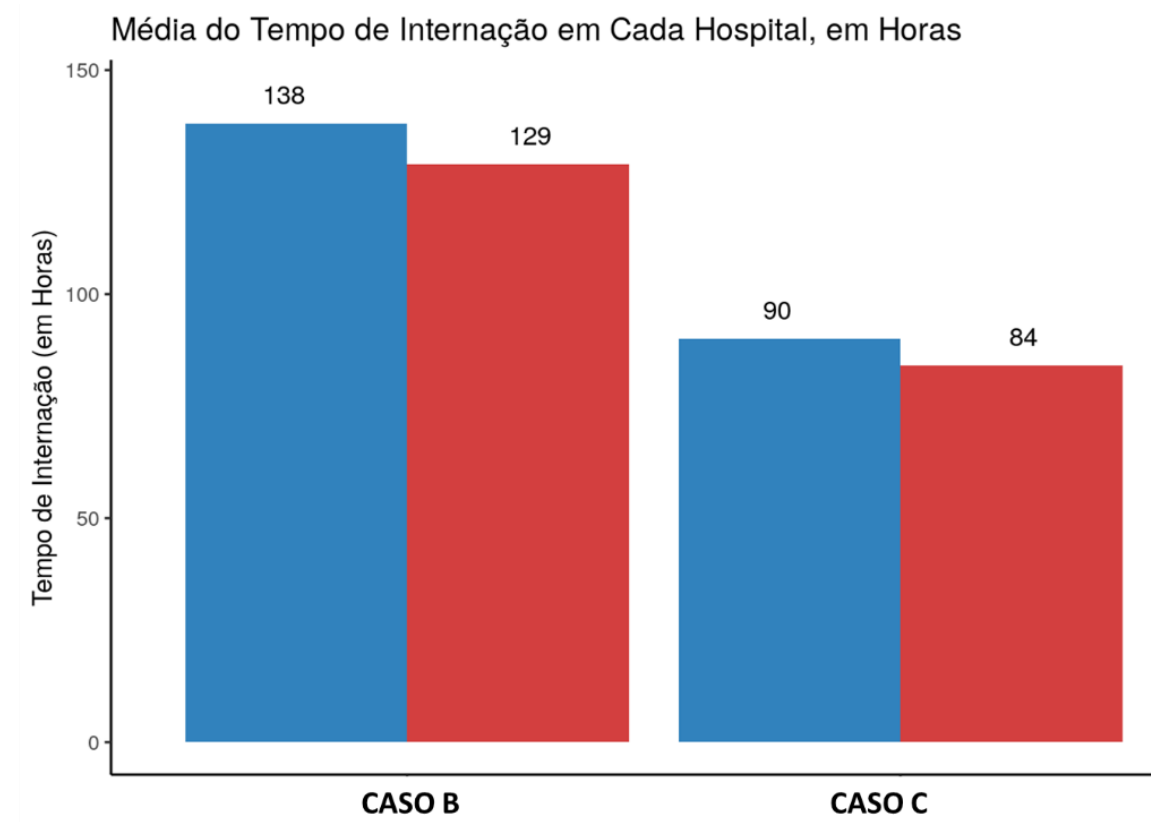

Fonte: Plataforma de Gestão Sepse. 


\section{DISCUSSÃO DOS RESULTADOS}

Partindo da aplicação do framework proposto (figura 17) nos casos A, B e C observouse que as variáveis dos modelos TOE, TAM e Assimilação não são levadas em conta no processo decisório. As variáveis são discutidas, porém não são trabalhadas de forma integrada e incorporadas na sistemática da avaliação das tecnologias. Nos três casos, os entrevistados discutiram os impactos destas variáveis quando foram questionados e descrevem com detalhes a importância de cada uma na assimilação das novas tecnologias, porém para tomada de decisão da adoção da tecnologia os hospitais conduzem somente os estudos de efetividade comparativa, destacando ensaios clínicos randomizados. No caso A, a análise passou por uma modelagem econômica através do custo-efetividade. Nos casos B e C apenas trabalham parecer técnicocientífico. Conforme os resultados obtidos, a aplicação do framework apresenta aderência como uma ferramenta de avaliação da HIT, e reforçando a sua importância os entrevistados destacaram a necessidade de trazer para a área de gestão em saúde questões que vão além dos ensaios randomizados.

A adoção e assimilação assertiva são extremamente importantes para o melhor aproveitamento de quaisquer tecnologias implantadas nas organizações, sendo necessário entender os métodos de adoção, como exemplo o TOE e TAM de forma combinada e buscar o máximo de assimilação possível. Alinhado aos autores Yusof et al. (2008), a adoção de HIT demanda uma avaliação rigorosa sendo necessário abordar problemas de tecnologia, humanos e organização. Os métodos de avaliação atuais avaliam diferentes aspectos do HIT e podem ser melhorados, demandando uma nova estrutura de avaliação humana, organizacional e de adequação à tecnologia, desenvolvida após uma análise crítica dos resultados dos estudos de avaliação HIT desenvolvidas A aplicação dos modelos teóricos TOE e TAM conforme discutido por Marques et al. (2010) apresentam-se como abordagens que auxiliam no entendimento das tecnologias implantadas, sendo útil para examinar os fatores que afetam a assimilação da TI e os resultados obtidos. Combinar os modelos de adoção de tecnologia, permite um direcionamento para obtenção de melhores resultados em investimentos em Tecnologia da Informação em Saúde. Ao aplicar o framework nos hospitais para avaliação das tecnologias adotadas, houve a concordância de que vários pontos poderiam ser melhorados com a aplicação de uma estrutura de avaliação de tecnologia ampla.

No hospital caso A, pode-se constatar que vários impactos de gestão não foram incorporados na avaliação do custo-efetividade. Durante as entrevistas os aspectos organizacionais como melhoria dos processos e a melhoria com a gestão visual, as quais causam 
impactos em custos, não foram levantados e colocados em discussão no processo decisório. Os aspectos tecnológicos para a implantação desta plataforma não foram evidenciados, pois o monitor LiDCO não demandava de nenhuma infraestrutura de comunicação, porém outras tecnologias que estão sendo analisadas demandam de um entendimento dos aspectos tecnológicos. Os resultados obtidos, não refletem o impacto da tecnologia implantada, utilizando somente como critério o custo-efetividade.

De acordo com os entrevistados nos casos B e C, houve indicação da falta de profissionais habilitados para operar o sistema, ou seja, observa-se problemas de formação acadêmica tornando um inibidor da adoção de novas tecnologias voltadas para a saúde, pois as escolas médicas e de enfermagem não formam o aluno para lidar com as novas tecnologias de informação.

Na mesma linha do caso A falta um modelo formal de avaliação de tecnologia em saúde que seja capaz de trazer para o processo decisório uma visão holística dos fatores que impactam a implantação e uso de novas tecnologias me saúde.

Considerando os casos estudados, os entrevistados levantaram os benefícios da gestão visual que as tecnologias implantadas estavam trazendo, porém esta é uma variável organizacional e não se enquadra nos aspectos de avaliação que eles fazem para discutir a implantação e rotinização da tecnologia. Observa-se que esta parte organizacional é uma das dimensões que não é capturada, assim quando o framework proposto neste trabalho foi discutido junto com os profissionais e houve uma convergência que a avaliação feita atualmente precisava mudar para uma avaliação rigorosa sendo necessário abordar problemas de tecnologia, humanos e organização.

Alinhados aos autores Silva et. al. (2008) os casos indicaram que as análises feitas pelos hospitais relacionados à adoção de tecnologias da informação, não conseguem explicar todos os fenômenos que lhe estão associados. Tal fato se deve pela complexidade dos processos de adoção, principalmente porque envolvem pessoas e interferem com as suas percepções de natureza cognitiva, as quais nem sempre se regem por interesses organizacionais (antes são afetados por questões de natureza individual e cultural) e, por outro, à natureza fortemente dinâmica e evolutiva das tecnologias da informação, mudando muito rapidamente os paradigmas tecnológicos e criando novos campos de investigação.

Os casos estudados evidenciam através da aplicação do framework que a avaliação de tecnologias em saúde (HIT) é um campo multidisciplinar com implicações clínicas, sociais, éticas e econômicas do desenvolvimento, difusão e uso da tecnologia em saúde, demandando 
de fato modelos que auxiliem na avaliação das tecnologias capturando esta multidisciplinariedade. 


\section{CONCLUSÃO}

O cuidado com a saúde representa um importante desafio social e econômico que cada país enfrenta. O aumento do custo da assistência médica, envelhecimento e o constante crescimento populacional influenciam as demandas de saúde e ditam a necessidade de novas e mais avançadas soluções científicas. Este cenário demanda a implantação de novas tecnologias em saúde, que contribuam com a segurança do paciente, auxiliem o processo de tomada de decisão ao médico, e que suportem o processo de gestão da saúde. A implementação de HIT de uma forma eficaz não está relacionada somente com complexidade técnica, mas está relacionada também com fatores sociais e organizacionais, os quais têm impacto significativo nos resultados. Partindo do objetivo geral da pesquisa de propor um framework de avaliação de tecnologia da informação em saúde na perspectiva do custo efetividade, combinando diferentes modelos de adoção de tecnologia, constatou-se que os modelos apresentados são capazes de se completar, pois fatores de análise que faltam em um modelo estão presentes no outro, sendo assim, o framework proposto apresenta-se como uma estrutura de avaliação, composta pela junção dos modelos TOE, TAM e Assimilação combinados com a análise do custo-efetividade.

Como limitações, primeiro por se tratar de uma pesquisa qualitativa, não se deve considerar a generalização dos resultados obtidos, considerando-se que o presente estudo tem por base três casos envolvendo a implantação de tecnologias em saúde. Outra limitação que pode ser apontada é a representatividade da fala individual em relação a um coletivo maior. $\mathrm{Na}$ tentativa de minimizar os impactos dessas limitações, foram utilizados dados secundários, relatórios dos projetos e contatos com fornecedores das tecnologias como forma de fundamentar a avaliação do framework proposto neste estudo.

Para estudos futuros, sugere-se um estudo longitudinal em projetos de Tecnologia em Saúde aplicando o conceito integrado dos modelos de adoção e assimilação de tecnologia, e custo-efetividade permitindo formalizar a avaliação das ferramentas tecnológicas na gestão da saúde. O desenvolvimento de um estudo quantitativo buscando validar os fatores de assimilação discutidos ao longo desta pesquisa consiste também, uma oportunidade de estudos futuros.

A adoção de um modelo combinando fatores organizacionais, sociais e técnicos que permita uma avaliação criteriosa sobre os benefícios, riscos e impactos econômicos das tecnologias em saúde são componentes fundamentais para auxiliar tomadores de decisão sobre a adoção, alteração ou exclusão dessas tecnologias nos sistemas de saúde. 


\section{Contribuição Teórica}

Implementação de Tecnologias em saúde são frequentemente baseadas em estudos de caso que relatam avaliações de resultados antes e depois da implantação da tecnologia como uma intervenção. Embora eles possam fornecer detalhes ricos em exemplos específicos, eles são muitas vezes focados nos aspectos dos casos em questão e vários aspectos relacionados com impactos para os usuários e organizacionais acabam sendo subestimados. O estudo traz discussões, as quais podem contribuir para a literatura sobre avaliação de tecnologia em saúde. Há poucos estudos com foco em framework analisando TOE, Assimilação e Protocolo efetividade. Para entender melhor essas questões, a pesquisa buscou preencher a lacuna e propôs um modelo de avaliação abrangente contribuindo para melhoria do processo decisório em adotar tecnologias em saúde e de fato alavancar resultados tanto para o paciente como uma forma de melhorar a gestão. A estrutura organizacional para HIT fornece um passo crítico em direção ao desenvolvimento de uma modelo de implementação, fornecendo uma estrutura para organizar e capturar informações sobre seu uso, as medidas e ferramentas relevantes, e as relações entre e entre diferentes fatores.

\section{Contribuição Prática}

Vários modelos de avaliação de TI foram desenvolvidos e testados em áreas de negócios e na área médica, mas observa-se que ainda é um campo que está em evolução. Estudos têm sido desenvolvidos buscando melhorar a gestão em hospitais, aplicando conceitos de avaliações de tecnologias em saúde, porém há muitos fatores a serem investigados que contribuam para uma compreensão mais rica das HIT. Neste sentido, o framework proposto e avaliado nos casos descritos, suportam um modelo de avaliação a ser aplicado na prática, instrumentalizando os profissionais a avaliar e demonstrar a efetividade e segurança de uma tecnologia em saúde (fármaco, equipamento, dispositivo, entre outros), com relação às tecnologias ofertadas pela concorrência. Adicionalmente, o framework permite que os profissionais saibam demonstrar o valor e atratividade econômica das tecnologias de interesse - destacando as que são mais vantajosas ou as que rendem mais com a mesma quantidade de recursos investidos, através do conceito do custo efetividade. 


\section{REFERÊNCIAS}

AJZEN, I. Residual Effects of Past on Later Behavior: Habitual and Reasoned Action Perspectives. Personality and Social Psychology Review, v. 6, n. 2, p. 107-122, 2002.

ALKRAIJI et al. "Factors impacting the adoption decision of health data standards in tertiary healthcare organizations in Saudi Arabia", Journal of Enterprise Information Management, Vol. 29 Issue: 5, pp.650-676, 2016.

AMMENWERTH E. et al. Simulation studies for the evaluation of health information technologies: experiences and results. Health Information Management Journal. Vol 41. Issn 1833-3583, 2012.

ANGST, C.M.; AGARWAL, R. Adoption of electronic health records in the presence of privacy concerns: The elaboration likelihood model and individual persuasion. MIS quarterly, v. 33, n. 2, p.339-370, 2009.

ARAÚJO, D. V.; BAHIA, L. Análise de custo-efetividade, In: NITA, M. E.; SETOLI, S. R.; NOBRE, M.; CARILHO, J. F. Avaliação de tecnologias em saúde, evidencia clínica, análise econômica e análise de decisão. Porto Alegre: Artmed, p. 330-342, 2010.

ARMitAGE, C. J.; CHRISTIAN, J. From Attitudes to Behavior: Basic and Applied Research on the Theory of Planned Behavior. Current Psychology, v. 22, n. 3, p. 187-195, 2003.

ASH, J.; BERG, M.; COIERA, E. Some unintended consequences of information technology in healthcare: The nature of patient care information system-related errors. Journal of the American Medical Informatics Association, 11, 104-113, 2004.

BAKER, J.; The Technology-Organization-Environment Framework. Information Systems Theory. 231-245. 10.1007/978-1-4419-6108-2_12, 2011

BARRETT, D.; LIAW, S. T.; LUSIGNAN, S. Unravelling the tangled taxonomies of health informatics. Informatics in Primary Care, 21(3), 152-155, 2014

BAX M. P.; Design science: filosofia da pesquisa em ciência da informação e tecnologia. Ci.Inf., Brasília, DF, v. 42 n. 2, p.298-312, maio/ago., 2013

BAYAZIT, N. Investigating Design: A Review of Forty Years of Design Research, Massachusetts Institute of Technology. Design Issues, v. 20, n. 1, p. 16-29, 2004.

BRASIL, Ministério da Saúde. Secretaria-executiva. Área de Economia da Saúde e Desenvolvimento. Avaliação econômica em saúde: desafios para gestão no Sistema Único de Saúde. Brasília, DF, 2008. (Série A. Normas e Manuais Técnicos).

BUENO, U. et al. Um estudo comparativo do modelo de aceitação de tecnologia aplicado em sistemas de informações e comércio eletrônico. In: CONGRESSO INTERNACIONAL DE GESTÃO DE TECNOLOGIA E SISTEMAS DE INFORMAÇÃO, 2004. São Paulo, SP. 2004. 
CIMPERMAN, M. et al. Analyzing older users' home telehealth services acceptance behavior applying an extended utaut model. International Journal of Medical Informatics, 90, 22-31, 2016.

COLE, R. et al. Being proactive: where action research meets design research. ICIS 2005 Proceedings, p. 27, 2005.

DAVIS, F. D. Perceived usefulness, perceived ease of use and user acepptance of information technology. Mis Quarterly, v. 13, n. 3, p. 319-340, 1989.

DIAS, M. C. et al. Análise do modelo de aceitação de tecnologia de Davis. R. Spei, Curitiba, v. 4, n. 2, p. 15-23, jul./dez., 2003.

DOBRZYKOWSKI, D. D. Understanding information exchange in healthcare operations: Evidence from hospitals and patients. Journal of Operations Management, 36, , pp. 201-214, 2015.

DRESCH, A., LACERDA, D. P., \& JÚNIOR, J. A. V. A. Design science research: método de pesquisa para avanço da ciência e tecnologia. Bookman Editora, 2015

ELLIOTT, R. A.; PUTMAN K. D; FRANKLIN, M. Cost Effectiveness of a Pharmacist-Led Information Technology Intervention for Reducing Rates of Clinically Important Errors in Medicines Management in General Practices. PharmacoEconomics Volume 32, n 6, p 573590, June 2014.

FAN, W. et al. Investigating the impacting factors for the healthcare professionals to adopt artificial intelligence-based medical diagnosis support system (AIMDSS). Annals of Operations Research. 10.1007/s10479-018-2818-y, 2018.

FARAJ, S.; AZAD, B. The materiality of technology: An affordance perspective. In P. M. Leonardi, B. A. Nardi, \& J. Kallinikos (Eds.), Materiality and organizing: Social interaction in a technological world. Oxford, UK: Oxford University Press,pp. 237-258, 2012.

FREEDMAN, S.; LIN, H.; PRINCE, J. Information technology and patient health: Analyzing outcomes, populations, and mechanisms. American Journal of Health Economics, v. 4, n. 1, p. 51-79, 2018.

GARTNER. Gartner Top 10 Strategic Technology Trends for 2019. Disponível em:

$<$ https://www.gartner.com/smarterwithgartner/gartner-top-10-strategic-technology-trends-for2019/> acesso em: 03 set 2019.

GREENHALGH, T. et al. "Diffusion of Innovations in Health Service Organisations: A Systematic Literature Review". 328 p, 2007

HANDAYANI, P.W. et al. Acceptance model of a hospital information system.

International journal of medical informatics, v. 99, p. 11-28, 2017.

HEVNER, A.R. A three-cycle view of design science research. Scandinavian Journal Of Information Systems. v. 19, n. 2, p. 4, 2007. 
HEVNER, A.R. et al. Design science in information systems research. MIS Quarterly, v.28, n.1, p.75-105, 2004.

JOHANSTON, H. Sistemas de Informação Hospitalar: Presente e Futuro. Revista Informédica, Unysis Corporation, EUA n 2, p 5-9, 1993.

KALIL, Aline J. - Avaliação Do Impacto Na Identificação De Pacientes Com Risco De Sepse Após Implantação De Um Robô Cognitivo Gerenciador De Risco - Universidade Tecnológica Federal Do Paraná Programa De Pós-Graduação Em Engenharia Biomédica Curitiba, 2017.

KRAUSS, S. Avaliação tecnológica e análise custo-efetividade em saúde: a incorporação de tecnologias e a produção de diretrizes clínicas para o SUS, Ciência \& Saúde Coletiva, 2003.

KRITTANAWONG, C. et al. Artificial Intelligence in Precision Cardiovascular Medicine. Journal of the American College of Cardiology. vol. 69, n 21, 2017.

LACERDA, D.P. et al. Design Science Research: método de pesquisa para a engenharia de produção. Gest. Prod., vol.20, n.4 pp.741-761, 2013. Disponível em: < http://www.scielo.br/scielo.php?script=sci_arttext\&pid=S0104-530X2013000400001> acesso em: 08 nov. 2018.

LAURA NETWORKS. Disponível em: < http://www.lauranetworks.com/> acesso em $10 \mathrm{dez}$. 2017.

LESLIE, M.; PARADIS, E. Is health information technology improving interprofessional care team communications? An ethnographic study in critical care. Jornal of Interprofessional Education \& Pratice, pp. 1-5, 2018.

LILFORD et al. Protocol for evaluation of the cost-effectiveness of ePrescribing systems and candidate prototype for other related health information technologies. BMC Health Services Research, p 14-314, 2014

LITTLEJOHNS, P.; WYATT, J.C.; GARVICAN, L. Evaluating computerised health information systems: hard lessons still to belearnt. BMJ, vol. 326, no. 7394, pp. 860-3, 2003.

MAIA, L.C.G.; CENDÓN, B.V. Um estudo sobre o uso de sistemas de recuperação de informação: o portal de periódicos CAPES na UFMG. In: SIMPOSIO MINEIRO DE SISTEMAS DE INFORMAÇÃO, 2, 2005. Belo Horizonte, MG. Anais...Belo Horizonte, 2005, [s.n].

MARIN, H. Health information system: general considerations. J. Health Inform. 2010

MARQUES, A. et al. (2010). Adoption of medical records management system in European hospitals. 4th European Conference on Information Management and Evaluation, ECIME 2010. 265-274.

MATTOS, C.; LAURINDO, F. Information Technology Adoption: Assimilation Analysis of Suppliers Portal for supply chain integration. Espacios. vol. 37,n 24), 2016, p 26. 
MOEN, A.; KNUDSEN, L. M. M. Nursing Informatics: Decades of Contribution to Health Informatics. Health Informatics Research, 19(2), 86-92, 2013.

NAKANO, D. Métodos de Pesquisa Adotados na Engenharia de Produção e Gestão de Operações. In: MIGUEL, P. A. C. et al. Metodologia de Pesquisa em Engenharia de Produção e Gestão de Operações. Rio de Janeiro: Campus, 2010. cap. 4, p. 63-72.

OLIVEIRA, T.; MARTINS, M. Literature Review of Information Technology Adoption Models at Firm Level. The Electronic Journal Information Systems Evaluation, v.14, n.1, p.110-121, 2011.

ORSZAG, P.R. Evidence on the costs and benefits of health information technology. In: testimony before Congress. 2008.

PANAHIAZAR M. et al. Using EHRs and machine learning for heart failure survival analysis. Stud Health Technol Inform, n 216, p 40-4, 2015.

PWC. Five distinct trends are converging to determine how artificial intelligence (AI) and robotics will define New Health. Disponível em:

$<$ https://www.pwc.com/gx/en/industries/healthcare/publications/ai-robotics-new-health/fivetrends.html> acesso em: 03 set 2019.

RAAIJ, E. M.; SCHEPERS, J. J. L.. The acceptance and use of a virtual learning environment in China. Computers \& Education, n 50, p 838-852, 2008.

RASCATI, K. L. Introdução à farmaeconomia. Tradução Cristina Bazán, Rodrigo Lopes Sardenberg e Christiane de Brito Andrei. Porto Alegre: Artmed, 2010.

REJEB, O. et al. Performance and cost evaluation of health information systems using micro-costing and discrete-event simulation. Health Care Management Science,, pp. 1-20, 2017.

RODRIGUES J.; XAVIER J. C. B.; ADRIANO, A. L. A tecnologia da informação na área hospitalar: um caso de implementação de um sistema de registro de pacientes. Revista administração contemporânea, vol.5, n.1 Curitiba Jan./Apr, 2001

ROGERS, E. Diffusion of innovations. 4ed. New York: Free Press, 1995.

ROGERS, E. Diffusion of Innovations, 5ed. New York: Free Press, 2003.

ROMME, A. G. L. Making a difference: Organization as Design. Organization Science, v.14, n. 5, p. 558-573, 2003.

SEDIG, K.; NAIMI, A.; HAGGERTY, N. Aligning Information Technologies With Evidence-Based Health-Care Activities: A Design And Evaluation Framework. Humam Technology. v 13, n 2, pp. 180-215. nov 2017

SILVA, P. M.; DIAS, G. A.; SENA, M. R.; Enc. Bibli: R. Eletr. Bibliotecon. Ci. Inf., Florianópolis, n. 26, $2^{\circ}$ sem.2008 
SIMON, H. A. The Sciences of the Artificial. Cambridge: MIT Press, 1969

SIMON, H. A. The Sciences of the Artificial. 3rd ed. Cambridge: MIT Press, 1996.

SINCAK, P. et al. Artificial Intelligence in Public Health Prevention of Legionelosis in Drinking Water Systems. Int. J. Environ. Res. Public Health, 2014

SOUZA, H. C. Avaliação Econômica da Saúde: Estudos de Eficácia, Eficiência, Custo Efetividade e Custo benefício. Instituto Master de Ensino Presidente Antonio Carlos, 2011.

SULAIMAN, H.; WICKRAMASINGHE, N. "Critical Issues in Assimilation of Healthcare Information Systems". PACIS 2010, 2017, p 176.

SULAIMAN, H.; WICKRAMASINGHE, N. (2014) "Assimilating Healthcare Information Systems in a Malaysian Hospital," Communications of the Association for Information Systems: vol. 34 , n 77, 2014.

TAYLOR, A.; TAYLOR, M. Operations management research: contemporary themes, trends and potential future directions. International Journal of Operations \& Production Management, v. 29, n. 12, p. 1316-1340, 2009.

TERRY, H.P et al. AI, Machine learning and data Fuel the future of productivity. The Golden Sachs Group, Inc. November 14, 2016.

TOLETINO, R. et al. Individual performance analysis of information system users: an integrative study of the tam and ttf models. FACES R. Adm. Belo Horizonte. v. 6, n. 2, p. 91-103, mai./ago. 2007

TORNATZKY, L.; FLEISCHER, M. The Processes of Technological Innovation. Massachusetts: Lexington Books, 1990.

VAISHNAVI, V.; KUECHLER, W. Design Research in Information Systems. 2009. Disponível em: <http:// desrist.org/design-research-in-information-systems $>$. Acesso em: 28 nov. 2018.

VAN AKEN, J. E. Management Research Based on the Paradigm of the Design Sciences: The Quest for Field- Tested and Grounded Technological Rules. Journal of Management Studies, v. 41, n. 2, p. 219-246, 2004.

VENKATESH, V. et al. User acceptance of information technology: toward a unified view. MIS Quarterly, Minneapolis, vol 27, n 3, p 425-478, 2003.

VENKATESH, V., DAVIS, F.D. A theoretical extension of the techonology acceptance model: four longitudinal field studies. Manage. Sei, New York, v. 46, n. 2, p. 186-204, 2000.

WHO, World Health Organization. Making choices in health: WHO guide to effectiveness analysis. Edited by T. Tan-Torres Edejer et al. Geneva, 2003. 
YIN, R.K. Estudo de caso: planejamento e métodos. 3. ed. Porto Alegre: Bookman, 2005.

YUSOF, M. M. et al. An evaluation framework for Health Information Systems: human, organization and technology-fit factors (HOT-fit). International journal of medical informatics, vol 77, n 6, p 386-398, 2008.

ZHU, K.; KRAEMER. K.; XU, S. "Electronic Business Adoption by European Firms: A Cross-country Assessment of the Facilitators and Inhibitors", European Journal of Information Systems, vol 12, n 4, p. 251-268, 2003. 
APÊNDICE A- LISTA DE VERIFICAÇÃO DSR 


\section{LISTA DE VERIFICAÇÃO DSR}

1. Qual é a pergunta de pesquisa (requisitos de design)?

2. Qual é o artefato? Como o artefato é representado?

3. Quais processos de design (heurística de busca) serão usados para construir o artefato?

4. Como o artefato e os processos de design são fundamentados pela base de conhecimento? Quais teorias, se alguma, suportam o design de artefatos e o processo de design?

5. Que avaliações são realizadas durante os ciclos internos de projeto? Quais melhorias de design são identificadas durante cada ciclo de design?

6. Como o artefato é introduzido no ambiente do aplicativo e como ele é testado em campo? Quais métricas são usadas para demonstrar utilidade e melhoria de artefatos em relação a artefatos anteriores?

7. Que novo conhecimento é adicionado à base de conhecimento e de que forma (por exemplo, literatura revisada por pares, meta-artefatos, nova teoria, novo método)?

8. A pergunta de pesquisa foi satisfatoriamente abordada? 
APÊNDICE B- CHECKLIST FRAMEWORK TOE E TAM 


\section{FRAMEWORK TOE}

[1] Qual é a infraestrutura necessária que o hospital tenha para implantar Robô Laura?

[2] Quais casos de implantação? - indicar hospital (porte/ privado ou público), quando foi implantado?

[3] Observou percentual de redução de casos de SEPSE entre os pacientes nestes hospitais em que foi implantado o robô Laura? Se sim, quais hospitais?

[4] Quais os impactos da implantação da tecnologia na identificação e manejo precoce de pacientes em risco (o intervalo de tempo entre o primeiro sinal de infecção identificado e a prescrição da primeira dose de antimicrobiano)?

[5] Qual o tempo médio de atendimento (TMA*) em minutos antes e após a implantação do robô? (*Tempo médio de atendimento em minutos - refere-se ao tempo médio para qualquer tipo de inserção de dados no sistema de prontuário eletrônico).

[6] Quais são os principais custos associados com a adoção da ferramenta? (Pagamento de licença, infraestrutura, treinamento de pessoal, entre outros custos necessários para a implantação)

[7] Qual foi a motivação organizacional? Ou seja, quais motivos levaram o hospital a buscar pela adoção da ferramenta?

\section{FRAMEWORK TAM}

Como foi a aceitação da tecnologia por parte dos profissionais?

Sobre facilidade de uso, como é a experiência de entre profissionais e o Robô?

Os profissionais usam com frequência a tecnologia? Há, por parte desses profissionais, a inclusão frequente das informações dos pacientes?

Sobre a qualidade das informações, os profissionais perceberam resultados positivos com a adoção da tecnologia? 
APÊNDICE C- MAPAS VOSVIEWER 
1) Keywords: health information technology and adoption

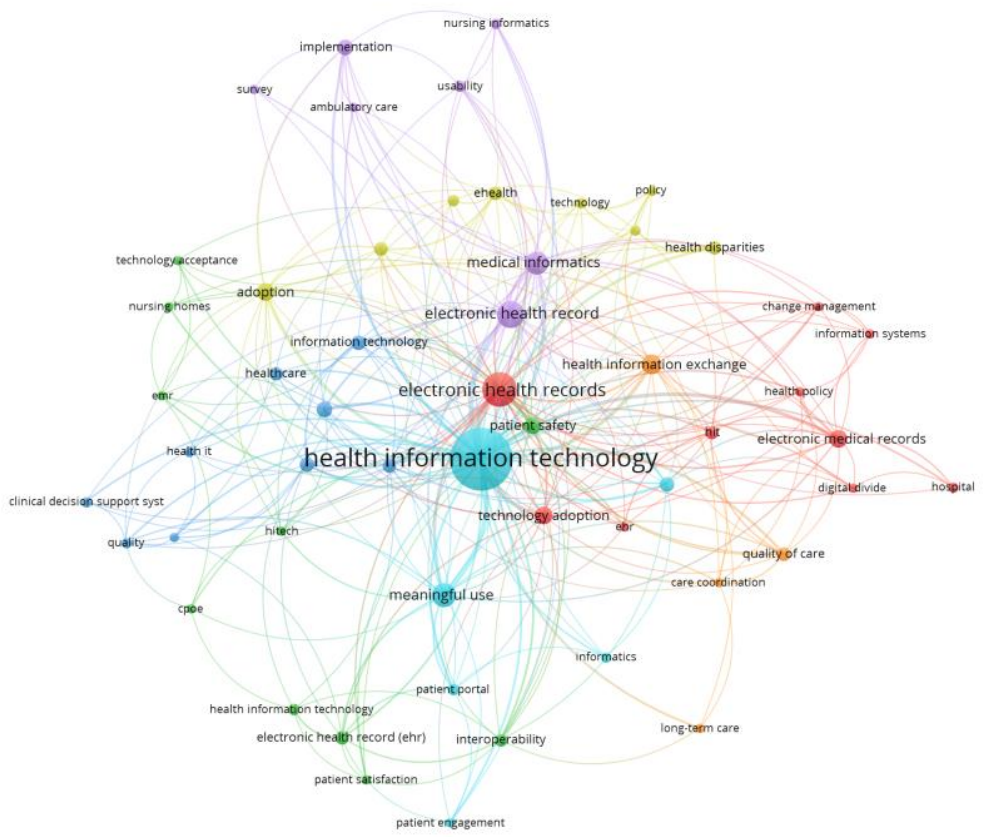

\& vosviewer

Fonte: Vosviewer, 2019

2) Keywords: health information technology and evaluation

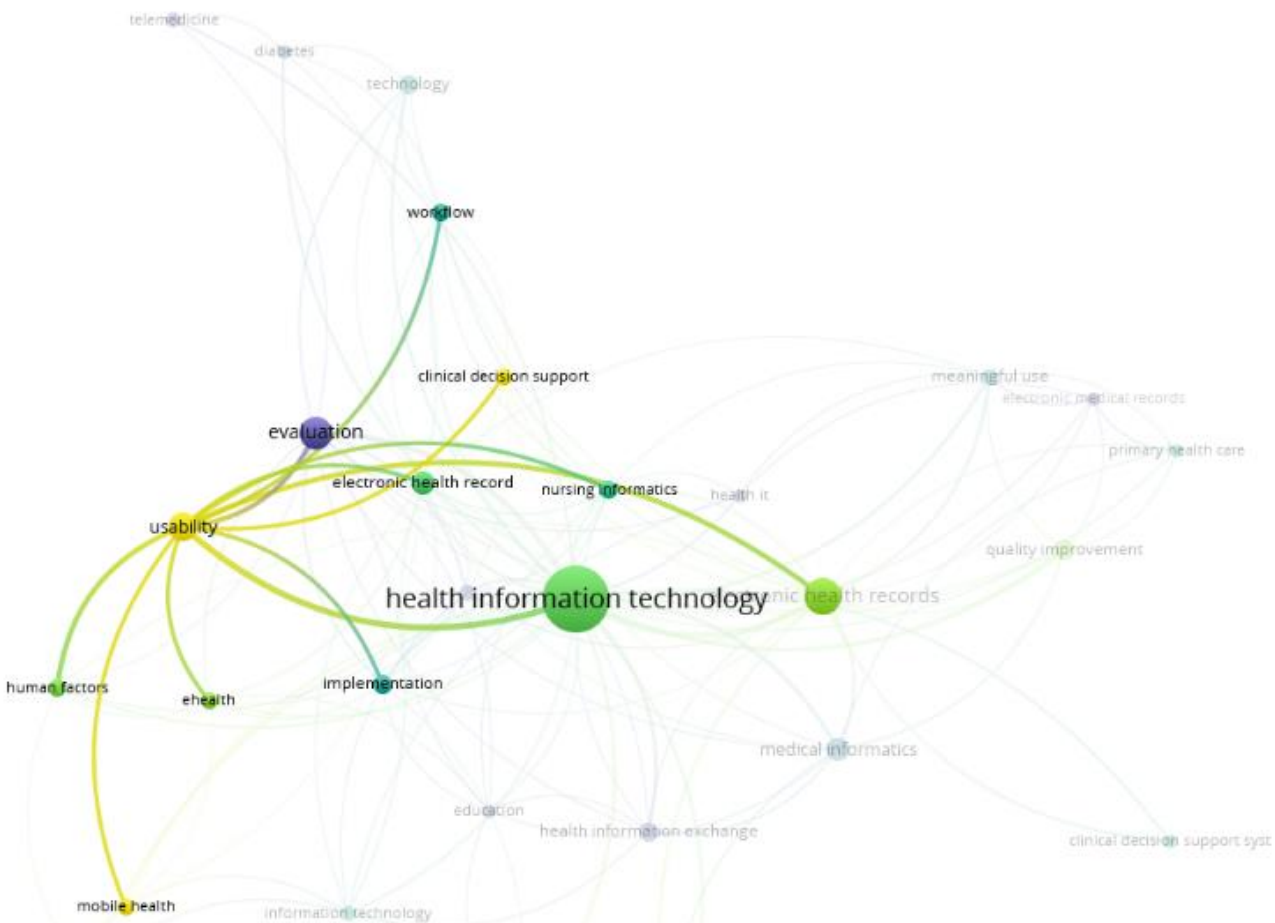

Fonte: Vosviewer, 2019 